\title{
Arrhythmias in general practice : prevalence and clinical diagnosis
}

Citation for published version (APA):

Zwietering, P. J. (1999). Arrhythmias in general practice : prevalence and clinical diagnosis. [Doctoral Thesis, Maastricht University]. Datawyse / Universitaire Pers Maastricht. https://doi.org/10.26481/dis.20000121pz

Document status and date:

Published: 01/01/1999

DOI:

10.26481/dis.20000121pz

Document Version:

Publisher's PDF, also known as Version of record

\section{Please check the document version of this publication:}

- A submitted manuscript is the version of the article upon submission and before peer-review. There can be important differences between the submitted version and the official published version of record.

People interested in the research are advised to contact the author for the final version of the publication, or visit the DOI to the publisher's website.

- The final author version and the galley proof are versions of the publication after peer review.

- The final published version features the final layout of the paper including the volume, issue and page numbers.

Link to publication

\footnotetext{
General rights rights.

- You may freely distribute the URL identifying the publication in the public portal. please follow below link for the End User Agreement:

www.umlib.nl/taverne-license

Take down policy

If you believe that this document breaches copyright please contact us at:

repository@maastrichtuniversity.nl

providing details and we will investigate your claim.
}

Copyright and moral rights for the publications made accessible in the public portal are retained by the authors and/or other copyright owners and it is a condition of accessing publications that users recognise and abide by the legal requirements associated with these

- Users may download and print one copy of any publication from the public portal for the purpose of private study or research.

- You may not further distribute the material or use it for any profit-making activity or commercial gain

If the publication is distributed under the terms of Article $25 \mathrm{fa}$ of the Dutch Copyright Act, indicated by the "Taverne" license above, 
Arrhythmias in general practice 
(C) PJ Zwietering, Maastricht 1999

ISBN: 9052782687

vormgeving en druk:

Datawyse / Universitaire Pers Maastricht

illustratie omslag:

Guus van Rooy 


\title{
Arrhythmias in general practice Prevalence and clinical diagnosis
}

\author{
Proefschrift \\ ter verkrijging van de graad van doctor \\ aan de Universiteit Maastricht, \\ op gezag van de Rector Magnificus, \\ Prof. dr A.C. Nieuwenhuijzen Kruseman, \\ volgens het besluit van het College van Decanen, \\ in het openbaar te verdedigen op \\ vrijdag 21 januari 2000 om 16.00 uur \\ door \\ Paul J Zwietering
}

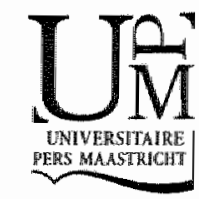


Promotor

Prof dr JA Knotmerus

\section{Co-promotor}

Dr APM Gorgels

\section{Beoordelingscommissie}

Prof. dr HJ] Wellens (voorzitter)

Prof. dr E van der Does (Erasmus Universiteir Rotterdam)

Prof dr F Sturmans

Prof. dr P Pop

Dr A Kester

The study presented in this thesis was performed at the institute ExTra, part of the Netherlands School of Primary Care Research (CaRe) acknowledged in 1995 by the Royal Netherlands Academy of Sciences (KNAW). This study was supported by grant no 900-715-153 of the Council of Medical Research of the Netherlands Organisation of Scientific Research (NWO).

Financial support by the Netherlands Heart Foundation for the publication of this thesis is gratefully acknowledged. 


\section{Contents}

\section{CHAPTER 1 \\ 7 Introduction}

CHAPTER 2

19 Occurrence of arrhythmias in general practice

\section{CHAPTER 3}

31 Arrhythmias in general practice. Diagnostic value of patient characteristics, medical history and symptoms

\section{CHAPTER 4}

49 The diagnostic value of physical signs in arrhythmias

\section{CHAPTER 5}

67 How accurate do general practitioners diagnose arrhythmias presenting as a coincidental finding? Diagnostic value of patient characteristics, medical history, symptoms and physical signs

\section{CHAPTER 6}

83 Atrial fibrillation in general practice. Diagnostic value of signs and symptoms

\section{CHAPTER 7}

101 General discussion

$$
\text { CHAPTER } 8
$$

109 Summary

\section{CHAPTER ?}

113 Samenvarting

117 Dankwoord

121 Curriculum vitae

123 Appendix 



\section{Introduction}

\section{INTRODUCTION}

Since the development of electrocardiography by Einthoven knowledge of clinical arrhythmias has been initially gathered by studying the surface $\mathbb{E C G}$, mostly recorded by single channel electrocardiographs. Many mechanisms of arhythmias have been grasped through deductive analysis of these rhythm strips, Drs Karz, Pick and Langendorf belonging to the most prominent representatives of this episode 1 . In the 1960 s it became technically feasible to stimulate and record electrical activity within the human heart. The finding by Durrer and Wellens in Amsterdam ${ }^{2}$ and by Coumel in Paris ${ }^{3}$ in 1967 that sustained tachycardias could be reproducibly initiated and terminated by electrically stimulated premature beats has revolutionised the study of these arrhythmias. The use of multiple intracardiac recordings to record impulse conduction in the human heart has led to understanding not only of tachycardias but also of slow heart rhythms, such as atrioventricular conduction disturbances. Translation of the intracardiac findings to the surface ECG has led to a better interpretation and classification of atrhythmias ${ }^{4,5}$, more accurate knowledge of clinical and demographic characteristics ${ }^{6}$ and improved management not only by the cardiologist but also by the general practitioner.

Because arrhythmias present to the general practitioner as symptoms and/or signs, it is useful to classify those according to their clinical presentation. Also a classification according to clinical relevance is important allowing appropriate management of the presented problem. In lirerature a definite picture about the incidence and prevalence of most of the arrhythmias can not be found, while most studies are based on selected popularions. ${ }^{7-13}$ Because of the paroxysmal character of most of the arrhythmias the incidence and prevalence also depend largely on the mode of their derection. Therefore, a rough overview is given about the prevalence, clinical relevance and clinical picture of the respective arthythmias (Table 1).

In the literature various patient characteristics, medical history findings, symptoms and signs are described related to the presence of arrhythmias. ${ }^{14-20}$ General practitioners are frequently confronted with patients ptesenting with these signs and/or symptoms ${ }^{21}$. However, there is little evidence about the predictive value of clinical variables in the unselecred general practice population. Diagnosing arrhythmias in general practice depends largely upon experience based knowledge. This study was performed to generate quantirative data about the predictive value of these clinical variables in diagnosing arrhythmias. 


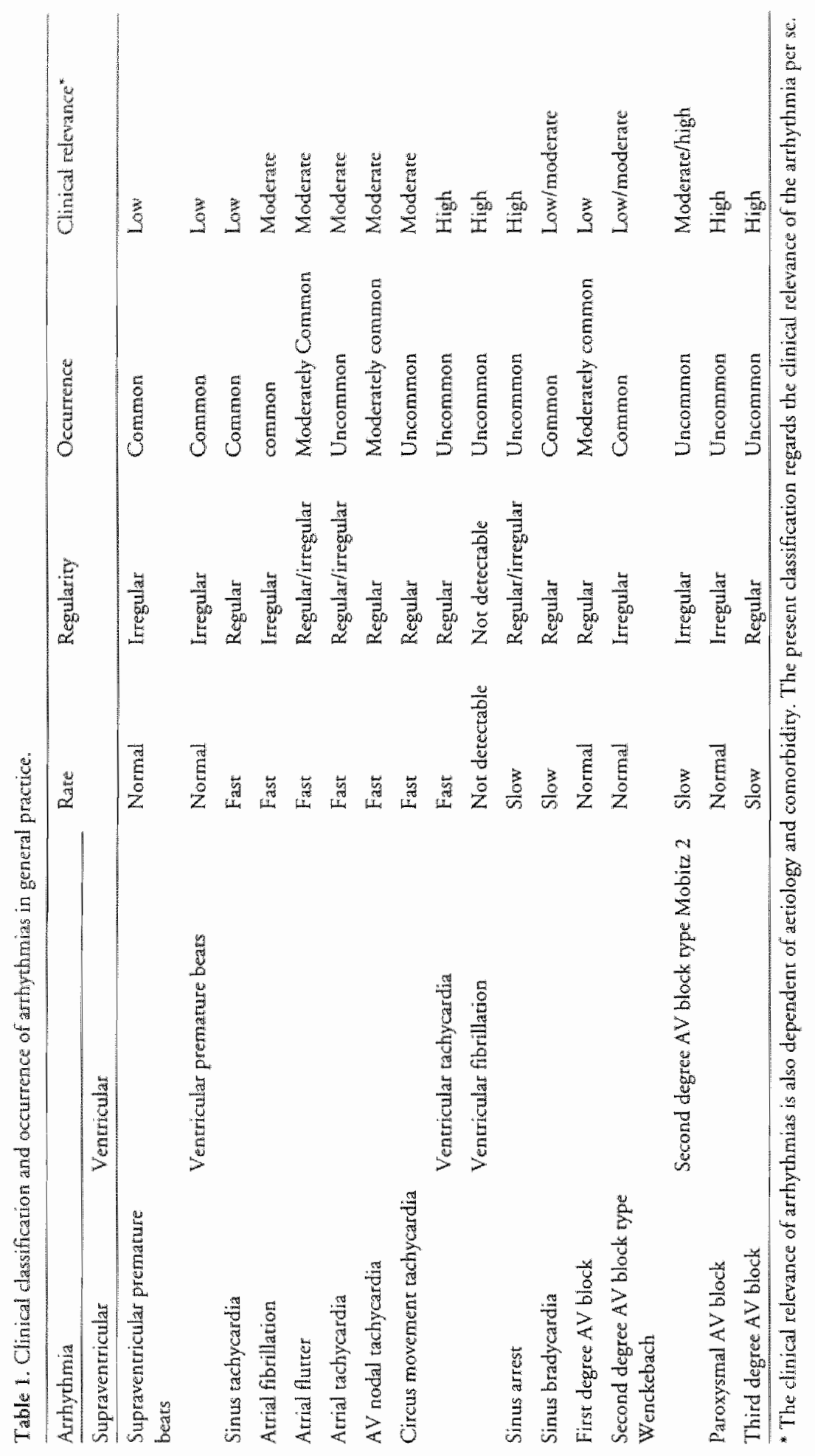


The presence of internationally arrhythmological expertise in the Cardiology Department of the Maastricht University and a similar interest in the Department of General Practice led to productive cooperation in this field such as the Sudden Death Registry"2, the PATAF trial ${ }^{23}$, the "Hartslag" project, and the forelying Arrhythmia in Clinical Practice Study.

\section{ARRHYTHMIAS IN GENERAL PRACTICE}

Cardiac arrhythmias can be defined as all rhythms, different from a normally conducted sinus rhythm. Tachyarrhythmias are caused by abnormal automaticity, re-entry or triggered activity. Arrhythmias also include conduction disorders such as bradycardias like a 2 nd or 3 rd degree AV-block. Arrhythmias can also be classified as paroxysmal or incessant. The clinical significance of arrhythmias depends on the type of the arrhythmia, heart rate, aetiology, presence of cardiovascular comorbidity, such as impaired ventricular function, and the possible consequences of the arrhythmia for daily life.

The incidence and prevalence of arrhythmias depend highly on the population selected and the method of documentation, such as a short lasting 12-lead electrocardiogram (ECG), a $24 \mathrm{~h}-\mathrm{ECG}$ recording, event recording with or without transtelephonic transmission or electrophysiological testing. ${ }^{9,24-29}$ Incidence and prevalence of some arrhythmias are correlated significantly with advancing age, such as extrasystoles, atrial fibrillation and arrhythmias occurring in the setting of the sick sinus syndrome. ${ }^{10-12,26}$

The management of arrhythmias in general practice consists of reassurance (in case of extrasystoles, sinus tachycardia), drug treatment (atrial fibrillation) and referral (atrial fibrillation, ventricular tachycardias, 3rd degree AV-block).

Van der Does and Prins described the difficulties of diagnosis and management of cardiac arrhythmias in general practice. ${ }^{30}$

There is no clear relation between palpitations and the occurrence of myocardial infarction and sudden death in general. ${ }^{31}$ However, diagnosing a potentially maligo nant arrhythmia is important to separate the benign from the dangerous. Besides, more than 3 extrasystoles per minute and tachycardia in parients with complaints suggestive for an acute myocardial infarction are predictors of acute coronary events. ${ }^{32}$

Clinically arrhythmias can be classified as tachycardias, bradycardias and extrasystoles (Table 1). Another classification is into regular and irregular thythms, the latter mostly being due to atrial fibrillation or premature beats. Besides, a differentiation can be made according to their origin (supraventricular or ventricular).

Isolated extrasystoles are innocent arrhythmias especially in individuals without organic heart disease. ${ }^{13,33,34}$ The spectrum of tachycardias ranges from a normal physiological response such as a sinus tachycardia caused by exertion, fever and stress 
to life-threatening arthythmias. A sinus tachycardia, which is usually innocent, may indicate serious pathology, such as acute ischaemia, heart failure and non-cardiovascular pathology, such as non-cardiovascular shock, respiratory insufficiency, pulmonary embolism, hyperthyroidism and anaemia. Other supraventricular tachycardias may occur without concomitant cardiac disease such as AV-nodal and circus movement tachycardia. Of these regular supraventricular tachycardias AV-nodal tachycardias are most frequent. ${ }^{20}$ Re-entry in the AV node causes this tachycardia. Arrial tachycardias may be idiopathic but can also result from ischaemia and merabolic or toxic disturbances, electrolyte disorders and drugs. ${ }^{35}$ The circus movement tachycardia based on an accessory connection between atria and ventricles (Wolff-Parkinson-White syndrome) has a low incidence but is clinically important because its first manifestation is usually in adolescents. The presence of an accessory pathway is potentially life-threatening due to the higher incidence of atrial fibrillation in these patients, an arrhythmia that may lead to extremely high ventricular rates through conduction over the accessory pathway. $9,36,37$

Atrial fibrillation is the most common (irregular) supraventricular tachycardia. In the industrialised world it is a disease of the ageing population. ${ }^{10,11,38-40}$ Differentiarion should be made between paroxysmal and chronic atrial fibrillation. Also a classification should be made into lone atrial fibrillation, without other cardiovascular abnormalities and atrial fibrillation in the presence of concomitant cardiac or noncardiac disease. Risk factors for atrial fibrillation are valvular heart disease, hyperthyroidism, coronary heart disease, hypertension, diabetes mellitus, congestive heart failure, cerebrovascular accidents and pneumonia. ${ }^{11,39,41-43}$ Atrial fibrillation has been identified as an important risk factor in short-term and long-term complications, such as congestive heart failure and thromboembolic events. ${ }^{39,43-45}$ In the recent literature the number of publications is increasing because of new insights in treatment ${ }^{46}$ and prognosis of this arrhythmia and because of its rising incidence caused by the ageing of our population and the recently proven impact of anticoagulation in the prevention of stroke. $23,47,48$

Sometimes, a parient suffers from more than one arrhythmia. In case of a sick sinus syndrome, sinus pauses can alternate with atrial fibrillation, atrial flutter and other rachycardias. ${ }^{49}$ General practitioners are confronted with arrhythmias based on complaints, occasional findings during physical examination or in emergencies, such as syncope or sudden circulatory arrest and death.

\section{THE IMPORTANCE OF THE MEDICAL HISTORY}

The medical history of patients is especially of importance in differentiating arthythmias and anxiery disorders. Attention must be drawn to the fact that arrhythmias can cause anxiety attacks and vice versa. Besides, the medical history can give an indication about the type of arrhythmia. Previously diagnosed arthythmias 
and their response to medication are important such as extrasystoles, paroxysms of atrial fibrillation or AV nodal tachycardia. Ventricular tachycardias, most frequently in patients with a history of a myocardial infarction can degenerate into ventricular fibrillation. ${ }^{50-52}$ Atrial fibrillation may be related to congestive heart failure, hyperthyroidism, cerebrovascular accident, chronic obstrucrive pulmonary disease (COPD) and valvular disorders. ${ }^{11,39,41-43}$ Finally, especially in case of medication use because of co-morbidity, general practitioners must anticipate proarthythmia caused by drugs such as antiarrhythmics, theophylline, betasympathicomimetics and antidepressive agents. ${ }^{53-57}$

\section{THE VALUE OF SYMPTOMS}

Various complaints can suggest the presence of arrhythmias. While taking the history, first it should be verified whether the complaints of the patient are indeed related to an arrhythmia or to an anorher disease. The specific circumstances surrounding complaints, can help in the differentiation berween arrhythmias and anxiety disorders. Panic attacks as part of an anxiety disorder are usually situational, while arrhythmias are more likely without evident psychosocial stress factors, although this general statement should be interpreted with caution in the individual patient.

When an arrhythmia is considered, the history can be of help in the further differentiation between the specific arrhythmias. It is of importance to take sufficient time for the history of the patient. Then, on the basis of specific questions more detailed information can be obtained. Patients should be asked whether they experience palpitations, dizziness, shortness of breath, angina, tiredness or falls especially when accompanied by loss of consciousness. The complaint of palpitations comprises multiple subjective phenomena such as a fast heart rate, a pounding heart beat, an irregular heart beat, and single irregularities in the heart rhythm, such as premarure beats. It is quite useful in the diagnostic process to derive information from the patient regarding the specific fearures of what is experienced as palpitations, and try to interpret the complaints accordingly. Typical features are mode of onset and termination, rate, regullarity, duration and accompanying symptoms. ${ }^{16-19}$ Dizziness, shortness of breath and falls can indicate hacmodynamic consequences of an arrhythmia. Angina can indicate cardiac ischaemia caused by the arrhythmia, although during fast arrhythmias this symptom may occur in individuals with perfectly normal coronary arteries. 


\section{THE IMPORTANCE OF THE PHYSICAL EXAMINATION}

Ideally a physical examination in a patient complaining of symptoms suggesting an arthythmia should take place during the complaints. First, the haemodynamic condition should be assessed such as consciousness, dyspnoea, sweating, and pallor. In case of a sitable haemodynamic situation differentiation can be made between a normal heartbeat, a tachycardia or a bradycardia by palpating the pulse or auscultating the heart. Auscultation of the heart is the best method to establish whether the rhythm is regular or (totally) irregular. Blood pressure measurement gives an indication about the haemodynamic consequences. A varying systolic blood pressure and a warying loudness of the first heart sound in case of a regular tachycardia indicates the presence of a ventricular tachycardia. In case of atrial fibrillation, also varying loudness of the first heart sound and varying systolic blood pressure can be obserwed, however in combination with an irregular tachycardia. Finally, one can observe abnormal jugular pulsations, such as canon waves in case of a ventricular tachycardia and synchronous prominent jugular pulsations when there is an atrioventricular nodal or circus movement tachycardia. 17.19 When patients have no specific symptoms during consultation, physical examination is of importance to derect etiologic factors, such as hypertension, thyroid pathology, signs of anaemia or cardiac murmurs.

\section{OTHER DIAGNOSTIC METHODS}

The 12-lead electrocardiogram (ECG) during symptoms is the most informative diagnostic tool for general practicioners to establish the type of arrhythmia. When a patient has no symptoms during consultation, the patient should be instructed to return when there is a recurrence of the symptoms. When patients are referred to a cardiology department, other facilities such 24-h Holter monitoring, event recorders and electrophysiological investigarions are available.

\section{DIFFICULTIES IN DIAGNOSING ARRHYTHMIAS}

Arrhythmias may be difficult to diagnose in an unselected general practice population. Firsty, complaints possibly related to arrhythmias may be non-specific. Especially anxiety disorders, such as panic attacks, depression and somatisacion disorders may present with symptoms of palpitations, sweating, chest pain, shortmess of breath, dizziness and fear. ${ }^{58-65}$ In these situations, general practitioners should consider a non-cardiac origin, to prevent somatisation and misdiagnosis. On the other side, it should be realised that arrhythmias can provoke anxiety attacks. 
Secondly, symptoms possibly suggesting an arrhythmia, are organ specific to a certain extent; dyspnoea is mostly related to respiratory diseases, while tiredness, falls and dizziness can be caused by different internal, neurological and otological diseases. In the elderly, these symptoms tend to be less important to establish a diagnosis because they occur commonly with increasing age thereby loosing their diagnostic significance. ${ }^{21}$ Besides, cardiovascular as well as non-cardiovascular diseases can cause arrhythmias. In case of anaemia, palpitations and tiredness may occur. Tiredness and palpitations can also be found in patients with hyperthyroidism and in atrial fibrillation, caused by hyperthyroidism. Furthermore, atrial fibrillation can be caused by a pneumonia, in which case it is not always clear whether the present dyspnoea is caused by the pneumonia or by atrial fibrillation complicated by heart failure.

Symptoms possibly indicating an arrhythmia are frequently of short duration (falls, dizziness, angina) and occur in paroxysms (palpitations), making it impossible to examine the patient or to make an ECG recording during signs and symptoms. 16,24-26,66-69 Finally, patients may have arrhythmias without any complaint. This is seen particularly in the elderly or in case of a persistent arrhythmia.

All this, makes diagnosing arrhythmias in general practice difficult. History taking and physical examination receive a lot of attention in medical textbooks and medical education. However, in most cases only a list of clinical signs and symptoms is given without giving attention to the quantitative value of clinical variables or combinations of them. Like in laboratory tests, the value of clinical findings can be quantified as to their sensitivity, specificity and predictive values. ${ }^{70}$ However, the predictive value depends upon prevalence, the population selected (general pracrice population, referred population) and the severity of the clinical picture..$^{71-75}$

There is little evidence about the predictive value of patient characteristics, medical history, symptoms and signs in diagnosing arrhythmias in general practice. Diagnosing arthythmias in general practice depends largely upon experience based knowledge. This study was performed to generate some quantitative dara about the predicrive value of clinical variables in diagnosing arthythmias.

\section{ALMS OF THE STUDY}

The purpose of this study is to investigate the occurrence of arrhythmias in general practice and to assess the value of patient characteristics, medical history, symptoms and signs (a) in diagnosing arrhythmias in general pracrice en (b) in identifying patients with clinically relevant arrhythmias. 


\section{OUTLINE OF THIS THESIS}

Chapter 2 describes the results of a cross-sectional prospective study concerning the occurrence and distribution of arrhythmias in 20 general pracrices during a 2 -year period, in 868 patients with complaints or coincidental findings possibly related to an arrhythmia.

Chapter 3 deals with the diagnostic value of clinical variables in diagnosing arrhythmias in a sub-group of 762 patients from the population described in chapter 2. In patients with complaints, possibly related to the presence of an arrhythmia, we evaluated the predictive value of patient characteristics, medical history and symptoms in diagnosing arthythmias and in differentiaring between clinically more and less relevant arrhythmias, using a cross-sectional study design.

In chapter 4 the assessed diagnostic value of signs in combination with patient characteristics and symptoms in diagnosing arrhythmias in 762 patients is reported Parients were included because of complaints possibly related to the existence of arrhythmias.

Chapter 5 describes the surplus value of medical history and physical examination in a subgroup of 106 patients, consulting their GP with complaints not directly related to the presence of arthythmias, with coincidental findings suggesting an arrhythmia.

Chapter 6 addresses to atrial fibrillation and the value of patient characteristics, medical history, symptoms and signs in diagnosing this specific arrhythmia.

In chapter 7 , in the general discussion, the most important results are summarised and the methodology is critically analysed. Also, the implications diagnosing arrhythmias in daily general practice are described.

Chapter 8 and 9 are summaries in English and Dutch.

\section{REFERENCES}

1. Pick A, Langendorf R Interprention of complex arthythmias. Philadelphia: Lea \& Febiger, 1979.

2. Durter D, Shoo L, Schuilenburg RM, Wellens HIJ. The role of premature bears in the intiation and termination of supraventricular tachycardias in the Wolff-Parkinson- White syndrome. Circullation 1967: 36: 644-662.

3. Coumel Ph, Cabrol C. Fabiato A, Gourgon R, Siana R. Tadycardie permanente par tythme reciproque en dehors du syndrone de Wolf-Parkinson- White syndrome. Arch Mal Coeur 1967; $60: 1830-1837$.

4. Wellens HJ], Bar FW, Farre I, Whener J, Ross DL, Gorgels AP, Vanagt El, Brugada P. Diagnosis and incidence of concealed accessory pathways in patients suffering from paroxysmal AV juncrional tachycardias. Rev Lat Cardiol 1980; 1: 60-67. 
5. Farre J. Wellens HJ. The value of the elecrocardiogram in diagnosing site of origin and mechanism of supraventricular tachycardia. In: Wellens HJ], Kulbertus HE (eds). What's new in electrocardiography? 1st ed. The Hague: Nijhof 1981: 131-171.

6. Rodriguez LM, de Chillou C, Selhlapfer J, Metzeger J, et all. Age at onset and gender of patients suffering from different types of supraventricular tachycardias. Am J Cardiol 1992; 70: 1213-1215.

7. Rose G, Baxter PJ, Reid DD, McCartney P. Prevalence and prognosis of electrocardiographic find ings in middle-aged men. Br Heart ] 1978;40:636-43.

8. Green MS, Jucha E, Luz J, Cocos M, Nurynberg M, Rosenberg N. Prevalence and correlares of ventricular premarure beats detected by ambularony electrocardiography in working populations. I Epidemiol 1988;127:955-68.

9. Barret PA, Perer CT, Swan HJC, Singh BN, Mandel WJ. The frequency and prognostic signilcance of electrocardiographic abnormalities in clinically normal individuals. Prog Cardiovasc Dis $1981: 23: 299-312$.

10. Kulbertus. HE, Leval-Rutren F de, Albert A, Dubois M, Petit JM. Electrocardiography changes oc curring with advancing age. In: Wellens HJJ, editor. What's new in electrocardiography? Ist ed. The Hague: Nijhof 1981:300-13.

11. Kannel WB, Abbort RD, Savage DD, McNamara PM. Epidemiologic fearures of chronic atrial fibrillation. The Framingham Study. New Engl J Med 1982;306:1018-22.

12. De Bacquer D, Marrins Pereira LS, De Backer G, De Henauw S, Kornitzer M. Prevalences and correlates of ECG abnormalities in the adult Belgian population. J Electrocardiol 1995:28:1-11.

13. Bethge KP, Bechge $D$, Meiners $G$, Lichtlen PR. Incidence and prognostic significance of wentricular arrhythmias in individuals without detectable heart disease. Eur Heart ] 1983;4:338-46.

14. Scthlant RC, Alexander RW, O'Rourke RA, Robers R, Sonnenblick EH, eds. Hurst's the herart: arteries and veins. 8th ed. New York: Mc Graw-Hill, 1994.

15. Braunwald E, ed. Heart Disease: A texrbook of cardiovascular medicine. 4th ed. Philadelphia: WB Saunders; 1992.

16. Bhandari AK, Anderson, JL, Gilber EM, et al. Correlation of symproms with occurrence of paroxysmal supraventricular rachycardia or atrial fibrillation: A transtelephonic monitoring study. Am Hear) 1992:124:381.

17. Wellens HJJ, Brugada P. Antiarhythraic therapy. The value of the history of the patient. Eur Heart ) 1987:8(suppl A): 71-75.

18. Wellens Hyj. Herkenning en behandeling van patienten met anvallen van paroxysmale tachycardie. Hart Bull 1982;13:51-58.

19. Lowenstein SR, Harken AH. A wide, complex look a cardiac dyshythmias. I Emerg Med $1987: 5.519-531$.

20. Lowenstein SR, Halperin BD, Reite MJ. Paroxysmal supraventricular tachycardias J Emerg Med $1996 ; 14: 39-51$.

21. Hale WE, Perkins LL, May FE, Marks RG, Stewart RB. Symprom Prevalence in the elderly. An ewaltuation of age, sex, distase and medication use. J Am Geriatr Soc 1986;34:333-340.

22. De Vreede-Swagemakers I. Widdershowen J. Acute coronary syndromes in the Matastricht area. (thesis). Maastricht, 1997. 
23. Hellemons-Boode $\mathrm{B}$, Langenberg-Ledeboer $\mathrm{M}$. Obsewations on atrial fibrillation in primary care (thesis). Maastricht. 1998.

24. Kinlay S, Leirch JW, Ne1 A, Chapman BL, Hardy DB, Fletcher PJ Cardiac event recorders yield more diagnoses and are more cost-effective than 48 -hour Holter monitoring in patients with palpitations. A controlled clinical trial. Ann Intern Med 1996; 124: 16-20.

25. DiMarco JP, Philbrick JT". Use of ambularory ellectrocardiographic (Holrer) monitoring Ann Int Med $1990 ; 113: 53-68$.

26. Bjerregaard P. Continuous ambulatory electrocandiography in healthy adult subjecrs over a 24-Jour period. Clinical datta, and ewaluation of instruments for ambulatory electrocardiography. Dan Med Bull 1984;31:283-97.

27. Coumel P. Diagnostic and prognostic values and limitations of Holter monitoring. Eur Heart J $1989 ; 105: 19-30$.

28. Grodman RS, Capone RJ, Most AS. Arthythmia surveillance by transtelephonic monitoring: Comparison with Holter monitoring in symptomatic ambulatory parients. Am Heart J $1979 ; 98: 459-464$

29. Connolly SJ, Cairns JA. Comaprison of one-, six, and 24-hour ambularory electrocardiographic monitoring for ventricular arthythmia as a predietor of mortality in survivors of acure myocardial infarcrion. Am J Cardiol 1992;69:308-313.

30. Van der Does E, Prins A. Rimestoomissen mogen die er zijn? Huisarts Wet $1987 ; 30$ (suppl) $23-26$.

31. Algra A. Electrocardiographic risk factors for sudden death. A study with 245 cases of sudden death during a two-year follow-up alter 24 -hour electrocardiography in 6693 patients (thesis). Roterdarn, 1990.

32. Van der Does $\mathbf{E}$. Lubsen J. Acute coronary events in general practice: the Imminent Myocardial Infarcrion Rotterdam Study (chesis). Rotrerdam, 1978.

33. Kennedy HL, Whirlock JA, Sprague MK, Kennedy LI, Buckingham TA, Goldberg RJ. Long-term follow-up of asympromatic healthy subjects with frequent and complex ventricular ecropy. N Engl J Med. 1985: 312(9): 193-7.

34. Horan MJ, Kenmedy HL. Ventricular ecropy. History, epidemiology, and dinical implications. IAMA 1984:251(3):380-6.

35. Josephson ME, Wellens HIJ. Differential diagnosis of supraventricular tachycardia. Cardiol Clin $1990 ; 8: 411-442$.

36. Klein Gl, Prystowsky EN, Yee R. Asymptomatic Wolff-Parkinson-White. Should we intervene? Circulation 1989:80:1902-1905.

37. Torner MP. Brugada P, Smeets ], er al. Ventricular fibrillation in the Wolff-Parkinson-White syndrome Eur Heart J 1991:12:144-150.

38. Feinberg WM. Blackshear JL, Laupacis A, Kronmal R, Hart RG. Prevalence, age distribution, and gender of patients with atrial fibrillation. Arch Intern Med; $155: 469-473$.

39. Onundarson PT, Thorgeirsson $G$, Jonmundsson E, Sigfusson N, Hardarson T. Chronic atrial fibrillation-epidemiologic fearures and 14-year follow-up: a case control study. Eur Heart J 1987:8: 521.7. 
40. Ostrander JD, Brandt RL, Kjelsberg MO, Epsrein FH. Elecrocardiographic findings among the adult population of a total natural community, Tecumsehy Michigan. Circulation 1965; 31 : 8.88-98.

41. Langenberg M, Hellemons BSP, Van Ree JW, er al. Arrial fibrillation in elderly patients: prevalence and comorbidiry in general practice. Br Med J 1996; $313: 1534$.

42. Lip GYH, Golding DJ,Nazir M, Beevers DG, Child DL, Flecher RI. A survey of atrial fibrillarion in general pracrice: the West Birmingham Atrial Fibrillation Project. Br J Gen Prack 1997; 47, 285-289.

43. Benjamin EI, Levy D, Vaziri SM, D'Agostino RB, Belanger AJ, wolf PA. Independent risk factors for arrial fibrillation in a population-based cohort. The Framingham Heart Study. JAMA 1994; 271(1.1): 840-4.

44. Wolf PA, Abbotr RD, Kannel WB. Atrial fibrillation: a major contributor to stroke in the elderly. The Framingham Study. Arch Incern Med 1987; 147: 1561 444.

45. Wolf PA, Abbort RD, Kannel WB. Atrial fibrillation as an independent risk factor for stroke: The Framingham study. Stroke $1991 ; 22: 983-988$.

46. Rodriguez LM, Smeets LRM, Xie B, et al. Improvement in left ventricular function by ablation of atrioventricular nodal conduction in selected patients with lone atrial fibrillation. Am J Cardiol $1993 ; 72: 1137-1141$.

47. Atrial fibrillation investigators. Risk factors for stroke and efficacy of antithrombotic treatment in atrial fibrillation. Analysis of pooled data from five randomized controlled trials. Arch Intern Med 1994; 154: 1449-1457.

48. Atrial fibrillation inyestigators. The efficacy of aspirin in patients with arrial fibrillation. Analysis of pooled data from 3 randomized controlled trials. Arch Intern Med 1997; 157: 1237-1240.

49. Rodriguez RD, Schocken DD. Update on sick sinus syndrome a cardiac disorder of aging. Gerintrics 1990;45:26-36.

50. Baerman JM, Morady F, DiCarlo LA, de Buirleir M, Arbor A. Differentianion of ventricular tachycardia from supraventricular tachycardia wich aberration: Value of the clinical history. Ann Emerge Med 1987; 16: 40-43.

51. Griffith MJ, de Belder MA, Linker NJ. Ward DE, Camm AJ. Multivatiate analysis to simplify the differential diagnosis of broad complex tachycardia. Br Heart J 1991:66:166-174.

52. Kastor \A. Ventricular tachycardia. Clin Cardiol 1989; 12:586.599.

53. Bigger JT, Sahar DT. Clinical types of proarrhythmic response to antiarrhythmic drugs. Am I Cardiol 1987,59:2E-9E.

54. Echr DS, Liebson $\mathbb{P R}$, Mitchell LB, et al. Mortality and morbidity in patients receiving encainide. flecainide or placebo. The cardiac arrhythmia suppression trial. N Engl J Med 1991; 324:781-8.

55. Marryn R, Somberg JC, Kerin N2. Proarhychmia of nonantiarrhythmic drugs. Am Heart J 1993; 126: $201-205$.

56. Kowey PR. Pharmacological effects of antiarrhythmic drugs. Review and update. Arch Inten Med 1998; 158: 325-332.

57. Zipes DP. Proarrhythmic effects of antiarrhythmic drugs. Am J Cardiol 1987; 59: 26E-31E,

58. American Psychiatric Associarion. Diagnostic and Statistical Manual of Mental Disorders. 4th ed. Washington DC: American Psychiatric Association, 1994. 
59. Weber BE, Kapoor WN. Evaluation and outcomes of pariens with palpitations. Am J Med 1996; 100: $138-148$.

60. Barsky AJ, Cheary PD, Sarnie MK, Ruskin JN. Panic disorder, palpitations, and the awareness of cardiac activity. I Nery Ment Dis 1994; 182:63-71.

61. Barsky Al. Palpitations, cardiac awareness and panic disorder. Am I Med 1992;92(1A Suppl: $315-345$.

62. Barsky A], Ahern DK, Bailey ED, Delamaver BA. Predictors of persistent and continued medical utilization. I Fam Pract 1996; 42:465-472.

63. Knudson MP. The natural history of palpitations in a family practice. J Fam Pract $1987 ; 24: 357-60$.

64. Lochen M. The Tromso Study: Associations between self-reported arrhythmia, psychological conditions, and lifestyle. Scand I Prim Health Care 1991;9:265-270.

65. Lochen M, Snaprud T, Zhang W, Rasmussen K. Arrhythmias in subjects without a history of palpirations: The Tromso Study. Eur Hearr J 1994; 15: 345-349.

66. Grodman RS, Capone RI, Most AS. Arrhythmia surveillance by transtelephonic monitoring: Comparison with Holrer monitoring in symptomatic ambulatory parients. Am Heart J 1979; $98: 459-464$

67. Zimetbaum PJ, Josephson ME. The evolving role of ambulatory arrhythmia monitoring in general cinical practice. Ann Intern Med 1990; 130: 848-856.

68. Shen W, Holmes DR, Hammill SC. Transrelephonic monitoring: Documentation of transient cardiac rhythm disturbances. Mayo Clin Proc 1987; 62: 109-112.

69. Reiffel JA, Schuthof E, Joseph B, ex al. Optimum duration of transtelephonic ECG monitoring when used for transient symptomatic event detection. J Electrocardiol 1991; 24: 165-167.

70. Sacket DL. Haynes RB, Tugwell P. Clinical epidemiology. A basic science for clinical practice. Boston/Toronto: Little, Brown and Company, 1985.

71. Knotmerus JA. Inrerpretation of diagnostic data: an unexplored field in general practice. J R Coll Gen Pract 1985; 35: 270-274.

72. Knotmerus IA. The effeces of disease werificarion and referral on relationship between symproms and diseases. Med Decis Making 1987; 7: 139-148.

73. Knotmerus IA. Medical decision making by general practitioners and specialists. Family Practice $1991 ; 8 ; 305-307$.

74. Knotmerus JA. Symptoms and selection bias: the influence of seleccion rowards speciatist care on the retation berwern symproms and diagnoses. Theorerical Med 1989; 10:67-81.

75. Knotmens JA, Leffers $P$. The influence of referral patterns on the characteristics of diagnastic tests. J Clin Epidemiol 1992; 45: 1143-1154. 
CHAPEER 2

\section{Occurrence of arrhythmias in general practice}

Zwrietering PJ, Knottnerus JA, Gorgels APM, Rinkens PELM 


\section{ABSTRACT}

Objective. To study the occurrence and distribution of arrhythmias in pacients with symptoms possibly caused by arrhythmias, in order co support the diagnostic process in general pracrice.

Design. From 1989-1991 all patients who consulted their general practitioner with symptoms or signs possibly indicating an arrhythmia had a transtelephonic electrocardiogram, which was sent to the Department of Cardiology for interpretarion. Setting. 20 Durch general practices, serving a population of nearly 50000 inhabitants. Sulbyects. A toral of 868 patients were included in the study.

Resmlts. An arrhythmia was documented by ECG in $32 \%$ of the parients. Of these, $31 \%$ clinically more relevant arrhythmias needed medical attention. An incidence of 2.6 arrhythmias per 1000 listed patients was calculated. There was a highly positive cortelation between the accurrence of arthythmias and age. Relatively more arhythmias were seen in men, in parients with occasional findings, and when there were symptoms that possibly indicated haemodynamic imbalance.

Conchusion. Clinically relevant arthythmas can be detected in general practice with 12-lead ECG recording in a significant proportion of patients with symptoms and physical findings suggesting an arhythmia. The distribution of arthytumias described in this study can help general pracritioners in their diagnostic management.

Key words. arthythmia, epidemiology, incidence, general practice. 


\section{INTRODUCTION}

Patients with symptoms that may be caused by arrhythmias are frequently seen in general practice. It is unclear to what extent such symptoms are caused by distinet arrhythmias, and how far they can be detected. General practitioners (GPs) in The Netherlands do not make ECG recordings routinely in these patients. Their management is largely based on an estimation of chance, whether an arrhythmiat is present or absent. From the one side GPs do nor like to use superfluous diagnostics but also do not want to misdiagnose a relevant arrhythmia. However, the literature reveals virtually no data about the occurrence of distinct arrhythmias in general practice, nor quantitative information about the likelihood that an arrhythmia can be found in patients with such symptoms. Froom and Froom ${ }^{1}$ described only electrocardiographic abnormalities in primary care patients during a one-year period, not focused on arrhythmias. By contrast, the incidences and prevalences of arrhythmias in selected working populations $s^{2-4}$ and in the community ${ }^{4-8}$ are well known. These studies are of little practical importance for GPs since arrhythmias do not always result in a consultation, and the diagnostic and prognostic value of clinical findings in patients may depend on the selected population. ${ }^{2,4,9}$ Besides, many of the population-based studies have been done with 24-hour ambulatory ECG, and there is poor correlation between arrhythmias detected by long-term ECG and a standard 12-lead ECG. ${ }^{3,8,10}$ Data about the occurrence of arrhythmias are of utmost importance for the GP because his diagnostic procedure is based on the prior probability of the occurrence. ${ }^{11}$

The existing Dutch registration networks do not give an extensive specification of the arrhythmias in general practice and use a classification which is not commonly used in clinical practice. ${ }^{12-15}$ The distribution of the distinct arrhythmias is meaningful for the risk stratification of cardiovascular morbidiry. For GPs, it is important to know whether they can properly reassure or treat the patients or whether they should be referred to a cardiologist. Because the prior probability is very important in the diagnostic process and in the differentiation between innocent and severe arrhythmias, we studied the occurrence of arrhythmias in general practice, and associations between arrhychmias and patient characteristics and medical history. The patients in our study had symptoms or coincidental findings possibly indicating an arrhythmia. Arrhythmias were detected with 12-lead recordings, equipment usually available in general practice.

\section{METHODS}

Over a 2-year period, 27 Dutch GPs from 20 practices in Maastricht and the direct surroundings (total population of nearly 50000 patients) participated in the study. There is only one hospital in the region, the Academic Hospital Maastricht; it 
collaborates with all the GPs. The mean duration of participation of practices was 22.6 months (range 3-26 months). Patients, consulting their GP because of palpitations were enrolled. In addition, patients presenting with dyspnoea, vertigo, angina pectoris, farigue, syncope and other symptoms were included, when the GP suspected that an arrhythmia was the cause of the symptoms. Furthermore, parients were included when an abnormal rhythm was found coincidentally during a consulration, e.g. an irregular pulse or heart beat, a rate of more than 100 or less than 60 bears per minute, or five or more extrasystoles per minute. Presenting symptoms and coincidental findings had to be new for the GP or should represent a diagnostic problem. Patients were excluded as follows: age less than 15 years; fever; unsuccessful ECG recording or loss of research forms; participation inconsistent with good practice, e.g. patients with acute myocardial infarction or circulatory arrest. Patients, who visited the emergency department of the hospital during the same period because of arrhythmias were registered. Registration and hospital charts were compared to check whether parients from the participating GPs were not included, incorrectly.

Transrelephonic ECGs from all the included patients were sent to the Department of Cardiology of the hospital. Patients who did not have symptoms during a consultation, were asked to come back for an ECG when symptoms occurred. If more than one ECG was available, the one taken when the patient had symptoms was used for analysis. The transtelephonic ECG recordings were obtained by an ECG modem 3 (Cardio Control BV, Rijswijk, The Netherlands), consisting of a 12-lead ECG taken during 36 seconds.

The interpretation of the ECGs was done by a cardiology fellow and checked by a senior cardiologist; they were unaware of the findings of the medical history and physical examination. When extrasystoles were present on the ECG in combination with a rhythm other than a sinus rhythm, the ECG was interprered as the leadling rhythm and no attention was paid to the extrasystoles.

GPs had to fill out the research forms before receiving the interpretation of the ECG. 'The GPs' registration system was used to collect patients' medical history data. Chi-square tests for independent proportions and linear trend were used in the statistical analysis.

Incidence $(Y)$ was calculated according the formula:

$Y=\frac{\sum P_{i} Y_{i}}{\sum P_{i}}$

where $Y_{i}=$ incidence per 1000 listed patients per year in practice $i, X_{i}=$ amount of detected arrhythmias in practice $i, P_{i}=$ participarion time practice $i \times$ patients per 1000 , and $Y_{i}=X_{i} / P_{i}$. 


\section{RESULTS}

A total of 878 patients met the inclusion criteria. Ten were excluded because the ECG recordings or the research forms were lost. During the study period, seven patients from the participaring GPs who were not under cardiologist supervision and were not previously known to have an arrhythmia wisited the emergency department of the hospital with a rather serious arrhythmia and were incorrectly not enrolled in the study: four had atrial fibrillation, two $A V$-nodal tachycardia and one atrial flutter. Of the 868 remaining patients, 794 were seen at the GP's office and 74 during home visits. Of the latter, 12 visits were emergency cases. In $75 \%$ of the cases a new symptom or coincidental finding was the reason for including patients; in the remainder the GP had a diagnostic problem in a patient known to have an arrhythmia. Most of the parients $(n=762)$ were enrolled because of specific symptoms, the remaining $(n=106)$ because of coincidental findings (Table 1). One hundred and mineteen patients (14\%) were included on more than one symptoms or findings. GPs succeeded in making an ECG recording while they had specific symptoms or signs in $36 \%$ of the cases. Most of the included patients $(63 \%)$ were women.

Table 1. Reasons for inclusion of the patients studied and arthyth nias detected.

\begin{tabular}{|c|c|c|c|c|}
\hline & \multicolumn{2}{|c|}{ Parients } & \multicolumn{2}{|c|}{ Arrhythmias derected } \\
\hline & $\mathrm{n}^{*}$ & $\%^{*}$ & $\mathrm{n}^{*}$ & $\%$ \\
\hline \multicolumn{5}{|l|}{ Presenting symptoms } \\
\hline Palpitations & 557 & $(64.2)$ & 138 & 24.8 \\
\hline Angina pectoris & 138 & $(15.9)$ & 34 & 24.6 \\
\hline Verrigo & 76 & $(8.8)$ & 35 & 46.1 \\
\hline Dyspnoeca & 67 & $(7.7)$ & 33 & 49.3 \\
\hline Fangue & 40 & $(4.6)$ & 15 & 37.5 \\
\hline Collapse & 22 & $(2.5)$ & 13 & 59.1 \\
\hline Orher & 22 & $(2.5)$ & 4 & 18.2 \\
\hline Subtotal & 762 & $(87.8)$ & 215 & 28.2 \\
\hline \multicolumn{5}{|l|}{ Occasional findings } \\
\hline Irregular pullse and or heart acrion & 46 & $(5.3)$ & 31 & 67.4 \\
\hline Pulse rate and or heart rate $>100$ & 42 & $(4.8)$ & 20 & 47.6 \\
\hline Pulse rate and or heart rare $<60$ & 10 & $(1,2)$ & 8 & 80.0 \\
\hline$\geq 5$ extrasystoles & 14 & $(1.6)$ & 11 & 78.6 \\
\hline Subtatal & 106 & $(1.2 .2)$ & 65 & 61.3 \\
\hline Total & 868 & $(100,0)$ & 280 & 32.3 \\
\hline
\end{tabular}

* Patienrs could be included on more than one symptom.

*** Row percentages. 
An arrhythmia was derected in nearly one third of the cases. The same arrhythmia was detected in only $27 \%$ of the patients who were known to have an arrhythmia. Taking participation time and practice size into account, an overall incidence of 2.6 $(95 \% \mathrm{Cl}=1.9-3.3 ; \mathrm{SD}=1.6)$, and incidences of $2.2(\mathrm{SD}=1.6)$ and $2.9(\mathrm{SD}=1.9)$ arrhyrhmias per 1000 listed men and women per year, respectively were calculared. An arrhythmia was detected in $48 \%$ of the patients who had specific symptoms during the $E C G$, and in $19 \%$ without symptoms at the recording. Of the patients who were included because of coincidental findings, an arrhythmia was found in $81 \%$ with signs during recording and in $7 \%$ without signs. The majority of the patients $(64 \%)$ were included because of palpitations. An arrhythmia was found, depending on the inclusion criteria, in $48-80 \%$ of the patients who were included because of occasional. findings and in $18-59 \%$ of the patients who were included because of symptoms. An arrhythmia was detected in nearly half of the patients, who were suspected by the GP of having an arrhythmia based on symptoms, possibly caused by haemodynamic imbalance, e.g. vertigo, dyspnoea, fatigue, and collapse.

Table 2. Medical history in patients with syrnptoms or physical findings suggesting an arrhythmia, by sex.

\begin{tabular}{|c|c|c|c|c|c|c|c|}
\hline \multirow[t]{2}{*}{ Medical history } & \multicolumn{2}{|c|}{ Men } & \multicolumn{2}{|c|}{ Women } & \multirow[b]{2}{*}{ OR $(95 \% \mathrm{Cl})$} & \multicolumn{2}{|c|}{ Toral } \\
\hline & $\mathrm{n}$ & $\%$ & $\mathrm{n}$ & $\%$ & & $n$ & $\%$ \\
\hline Coronary disease & 31 & $(9.6)$ & 22 & $(4.0)$ & $2.54(1.39-4.63)^{* *}$ & 53 & (6.1) \\
\hline Myocardial infarcrion & 17 & $(5.3)$ & 6 & $(1.1)$ & $5.02(1.86-15.68)^{* * *}$ & 23 & $(2.7)$ \\
\hline Valve disorder & 5 & (1.6) & 12 & $(2.2)$ & $0.70(0.21-2.17)$ & 17 & $(2.0)$ \\
\hline Arrhythmia & 33 & $(10.2)$ & 45 & $(8.3)$ & $1.27(0.77-2.09)$ & 78 & $(9.0)$ \\
\hline Heart failure & 14 & $(4.3)$ & 13 & $(2.4)$ & $2.76(1.20-6.36)^{* *}$ & 27 & (3.1) \\
\hline Conducrion disturbances & 1 & $(0.3)$ & 1 & $(0.2)$ & $1.70(0.02-133.5)$ & 2 & $(0.2)$ \\
\hline Hypertension & 66 & $(20.6)$ & 114 & $(21.0)$ & $0.98(0.69-1.39)$ & 180 & $(20.8)$ \\
\hline Orthostatic hyporension & 3 & $(0.9)$ & 11 & (2.0) & $0.46(0.08-1.75)$ & 14 & (1.6) \\
\hline COPD & 36 & $(11.2)$ & 24 & $(4.4)$ & $2.74(1.55-4.84)^{* * *}$ & 60 & (6.9) \\
\hline Neurological disease & 26 & $(8.1)$ & 30 & $(5.5)$ & $1.51(0.85-2.69)$ & 56 & $(6.5)$ \\
\hline Ear disease & 9 & $(2.8)$ & 19 & (3.5) & $0.80(0.33-1.88)$ & 28 & $(3.2)$ \\
\hline Diabetes mellinus & 11 & $(3.4)$ & 15 & $(2.8)$ & $1.25(0.53-2.93)$ & 26 & $(3.0)$ \\
\hline Psycharric illness & 21 & $(6.5)$ & 29 & $(5.3)$ & $1.23(0.67-2.30)$ & 50 & (5.8) \\
\hline Hyperentilation syndrome & 42 & $(13.0)$ & 108 & $(19.8)$ & $0.61(0.41 \times 0.92)^{*}$ & 150 & (17.3) \\
\hline Other & 70 & $(21.7)$ & 109 & $(20.0)$ & $1.11(0.78-1.58)$ & 179 & $(20.6)$ \\
\hline Positive medical history & 207 & $(64.3)$ & 342 & $(62.6)$ & $1.07(0.80-1.44)$ & 549 & $(63,2)$ \\
\hline Total & 322 & $(100.0)$ & 546 & $(100.0)$ & & 868 & $(100.0)$ \\
\hline
\end{tabular}

1) Column percentage exceds $100 \%$ because patients could have more than one known disease.

*) $p<0.05$

*) pe0.01 
Table 3. Arrhythmias detected in patients with symptoms or physical findings suggesting an arthythmia, by age and sex $(n=868)$.

\begin{tabular}{|c|c|c|c|c|c|c|c|c|c|}
\hline \multirow[b]{2}{*}{ Age group } & \multicolumn{3}{|l|}{ Patients } & \multicolumn{3}{|c|}{ Arrhythmias detecred } & \multicolumn{3}{|c|}{ Oo Artyythmias } \\
\hline & Both sexes & Men & Women & Both sexes & Men & Women & Both sexes & $\mathrm{Men}$ & Women \\
\hline $15-24$ & 36 & 15 & 21 & 3 & 2 & 1 & 8.3 & 13.3 & 4.8 \\
\hline $25-34$ & 116 & 42 & 74 & 18 & 9 & 9 & 15.5 & 21.4 & 12.2 \\
\hline $35-44$ & 142 & 54 & 88 & 26 & 14 & 12 & 18.3 & 25.9 & 13.6 \\
\hline $45-54$ & 175 & 66 & 109 & 41 & 13 & 28 & 23.4 & 19.7 & 25.7 \\
\hline $55-64$ & 154 & 55 & 99 & 53 & 28 & 25 & 34.4 & 509 & 253 \\
\hline $65-74$ & 169 & 65 & 104 & 89 & 36 & 53 & 52.7 & 55.4 & 51.0 \\
\hline $75-84$ & 63 & 22 & 41 & 39 & 15 & 24 & 61.9 & 68.2 & 58.5 \\
\hline $85-94$ & 13 & 3 & 10 & 11 & 3 & 8 & 84.6 & 100.0 & 80.0 \\
\hline Total & 868 & 322 & 546 & 280 & 120 & 160 & 32.3 & 37.3 & 29.3 \\
\hline
\end{tabular}

About one fifth of the patients had a history of high blood pressure and $17 \%$ were known to have hyperventilation; one third of the patients had no relevant medical history (Table 2). A positive history of coronary disease, myocardial infarction, heart failure, and COPD was significantly more frequent $(p<0.01)$ in men, while more women had a history of hyperventilation $(p<0.05)$. Although the total incidence of arrhythmias in women was higher, the percentage of arrhythmias found in men with symptoms or coincidental findings was higher $(37 \%$ versus $29 \% \mathrm{p}<0.02)$. The percentage of arrhythmias increased significantly $\left(\mathrm{p}<10^{-8}\right)$ with age (Table 3). Almost no arrhythmias were found in the age category 15-24, while the majority was found in the elderly: half of the arrhythmias were found in patients 55-74 years of age. Table 4 gives an overview of the detected arrhythmias. There was a high percentage of patients with extrasystoles and atrial fibrillation. Severe arrhythmias such as sinus arrest, ventricular tachycardias and tachycardias in the setring of the Wolff-Parkinson-White syndrome, were infrequent in this general practice population. Most of the detected arrhythmias (87\%) were not previously known in these patients, including some severe arrhythmias. Apart from the increasing toral percentage of arrhythmias, the percentage of atrial fibrillation $\left(p<10^{-8}\right)$ and supraventricular and ventricular extrasystoles $\left(\mathrm{p}<10^{-4}\right)$ also increased with advancing age. Atrial fibrillation was found in 16\% of the patients aged 65 years and older. Correlations with age were not present for sinus bradycardia and sinus tachycardia. The occurrence of the remaining arrhythmias was also related $\left(\mathrm{p}<10^{-4}\right)$ to higher age (Table 5). 
Table 4. ECG diagnosis in parients with symproms or physical signs suggesting an arrhychmia, by sex and currency.

\begin{tabular}{|c|c|c|c|c|c|c|}
\hline \multirow[b]{2}{*}{ ECG diagnosis } & \multirow[b]{2}{*}{ Total } & \multirow[b]{2}{*}{$\%$} & \multicolumn{2}{|c|}{ Patients $(n=868)$} & \multirow[b]{2}{*}{$\begin{array}{l}\text { With new } \\
\text { complains }\end{array}$} & \multirow[b]{2}{*}{$\begin{array}{l}\text { With diagnostic } \\
\text { problem }\end{array}$} \\
\hline & & & $\begin{array}{l}\text { Men } \\
\mathrm{n}=322(\%)\end{array}$ & $\begin{array}{l}\text { Women } \\
\mathrm{n}=546(\%)\end{array}$ & & \\
\hline $\begin{array}{l}\text { Ventricular } \\
\text { extrasystoles }\end{array}$ & 68 & 24.3 & $26(8.1)$ & $42(7.7)$ & 52 & 16 \\
\hline $\begin{array}{l}\text { Supraventricular } \\
\text { extrasystoles }\end{array}$ & $34^{*}$ & 12.1 & $11(3.4)$ & $23(4.2)$ & 28 & 5 \\
\hline $\begin{array}{l}\text { Supra- and ventricular } \\
\text { extrasystoles }\end{array}$ & 5 & 1.8 & $3(0.9)$ & $2(0.4)$ & 5 & 0 \\
\hline Subroula exirasystoles & 107 & 38.2 & $40(12.4)$ & $67(12.3)$ & 85 & 21 \\
\hline Arrial fibrillation & 64 & 22.9 & $30(9.3)$ & $3.4(6.2)$ & 53 & 11 \\
\hline Sinus bradycardia & 40 & 14.3 & $24(7.5)$ & $16(2.9)$ & 39 & 1 \\
\hline Sinus rachycardia & 36 & 12.9 & $8(2.5)$ & $28(5.1)$ & 35 & 1 \\
\hline Atrial flutter & 6 & 2.1 & $4(1.2)$ & $2(0.4)$ & 5 & $\mathbb{1}$ \\
\hline Sinus arrhythmia & 5 & 1.8 & $3(0.9)$ & $2(0,4)$ & 5 & 0 \\
\hline $\begin{array}{l}\text { Supraventricular } \\
\text { tachyeardia nor specified }\end{array}$ & 4 & 1.4 & $2(0.6)$ & $2(0.4)$ & 4 & 0 \\
\hline Regular atrial rhythm & 4 & 1.4 & 1. $(0.3)$ & $3(0.5)$ & 4 & 0 \\
\hline Chaotic arrial rlyythm & 3 & 1.1 & $2(0.6)$ & $1(0.2)$ & 3 & 0 \\
\hline AV nodal tachycardia & 3 & 1.1 & 1. $(0.3)$ & $2(0.4)$ & 3 & 0 \\
\hline Atrial tachycardia & 2 & 0.7 & $1(0.3)$ & $1(0.2)$ & 2 & 0 \\
\hline Arrial bigeminy & 2 & 0.7 & $2(0.6)$ & $0(0.0)$ & 2 & 0 \\
\hline $\begin{array}{l}\text { Idioventricular rhythm } \\
\text { /sinus arrest }\end{array}$ & 2 & 0.7 & $1(0.3)$ & $1(0.2)$ & 2 & 0 \\
\hline Ventricular tachycardia & 1 & 0.4 & $1(0.3)$ & $0(0.0)$ & 0 & 1 \\
\hline $\begin{array}{l}\text { Circus movement } \\
\text { tachycardia }\end{array}$ & 1 & 0.4 & $0(0.0)$ & $1(0.2)$ & 1 & 0 \\
\hline Toral & 280 & 100.0 & $120(37.3)$ & $160(29.3)$ & 243 & 36 \\
\hline
\end{tabular}

") In one patient with supravencricular exrrasystoles ir was not known whether the arrhythmia was new.

**) Percentage of arthythmias detected. 
Table 5. ECG diagnosis in parients with symproms of physical finding: suggesting an atritythmia, by age $(\mathrm{N}=868$ ).

\begin{tabular}{|c|c|c|c|c|c|c|c|c|c|c|c|c|c|c|c|}
\hline \multirow[b]{2}{*}{ Age group } & \multirow[b]{2}{*}{ Total } & \multicolumn{2}{|l|}{$S R$} & \multicolumn{2}{|c|}{ SWES } & \multicolumn{2}{|c|}{ VES } & \multicolumn{2}{|c|}{$\mathrm{Al}$} & \multicolumn{2}{|c|}{$S T$} & \multicolumn{2}{|l|}{$\mathrm{SB}$} & \multirow{2}{*}{\multicolumn{2}{|c|}{$\frac{\text { other }}{\mathrm{n} \%}$}} \\
\hline & & $\mathrm{n}$ & $\%$ & $\mathrm{n}$ & $\%$ & n & $\%$ & $\mathrm{n}$ & $\%$ & $\mathrm{n}$ & 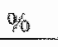 & $\mathrm{n}$ & 90 & & \\
\hline $15-24$ & 36 & 33 & 91.7 & 0 & 0.0 & 0 & 0.0 & 0 & 0.0 & 1 & 2.8 & 2 & 5.6 & 0 & 0.0 \\
\hline $25-34$ & 116 & 98 & 84.5 & 1 & 0.9 & 3 & 2,6 & 1 & 0.9 & 6 & 5.2 & 6 & 5.2 & 1 & 0.9 \\
\hline $35-44^{1,2}$ & 142 & 115 & 81.0 & 3 & 2.1 & 8 & 5.6 & 2 & 1.4 & 1 & 0.7 & 10 & 7.0 & 4 & 2.8 \\
\hline $45-54$ & 175 & 134 & 76.6 & 7 & 4.0 & 11 & 6.3 & 5 & 2.9 & 8 & 4.6 & 7 & 4.0 & 3 & 1.7 \\
\hline $55-64$ & 1.54 & 101 & 65.6 & 3 & 1.9 & 15 & 9.7 & 16 & 10.4 & 7 & 4.5 & 6 & 3.9 & 6 & 3.9 \\
\hline $65-74^{2}$ & 169 & 80 & 47.3 & 14 & 83 & 29 & 17.2 & 21 & 12.4 & 9 & 5.3 & 8 & 4.7 & 10 & 5.9 \\
\hline $75-84^{3}$ & 63 & 24 & 38.1 & 10 & 15.9 & 6 & 9.5 & 13 & 20.6 & 4 & 6.3 & 0 & 0.0 & & 11.1 \\
\hline $85-94$ & 13 & 2 & 15.4 & 1 & 7.7 & 1 & 7.7 & 6 & 46.2 & 0 & 0.0 & 1 & 7.7 & & 15.4 \\
\hline Total & 868 & 587 & 67.6 & 39 & 4.5 & 73 & 8.4 & 64 & 7.4 & 36 & 4.1 & 40 & 4.6 & 33 & 3.8 \\
\hline
\end{tabular}

Abbreviations: $S R=S$ inus rhythm, SVES $=$ Suptaventricular extrasystoles, $V E S=V$ entricular extrasystoles, $A F=$ Atrial fibrillation, $\mathrm{ST}=$ Sinus tachycardia, $\mathrm{SB}=$ Sinus bradycardia. I In one patient there was no complete ECG recording. 2) Two parients had VES and SVES. ${ }^{3}$ ) One parient had VES and SVES.

\section{DISCUSSION}

The figure of 2-3 new arrhythmias per 1000 listed patients per year seen by the GPs in our study is in accordance with the figures from existing registration networks. Most of the arrhythmias were detected as a result of symproms, particularly palpitations. Relatively more arrhythmias were detected in men and in patients with symptoms possibly caused by haemodynamic imbalance. The medical history of patients in this study population is a typical reflection of the history of patients in a general pracrice population, with relatively few cases of specific cardiovascular disease and quite a large amount of psychosocial and psychiatric morbidity. A positive medical history of cardiovascular disease was obtained relatively more frequently in men. The large percentage of patients known to have hyperventilation was striking. This is in accordance with other studies in which there was an apparent association between a history of psychiatric illness and palpitations. ${ }^{16,17}$ Of the detected arrhythmias, $90 \%$ were less severe and could be considered within the territory of the GP. The highly positive correlation between the occurrence of arrhythmias and age, especially atrial fibrillation and extrasystoles, is in accordance with the literature. ${ }^{5-8,10}$ The incidence found in this study was based on patients who consulted their GP because of symptoms or with coincidental findings. It is likely that the population-based incidence of arrhythmias such as extrasystoles and atrial fibrillation is larger because arrhythmias may be asymptomatic or do not bother the parient. The figures in our study give a reliable presentation of patients with arrhythmias in general practice because the parients were studied in a health care system in which all the patients are registered 
with a $\mathrm{GP}$ without free access to specialist care. More arrhythmias, e.g. arrhythmias of short duration would have been detected with 24-hour ambulatory ECG, but such equipment is not used in general practice. Furthermore, results from 24-hour ambulatory ECG cannot be adopted because then the majority of people would have had arrhythmias and its clinical relevance would have been questionable. According to the literature, only in a minority of patients, and particularly in the young, with symptoms that indicate an arrhythmia, an arthythmia can be detected in general practice. This is partly due to the paroxysmal character of most arrhythmias. Besides, symptoms such as palpitations are also associated with many other somatic and psychiatric diseases. Because of the low prior probability of severe arrhythmias, the GP has to be especially alert and must make use of information from the medical history and the symptoms and signs, complemented eventually by ECG monitoring when diagnostic certainty is needed. The large prior probability of arrhythmias in the elderly makes ECG monitoring in older patients witly symptoms useful in most instances. Despite the suggestion in the literature that patients with palpirations have in general no increased risk of sudden death or cardiovascular morbidity and mortality ${ }^{18}$, it is very important to check whether the symptoms could have been caused by an arrhythmia. It is important for GPs to detect rare severe arrhythmias and to diagnose innocent arrhythmias, which can be very unpleasant, in order to reassure the patient. Whilst the accessibility of general practices is in most instances better than that of hospitals, the GP can also play an important role in detecting paroxysmal arrhythmias of short duration. We conclude that an arrhythmia can indeed be detected in general practice in a substantial proportion of patients with symptoms or physical findings leading to the suspicion of an arrhythmia. In the detection of arrhythmias, and the differentiation between severe and innocent ones, nor only age and prior probability are important, but also gender and the diagnostic value of symptoms and signs. Further study on this diagnostic value in arrhythmias is recommended.

\section{ACKNOWLEDGEMENT}

This study was supported by grant no 900-715-153 of the Council of Medical Research of the Netherlands Organisation of Scientific Research. We thank the participating GPs and their assistants for their cooperation in the study, and $\operatorname{Dr} M$ Kleijne, cardiologist, for her interpretation of the ECGs.

\section{REFERENCES}

1. Froom J, Froom P. Electrocardiogram abnormalicies in primary care parients. J Fam Pract $1984: 18: 223-5$. 
2. Rase G, Baxter PJ, Reid DD, McCarmey P. Prevalence and prognosis of electrocandiographic find-

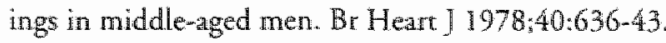

3. Green MS, Jucha E, Luz J, Cocos M, Nurynberg M, Rosenberg N. Prevalence and cortelates of ventricular premature bears derected by ambulatory electrocardiography in working populations. I Epidemiol 1988;127:955-68.

4. Barret PA, Peter CT, Swan HIC, Singh BN, Mandel WJ. The frequency and prognostic significance of electrocardiographic abnormalities in clinically normal individualls. Prog Cardiovasc Dis 1981;23:299-319.

5. Kulbertus. HE, Leval-Rutren F de, Albert A, Dubois M, Perir JM. Electrocardiography changes occurring with advancing age. In: Wellens HJ, editor. What's new in electrocardiography? Ilst ed. The Hague: Nijhof 1981:300-13.

6. Kannel WB, Abbott RD, Savage DD, McNamara PM. Epidemiologic features of chronic atrial fibrillacion. The Framingham Study. New Engl J Med 1982;306:1018-22.

7. De Bacquer D, Martins Pereira LS, De Backer G, De Henauw S, Kornitzer M. Prevalences and correlates of ECG abnormalities in the adult Belgian population.. J Electrocandial 1995;28:1-11.

8. Bethge KR, Bethge D, Meiners $\mathrm{G}$, Lichtlen PR. Incidence and prognostic significance of ventricular arthythmias in individuals without detectable heart disease. Eur Heart $\ 1983 ; 4: 338-46$.

9. Knotmerus JA. The effects of disease verification and refertal on relationship berween symproms and diseases. Med Decis Making 1987;7:139-48.

10. Bjerregaard P. Continuous ambulatory electrocardiography in healthy adult subjects over a 24-hour period. Clinical data, and evaluation of instruments for ambulatory electrocardiography. Dan Med Bull 1984;31:283-97.

11. Knotmerus JA. Interpretation of diagnostic data: an unexplored field in general practice. J R Coll Gen Practitioners 1985:35:270-4.

12. Lamberts $\mathrm{H}$, Wood $\mathrm{M}$, editors. ICPC. International Classification of Primary Care. Oxford: $\mathrm{Ox}$ ford University Press, 1987.

13. Van Lisdonk EH, Van den Bosch WJHM, Huygen FJA, Lagro-Janssen ALM. Ziekten in de huisarrsprakrijk (Diseases in general practice). Urrechr: Bunge, 1990.

14. Lamberts $H$. In her huis van de huisarts (In the house of the general practitioner). Leliestad: Meditekst, 1.991 .

15. Metsemakers JFM, Hoppener P, Knotnerus JA, Kocken RJJ, Limonard CBG. Computerized health information in the Nerherlands: a registration network of family practices. Br] Gen Practice 1992;42:102-6.

16. Barsky AJ. Palpitations, cardiac awareness and panic disorder. Am J Med 1992;92(1A Suppl):31S-34S.

17. Knudson MP. The natural history of palpitations in a family pracrice. I Fam Pract $1987 ; 24: 357-60$.

18. Algra A. Electrocardiographte risk facrors for sudden deach. A study with 245 cases of sudden death during a two-year follow-up after 24-hour electrocardiography in 6693 patients [dissertation]. Rotterdam, 1990. 



\section{Arrhythmias in general practice - diagnostic value of patient characteristics, medical history and symptoms -}

Zwietering PJ, Knottnerus JA, Rinkens PELM, Kleijne MAWJ, Gorgels APM 


\section{ABSTRACT}

Backgrond. Complaints possibly caused by arrhythmias are frequently seen in general practice. It is unclear to what extent such complaints can differentiare berween arrhythmias and other pathology in general practice.

Objectives. To assess the value of symptoms (a) in diagnosing arrhythmias in general practice and (b) in identifying patients with clinically relevant arthythmias.

Method. During a two-year period, a structured history from 762 patients with new complaints possibly related to an arrhythmia was taken by the general practitioner (GP) and a transtelephonic electrocardiogram (ECG) was made.

Reswits. In $28.3 \%$ of the patients arrhythmias were detected and $8.8 \%$ were dinically relevant. Several patient characteristics, symptoms and medical history findings have high predictive values in diagnosing arrhythmias. In the logistic regression analysis, age and to a lesser extent, male gender, palpitations and dyspnoea during consultarion and the use of cardiovascular drugs are associated with the presence of arrhythmias. In detecting clinically relevant arrhythmias the same parameters except gender are important, as well as a history of arrhythmias. The use of central nervous system medication and frequent psychosomatic complaints are negatively associated with the presence of dixically relevant arrhythmias.

Conclusiows. In general practice, patient characteristics, symptoms and medical history findings can be used in the detecrion of arrhythmias and the assessment of their severity. They can be useful in the decision to make an ECG recording.

Key wonds. Arrlythmia, medical history taking, physical examination, diagnosils, general practice, predictive value. 


\section{INTRODUCTION}

The diagnostic process in general practice depends largely upon the prior probability of disease and the predictive value of signs and symptoms. ${ }^{1}$ In general practice, an incidence of 2.6 arrhythmias per 1000 listed patients has recently been reported. ${ }^{2}$ Other studies in primary care patients have been focused more on electrocardiographic abnormalities than on arrhythmias. ${ }^{3,4}$ Data from Dutch general practice registration nerworks give incidences of 2-3 arrhythmias per 1000 patient-years for men and 2-5 for women, and period prevalences of 4-8 for men and 8-9 for women per 1000 per year. 5,6 The "Registration Network Family Practices" reports a point prevalence of 20 diagnosed arrhythmias per 1000 registered subjects. ${ }^{7}$

Incidences and prevalences of arrhythmias from population surveys are of little practical importance for general practitioners (GPs) since arrhythmias do not always result in a consultation, and the diagnostic value of symptoms and signs in unselected and selected study populations are different. ${ }^{8}$ Hence, the diagnostic value of findings from medical history-taking and physical examination in patients referred to cardiology departments cannot be generalised to general pracrice either. In patients with symptoms possibly indicating an arrhythmia, investigations must take place. Besides, when an arrhythmia is present a differentiation must be made berween innocent arrhythmias and clinically relevant arrhythmias which need further diagnostic exploration or medical trearment. Cardiology textbooks emphasize the importance of the medical history and describe the possible relation berween symptoms and various arrhythmias. "The physician must learn the predictive value of symptoms and determine whether or not the history obrained is sufficiently adequate to be used in the decision-making process about the patient", according to Hurst. ${ }^{9}$ However, we could not find research reports from a non-referred population, where attention is paid to the quantitative aspects of this relation in terms of sensitivity, specificity and predictive value and an independent "gold standard" is used. Wellens and Brugada drew attention to the value of the history of parients with arrhythmias. They described the misdiagnoses by GPs in patients with palpitations, having no signs and symptoms during consultation, in a referred population with proven supraventricular tachycardias, ${ }^{10,11}$

In general practice, recognition of arrhythmias is primarily based upon signs and symptoms. Further diagnostic procedures will follow when the GP wants to reassure the patient or if more dangerous arrhythmias are suspected. However, research data on the diagnostic value of signs and symptoms in arrhythmias in general practice is becoming more important because of a growing incidence of arrbythmias as a consequence of the ageing Dutch population. Therefore, we studied the value of patient characteristics, medicall history and symptoms in diagnosing arrhythmias in general practice and in identifying parients with clinically relevant arrhythmias. 


\section{METHODS}

\section{PATIENTS AND MEASUREMENTS}

Twenty-seven GPs from 20 urban and suburban practices in Limburg, the NetherJands, with a total population of nearly 50,000 patients, participated in the study for two years. The mean duration of participation of the practices was 22.6 months. All patients consulting their GP because of palpitations were enrolled. Palpitations were defined as all feelings of an abnormal heartbeat. In addition, patients consulting their GP with dyspnoea, faintness, angina pectoris, fatigue, collapse and other complaints were included, if the GP considered an arrhythmia as a possible cause of the complaints. Patients could be included in the study only once. Complaints had to be new for the GP or should represent a diagnostic problem. Patients younger than 15 years of age and parients with fever were also excluded. In addition, patients were excluded if participation were not be consistent with good practice since, immediate referral was indicated, for example patients with an acute myocardial infarction, circulatory arrest, or an otherwise poor circulatory condition. In all patients, a structured medical history was taken and a physical examination was done.

A rotal of 762 patients met the inclusion criteria. Table 1 gives a further specification of baseline characteristics. In all patients, a transtelephonic ECG was sent to the Department of Cardiology of the local hospital. Parients who did not have symptoms during consultation were asked to come back for an ECG registration during symptoms, throughout the study period. If there was more than one ECG, the ECG during complaints was used for analysis. Differentiation was made between patients with symptoms in general, during consultation and during ECG recording. In 21 patients, data about symptoms during ECG recording were missing. Of the remainder, an ECG was recorded during symptoms in $229(31 \%)$ patients, while $512(69 \%)$ parients did not have symptoms during ECG registration. The analysis was carried out both for the whole group and for the subgroup with symptoms during ECG recording. All patients, irrespective of the availability of an ECG recording during symptoms, were included in the analysis. The transtelephonic ECG recordings were obtained by an ECG modem 3 (Cardio Control BV, Rijswijk, The Netherlands), consisting of a 12 -lead ECG taken during 36 seconds.

The interpretation of the ECGs was done by a cardiologist trainee and checked by a senior cardiologist. Both were unaware of the findings from the medical history and physical examination. GPs recorded signs and symptoms on standardized forms, which were completed before they received the interpretation of the ECG. The GPS' registration system was used to collect additional patients" medical history data. 
Table 1. Characteristics of patients consulting their GP. with complaints possibly caused by atrhythmas $(n=762)$.

\begin{tabular}{|c|c|c|c|c|c|}
\hline & \multicolumn{2}{|c|}{ Patients } & & \multicolumn{2}{|c|}{ Patients } \\
\hline & $\mathbb{N}$ & $\%$ & & $N$ & 96 \\
\hline \multicolumn{3}{|l|}{ general characteristics } & \multicolumn{3}{|l|}{ medical history } \\
\hline women & 481 & 63.2 & atrial fibrillation & 18 & 2.4 \\
\hline home visits & 61 & 8.0 & extrasystoles & 16 & 2.1 \\
\hline ECG during symproms & 229 & 30.2 & paroxysmal SVT**w & 8 & 1.0 \\
\hline arrhythmia derected & 215 & 28.3 & other ardhythmias & 13 & 1.7 \\
\hline clinically relewant & 67 & 8.8 & unspecified & 15 & 2.0 \\
\hline \multicolumn{6}{|l|}{ arrhythmia detected } \\
\hline known arthychmia detected & 23 & 3.0 & coral arthythmias & 70 & 9.2 \\
\hline \multirow[t]{3}{*}{ new complaint } & 577 & 75.9 & coronary disease & 46 & 6.0 \\
\hline & & & heart failure & 21 & 2.8 \\
\hline & & & myocardial infarction & 19 & 2.5 \\
\hline reasons for inclusion * & & & walve discase & 16 & 2.1 \\
\hline palpitations & 557 & 73.1 & orthoseatic hyporension & 14 & 1.8 \\
\hline angina pectoris & 138 & 18.1 & hyperventilation syndrome & 145 & 19.0 \\
\hline faintness & 76 & 10.0 & psychiatric disease & 46 & 6.0 \\
\hline collapse & 22 & 2,9 & medication use & & \\
\hline \multirow[t]{5}{*}{ other } & 22 & 2.9 & berablockers & 49 & 4.6 \\
\hline & & & nitrates & 27 & 3.5 \\
\hline & & & glycosides & 19 & 2.5 \\
\hline & & & calcium entry blockers & 1.4 & 1.8 \\
\hline & & & antiarrhythmics & 10 & 1.3 \\
\hline \multirow{3}{*}{\multicolumn{3}{|c|}{$\begin{array}{l}\text { Column percentage exceeds } 100 \% \text { because } \\
\text { patients could be included on more than one } \\
\text { complaint. }\end{array}$}} & dinterics & 75 & 9.8 \\
\hline & & & other cardiovascular medication & 41 & 5.4 \\
\hline & & & central hervous system medication & 114 & 115.0 \\
\hline
\end{tabular}

\section{DEPENDENT VARIABLES}

The ECG diagnosis was used as dependent variable. Arrhythmias were defined as all rhythms which were not a normal rate sinus rhythm. Differentiarion was made between arrhythmias (ar) and no arrhythmias on the one hand, and clinically relevant arrhythmias (arrel) and innocent or no arrhythmias on the other. The categorizing of arrhythmias with regard to clinical relevance was done by the research team before the analysis. It was based upon the need for medical intervention and diagnostic work-up by the GP or possible cardiac aetiology that made further investigations by referral advisable. When extrasystoles were present in combination with a 
rhythm other than a sinus rhythm, the ECG was interpreted as to the leading thythm, and no attention was paid to the extrasystoles. Table 2 gives an overview of the detected arrhythmias and their assessed clinical relevance.

Table 2. Detected arrhythmias in 762 parients consulting their general practitioner with complaints possibly indicating an arthythmia.

\begin{tabular}{|c|c|c|c|}
\hline dinically retevant arrhythmias $(\mathrm{n}=67)$ & $\mathbb{N}$ & clinically less relevan arrhythmias $(\mathrm{n}=148)$ & $\mathbb{N}$ \\
\hline atrial fibrillation & 47 & extrasystoles & 81 \\
\hline arcial fluter & 5 & sinus bradycardia & 33 \\
\hline supraventricular tachycardia not specified & 4 & sinus tachycardia & 25 \\
\hline chaotic atrial rhyrthm & 3 & sinus arrhythmia & 4 \\
\hline AV-nodal toxchycardia & 3 & regulat atrial rhythm & 3 \\
\hline atrial tachycardia & 1 & atrial bigeminy & 2 \\
\hline idiowentricular ryythm / sinus arrest & 2 & & \\
\hline ventricular achycardia & 1 & & \\
\hline circus movement tachycardia (WPW) & 1 & & \\
\hline
\end{tabular}

INDEPENDENT VARIABLES

The independent variables were separated into basic patient characteristics, medical history, medication use and symptoms. A differentiation was made between symptoms present during consultation, present but not during consultation, and nor present.

\section{STATISTICAL ANALYSIS}

Statistical analyses were performed with BMDP. ${ }^{12}$ In bivariate analysis the Pearson chisquare test was used. When the expected frequency in at least one cell was less than 5, the Fisher exact test was used. In calculating the diagnostic value of symptoms, the denominator varied according to the subgroup analysed. Diagnostic value was expressed in posirive and negative predictive values and summarized in odds ratios with $95 \%$ confidence intervals. Variables with a significance level $p<0.10$ in bivariate analysis were entered into multiple logistic regression analysis. Besides, some variables related to arrhy thmias according to literature, not reaching this significance level, were entered in this analysis. In bivariate analysis, age was divided in three groups with the youngest group as reference group. In the logistic regression model, age was entered as a continuous variable.

Starting from the full models, multiple logistic regression with backward eliminarion of insignificant variables was performed for both "arrhythmias" and "clinically 
(more) relevant arrhythmias" as dependent variables, to derive reduced prediction models, taking all independent variables into consideration simultaneously. Variables were removed when $p>0.05$.

In addirion, logistic regression analysis was done with different subsets of independent variables: age and gender were respectively added with symproms, medical history and medication use. Significance testing between these models was done with the likelihood racio test. Receiver Operating Characteristics (ROC) curves, expressing the relation between sensitivity and specificity of the models for various cut-off points of the predicted posterior probability, were used to elucidate the surplus value of models with more variables. The area under the curve (AUC) of the distinct models, which is a measure of the diagnostic power of the different models, was calculated with BMDP.

\section{RESULTS}

Based on the arrhythmias detected, patients in this population had a prior probability of arrhythmias and clinically relevant arrhythmias of $28.3 \%$ and $8.8 \%$, respectively. Arrhythmias were detected in 110 patients (48.0\%) with symptoms during ECG recording, of these were $43(36.1 \%)$ dinically relevant. In the subgroup of patients without symptoms during ECG recording, arrhythmias and clinically relevant arrhythmias were detected in $98(19.1 \%)$ and $21(4.1 \%)$ patients, respectively. Nine patients in whom initially no arrhythmia was recorded consulted their GP for a second time with complaints pointing to an arrhythmia: 3 patients had sinus rhythm, 2 patients had atrial fibrillation, 3 patients had premature beats, 1 patient had atrial tachycardia and 1 had atrial bigeminy). Results of the bivariate analysis are presented in table 3. Using the age group 15-44 years as reference group, higher age was a significant determinant of the occurrence of arrhythmias. The absolute number of arrhythmias in women was higher than in men, while arrhythmias were detected relatively more frequently in men than in women $(33.9 \%$ vs. $24.9 \%)$. Arrhythmias in the past $\left(O R_{a r}=3.2, O R_{a r r e l}=8.5\right)$, cardiovascular disease $\left(O R_{a r}=2.1\right.$, $\left.O R_{a r r e l}=3.3\right)$ and hypertension $\left(O R_{a r}=1.9, O R_{a r r e l}=1.9\right)$ were also important factors contributing to the probability of both arrhythmias and clinically relevant arrhythmias. Frequently consulting the GP because of psychosomatic complaints was negatively associated with the occurrence of arrhythmias $\left(O R_{a r}=0.6\right)$ and particularly clinically relevant arrhythmias $\left(\mathrm{OR}_{\text {arrel }}=0.2\right)$. A medical history of psychiatric diseases and hyperventilation syndrome were also negative predictors of clinically relevant arrhythmias $\left(O R_{a r}=0.8, O R_{a r r e l}=0.3\right)$. Other known conditions did not contribute to the diagnosis of arrhythmias. The use of cardiovascular $\left(O R_{a r}=3.1\right.$, $\left.O R_{\text {arrel }}=5.8\right)$ and diuretic medication $\left(\mathrm{OR}_{\mathrm{ar}}=2.8, \mathrm{OR}_{\text {arrel }}=3.7\right)$ was positively associated with the occurrence of arrhythmias and clinically relevant arrhythmias. No rela- 


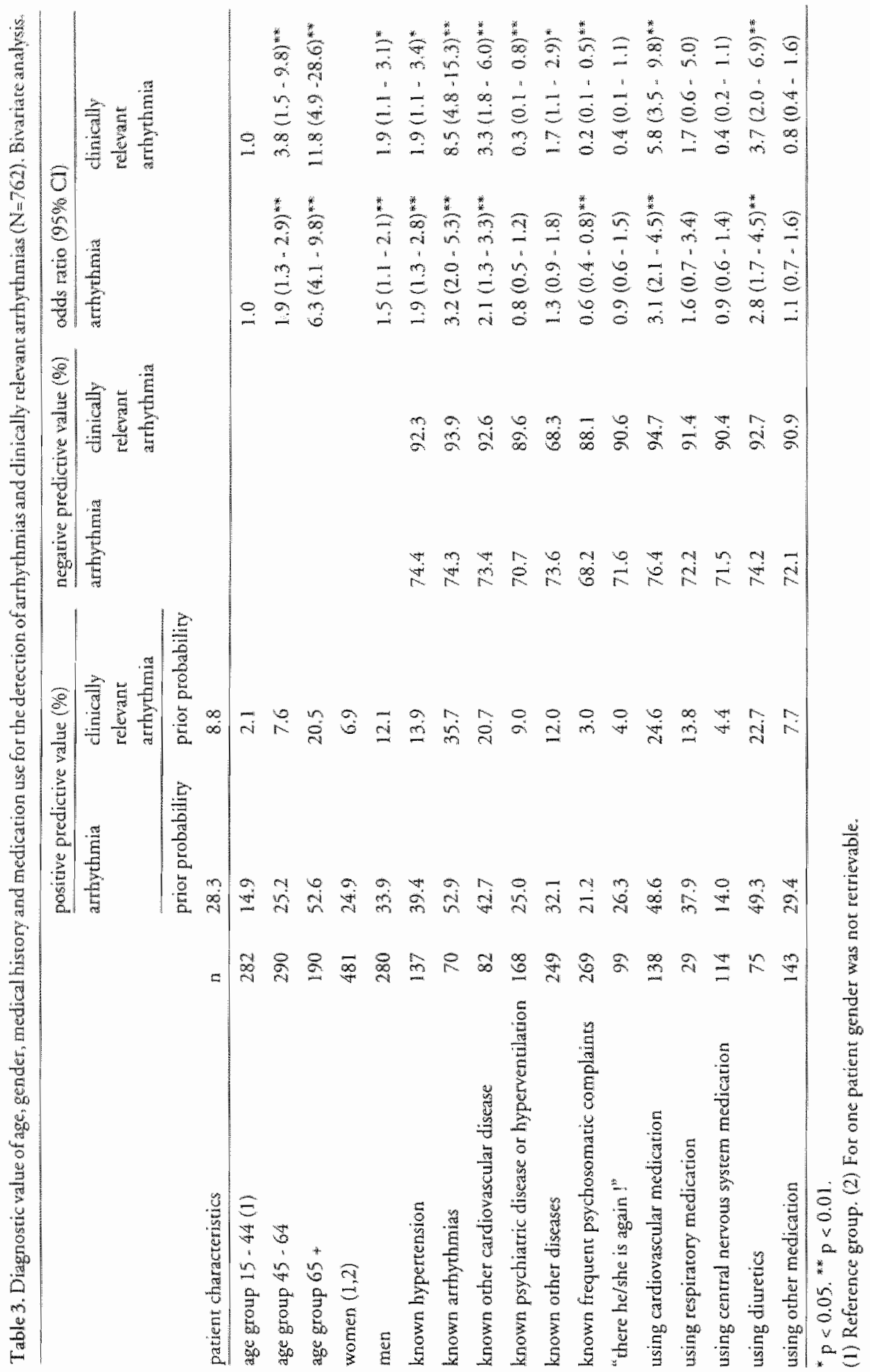




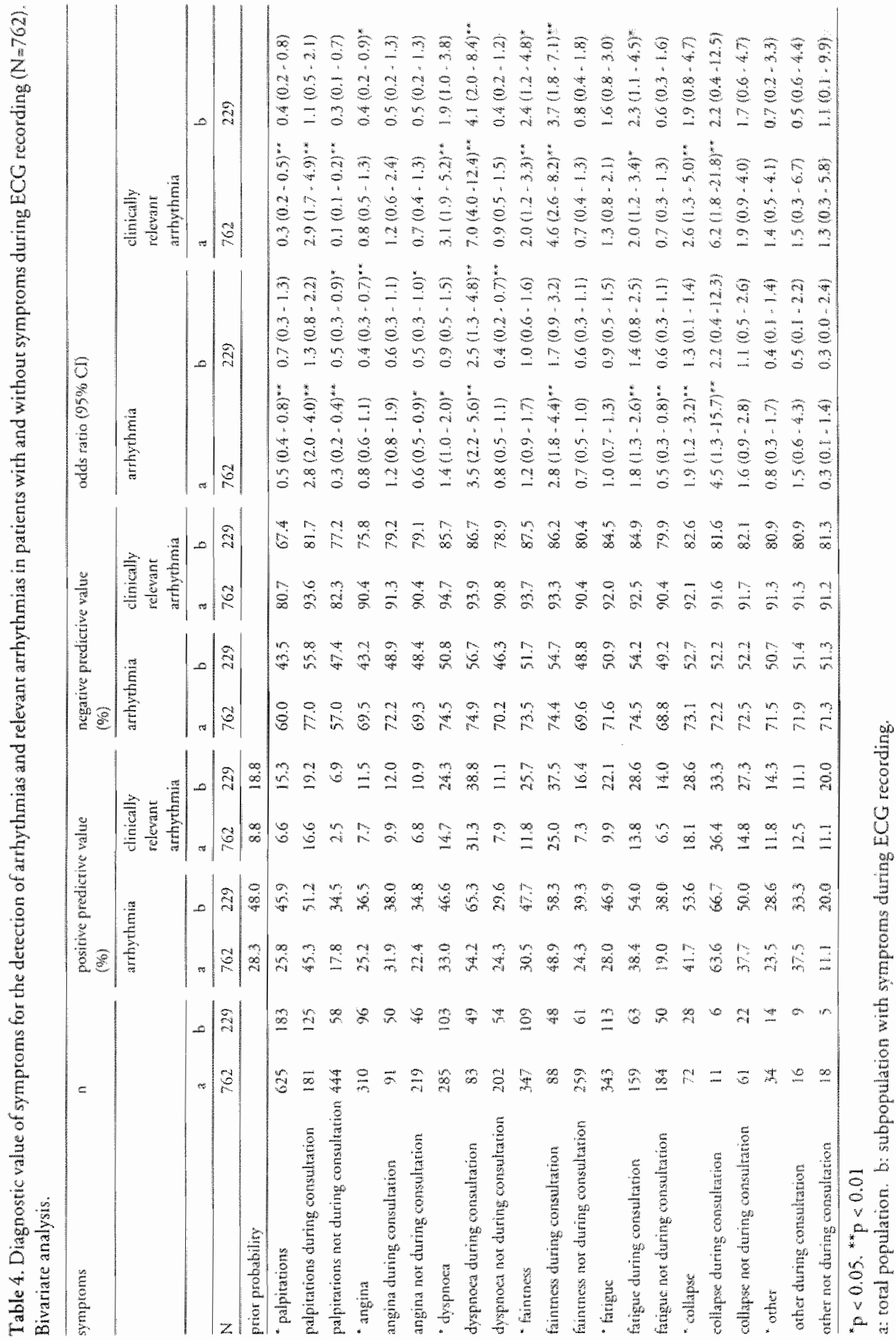


tion was found with the use of central nervous system medication, respiratory medication or other medication.

\section{DIAGNOSTIC VALUE OF SYMPTOMS FOR ARRHYTHMIAS}

IN BIVARIATE ANALYSIS

Collapse $\left(\mathrm{OR}_{\mathrm{ar}}=1.9, \mathrm{PV}^{+}{ }_{\mathrm{ar}}=41.7\right)$ and dyspnoea $\left(\mathrm{OR}_{\mathrm{ar}}=1.4, \mathrm{PV}^{+}{ }_{\mathrm{ar}}=33.0\right)$ had the highest positive predictive values for arrhythmias (Table 4 ). In this indicated population, palpitations had a significant negative odds ratio $(0.0<O R<1.0)$ for arrhythmias. Neither angina nor fatigue, faintness nor other symptoms supported the diagnosis of arrhythmias. If the analysis was focused on symptoms during consultation, the positive predictive value of collapse and dyspnoea increased. When present during consultation, faintness and fatigue were also significant predictors. Palpitations during consultation were positively correlated to arrhythmias, in contrast to this symptom in general.

\section{DIAGNOSTIC VALUE OF SYMPTOMS FOR CLINICALLY RELEVANT ARRHYTHMIAS IN BIVARIATE ANALYSIS}

For clinically relevant arrhythmias collapse $\left(\mathrm{OR}_{\text {arrell }}=2.6, \mathrm{PV}^{+}\right.$arrel $\left.=18.1\right)$ and dyspnoea $\left(\mathrm{OR}_{\text {arrel }}=3.1, \mathrm{PV}^{+}{ }_{\text {arrel }}=14.7\right)$ also had the highest predictive values. Faintness was a significant predictor of clinically relevant arthythmias. Palpitations had a significant negative odds ratio. In case of symptoms during consultation, the positive predictive values of collapse, dyspnoea and faintness increased sharply. Just as in arrhythmias, palpitations during consultation were positively associated with clinically relevant arrhythmias in contrast to this symptom in general. Finally, fatigue was also a significant predictor when present during consultation.

\section{DIAGNOSTIC VALUE OF SYMPTOMS IN PATIENTS WITH SYMPTOMS DURING ECG RECORDING}

In the subpopulation $(\mathrm{n}=229)$ with symptoms during $\mathrm{ECG}$ recording, an arrhythmia was detected in $48.1 \%$ of the patients and a dinically relevant arthythmia in $18.8 \%$. Predictive values of all symptoms were much higher. Collapse $\left(\mathrm{PV}^{+}{ }_{\mathrm{ar}}=53.6\right)$, faintness $\left(\mathrm{PV}^{+}{ }_{\mathrm{ar}}=47.7\right)$ and fatigue $\left(\mathrm{PV}^{+}{ }_{\mathrm{ar}}=46.9\right)$ had the highest predictive values. The predictive value of palpitations was nearly doubled. However, for arrhythmias a significant positive correlation was found only with dyspnoea during consultation. Clinically relevant arrhythmias were significantly associated with faintness in general, as well as dyspnoea, faintness and fatigue during consultation. 


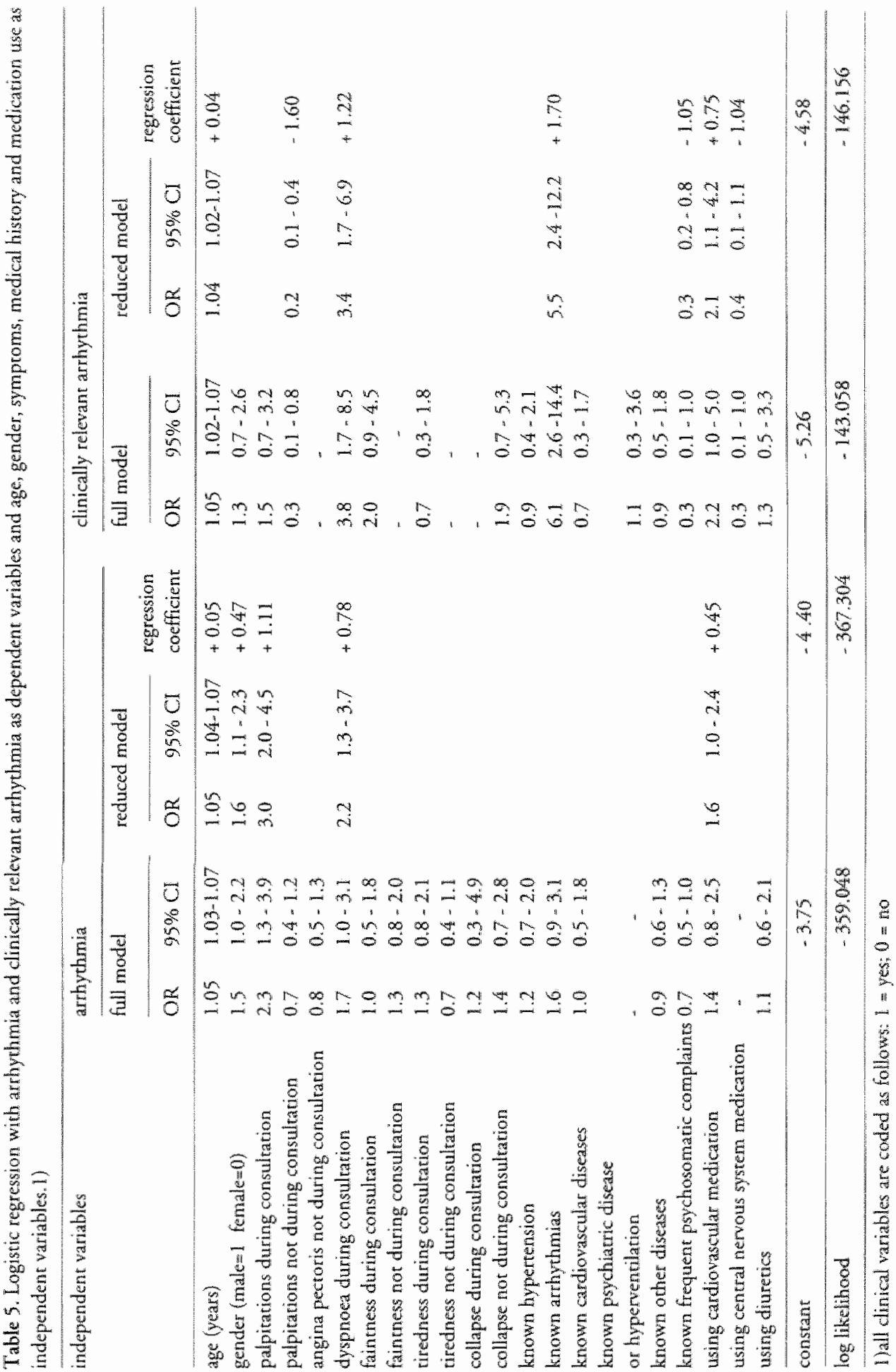


Taking all independent variables into consideration simutaneously, age (OR[per year $\left.\|_{\mathrm{ar}}=1.05\right)$ gender $\left(\mathrm{OR}_{\mathrm{ar}}=1.6\right)$, palpitations $\left(\mathrm{OR}_{\mathrm{ar}}=3.0\right)$ and dyspnoea during consultation $\left(\mathrm{OR}_{\mathrm{ar}}=2.2\right)$, and the use of cardiovascular medication $\left(\mathrm{OR}_{\mathrm{ar}}=1.6\right)$ were important determinants in diagnosing arrhythmias (Table 5). For clinically relevant arrhythmias as the dependent variable, age (OR [per year $\left.]_{\text {arrel }}=1.04\right)$, dyspnoea during consultation $\left(O R_{\text {arei }}=3.4\right)$, a history of arrhythmias $\left(O R_{\text {arrel }}=5.5\right)$ and the use of cardiovascular medication $\left(O R_{\text {arrel }}=2.1\right)$ were positive predictors. Frequent consultations because of psychosomaric complaints $\left(O R_{\text {arrel }}=0.3\right)$, the use of central nervous system medication, mainly benzodiazepines $\left(O R_{a r r e l}=0.4\right)$ ) and 'consultation because of palpitations not present during the consultation' $\left(O R_{\text {arrel }}=0.2\right)$ were negative predictors of clinically relevant arrhythmias.

The predicted probability of an arrhythmia can be estimated according to the formula:

$$
p(x)=\left[1+e^{-g}\right]^{-1}(13)
$$

where, based on the reduced model (Table 5), $g=-4.40+0.051 \times$ age(years) + $0.47 \times$ gender+ $1.11 \times$ palpitations during consultationt $0.78 \times$ dyspnoea during consultation+ $0.45 \times$ use of cardiovascular medication.

In clinically relevant arrhythmias $g=-4.58+0.042 \times$ age (years) $-1.60 \times$ palpitations not during consultation $+1.22 \times$ dyspnoea during consultation $+1.70 \times$ history of arrhythmias-1.05 $\times$ history of frequent psychosomatic complaints $+0.75 \times$ use of cardiovascular medicarion- $1.04 \times$ use of benzodiazepines.

These multivariable models allow one to calculate the predicted probability of arrhythmia in patients of particular ages consulting their GP with a variety of symptoms (Table 6).

A 30-year-old woman, not yet known to have an arrhythmia, consulring her GP with palpitations and dyspnoea during consultation, with frequent psychosomatic complaints and using benzodiazepines but no cardiovascular medication, has a probability of $27 \%$ of having an arrhythmia and a chance of $1 \%$ of having a clinically relevant arrhythmia. A 70-year-old man with palpitations and dyspnoea, using cardiovascular medication but no benzodiazepines and with a known history of arrhythmias and frequent psychosomaric complaints, has a probability of $88 \%$ of having an arrhythmia and $73 \%$ of having a clinically relevant arrhythmia. 


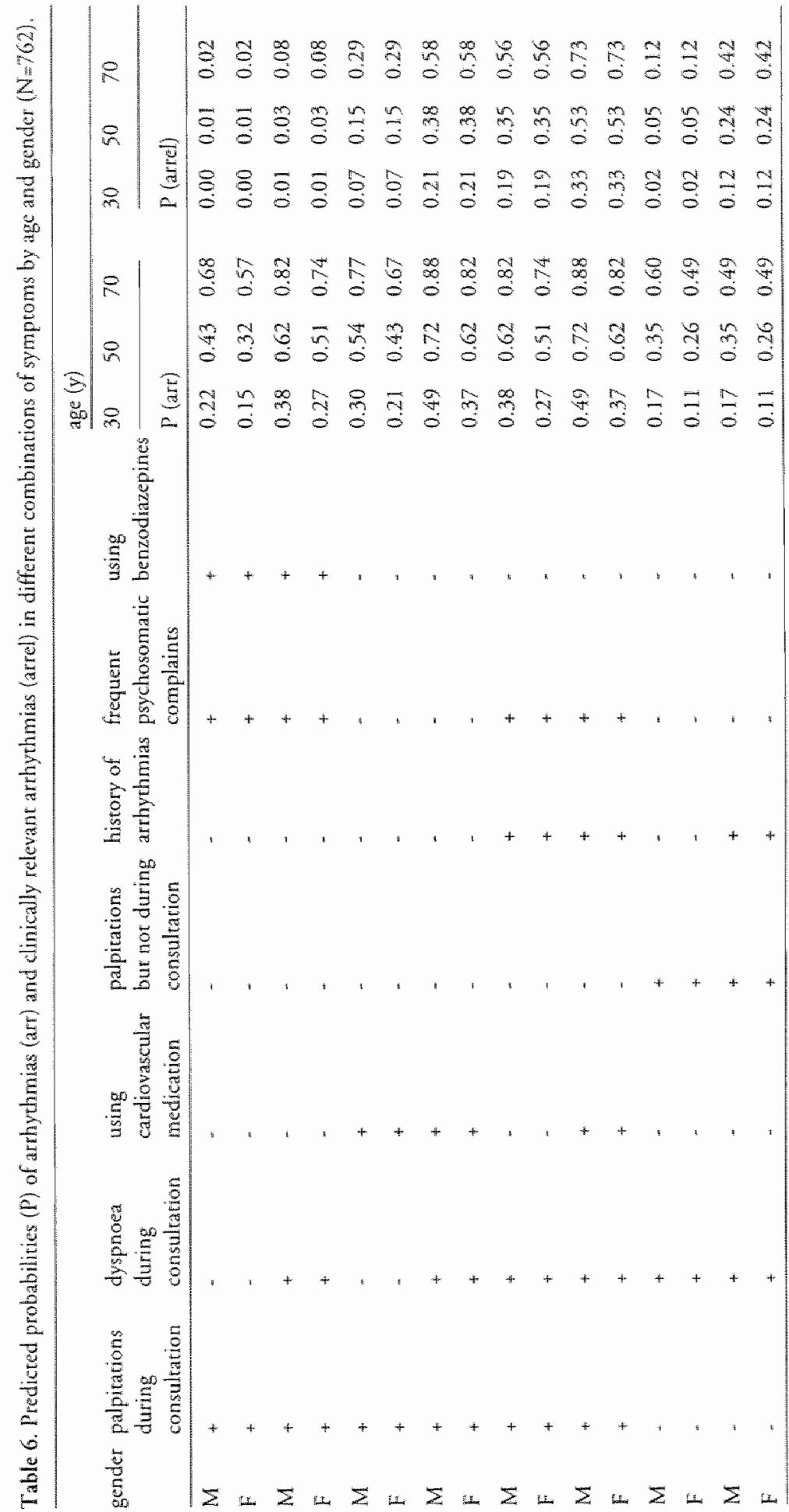




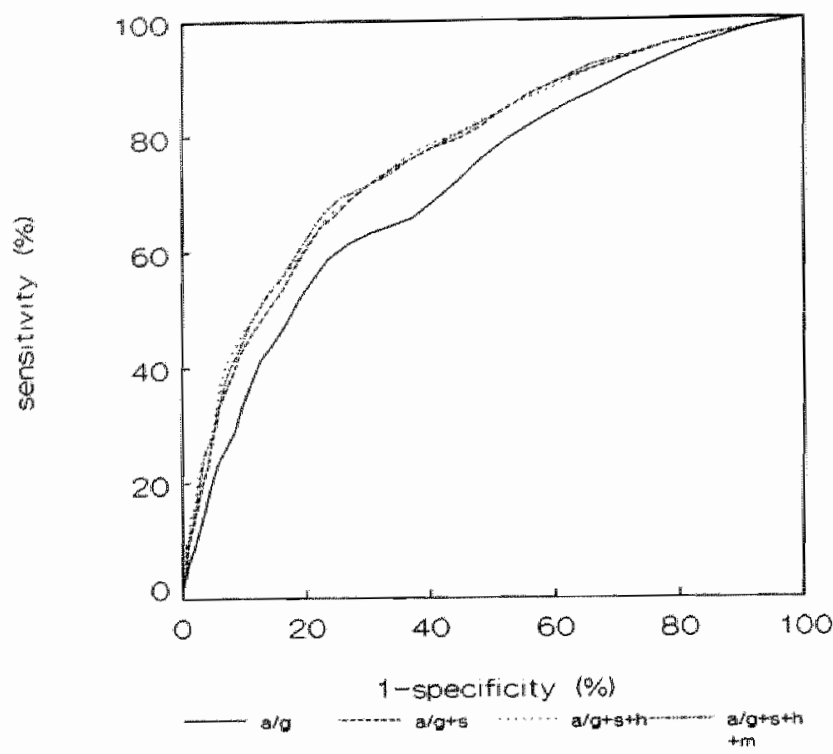

AUC

age and gender $(\mathrm{a} / \mathrm{g})$

0.717

age/gender and symproms $(\mathrm{a} / \mathrm{g}+\mathrm{s})$

0.768

age/gender, symptoms and medical history $(a / g+s+h)$

0.774

age/gender, symaptoms, medicall history and medicarion

$(\mathrm{a} / \mathrm{g}+\mathrm{s}+\mathrm{h}+\mathrm{m})$

0.774

Figure 1. ROC curve of warious regression models representing different subsets of parient characteristics and symptoms in predicting arrhythmias $(\mathrm{n}=762)^{*}$.

* This ROC curve was slightly smoothed using a program developed by Fons Kessels, Maastricht

RECEIVER OPERATING CURVES OF PATIENT CHARACTERISTICS AND SYMPTOMS IN PREDICTING ARRHYTHMIAS IN A LOGISTIC REGRESSION MODEL

The relarion between sensitiviry and specificity for various cut-off points of various prediction models with different subsers of independent variables are shown in figures 1 and 2 . To elucidate the surplus value of more extensive diagnostic information in the analysis, a set of symptoms, medical history and medication use are added to age and gender. For the model with age and gender as independent variables, the $A U C=0.717$ in detecting arrhythmias. When the model is extended with symptoms, its predictive value is significantly better $(\mathrm{p}<0.001)$. Medical history variables and medicarion use were of less importance. 


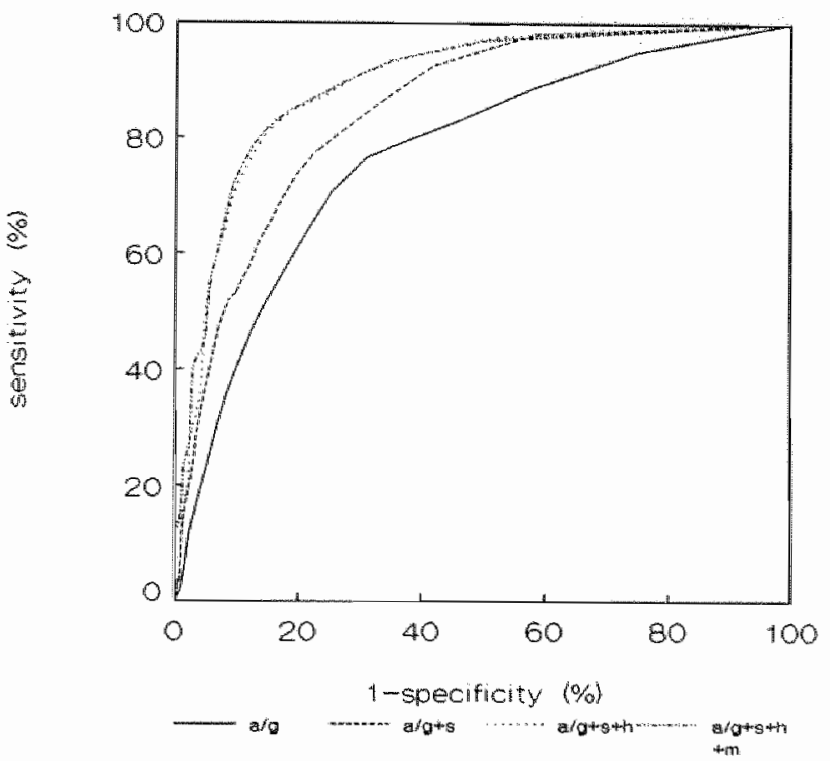

age and gender $(a / g)$

AUC

age/gender and symptoms $(\mathrm{a} / \mathrm{g}+\mathrm{s})$

0.780

age/gender, symptoms and medical history $(a / g+5+h)$

0.862

age/gender, symptoms, medical history and medication

0.900

$(\mathrm{a} / \mathrm{g}+\mathrm{s}+\mathrm{h}+\mathrm{m})$

0.905

Figure 2. ROC curve of warious regression models representing different subsets of patient characteristics and symptoms in predieting clinically relevant arrhychmias $(n=762)^{*}$.

* This ROC curve was slightly smoothed using an program developed by Fons Kessels, Maastricht

Regarding the logistic model for derecting clinically relevant arrhythmias with age and gender, the AUC $=0.780$. Symptoms, medical history and to a lesser degree medication use had significant contributions to the model $(\mathrm{p}<0.005)$. The final model (Figure 2) with age and gender combined wirh significant symptoms, medical history and medication variables had a good diagnostic performance (AUC=0.905).

\section{DISCUSSION}

To our knowledge, this is the first reported study executed in general practice yielding quantitative information about the value of patient characteristics and symptoms in diagnosing arrhythmias. As we were more interested in clinical relevance than in homogeneity, we formulated broad inclusion criteria to detect all new 
arrhythmias in patients, even in patients already known to have an arrhythmia, when there was a new diagnostic problem. This indicated population is the population in which GPs are interested in the diagnostic value of symptoms with regard to arrhythmias. Parients from the smaller study population presenting with coincidental findings suggesting an arrhythmia $(n=106)$, were separately analysed (chapter 5), because of their different prior probabiliries.

In more than a quarter of the cases, arrhythmias were registered. In nearly ten percent, a clinically relevant arrhythmia could be found. In logistic models, age especially was a good predictor in diagnosing arrhythmias and their clinical relevance. In population-based studies, this age-related increase of the most prevalent arrhythmias has also been reported. ${ }^{14}$ Relatively more arrhythmias and clinically relevant arrhythmias were found in men, bur gender was no independent predictor of the clinical relevance of the arrhythmia in the logistic model. Dyspnoea during consultation, possibly caused by haemodynamic instability, had a high odds ratio both in arrhythmias and in clinically relevant arrhythmias. Although in more than a quarter of parients with palpitations an arrhythmia could be detecred, palpitarions in general and not during consultation had negative odds ratios for both arrhythmias and their clinical relevance, in contrast to palpitations during consultation. On the one hand, this is because most of the other symproms in parients in this population have higher diagnostic values, resulting in reducing the relative diagnostic value of palpitations. In addition, it is likely to be caused by the paroxysmal character of this symptom in combination with a standard which was not optimal for the detection arrhythmias of short duration. However, these negative odds ratios were also observed in a subpopulation with complaints (not necessarily palpitations) during ECG recording. Finally, palpitations are frequently associated with psychiatric disease and anxiety disorders. 15,16 In contrast to the bivariate analysis, in the logistic model palpitations during consultation were not an indicator of clinically relevant arrhythmias, probably because of the impact of statistically more powerful variables such as dyspnoea during consultation, age and a history of arrhythmias. It is observed that odds ratios in the subgroup are generally lower than in the total population. This can be explained as a result of the higher probability in this subgroup, including those without the particular symptom. Correlations between the independent variables and specific arrhythmias could not be evaluated because of the low frequency of most of the arrhythmias. A very large source population would be necessary to evaluate specific diagnostic indicators of infrequent arrhythmias. The probability that the diagnostic value of predictor variables in arthythmias and clinical arahythmias is mainly based on atrial fibrillation can be rejected because nearly all variables remained significant when parients with atrial fibrillation were excluded (data not in this dissertation).

Holter monitoring or event recording seems more attractive than usual ECG recording because of the paroxysmal character of some arrhythmias. However, Holter monitoring is not very useful in intermittent palpitations, which occur infrequently. ${ }^{17,18}$ Besides, most studies abour the diagnostic yield of Holter monitoring 
have been executed in selected populations and there is a considerable inter- and intra-reader variability and intra-patient day-to-day variability. Furthermore, especially in a primary care population with a low prior probability and less developed clinical pictures of clinically relevant arrhyrhmias, Holter registration might result in more false posirive findings. ${ }^{19,20}$

Event recording is not an adequate standard for long-lasting symptoms like faintness and tiredness. Moreover, in a recent study only one third of the patients with palpitations were eligible for event recording. .7

Finally, the 12-lead ECG is the kind of equipment used in regular general practice. In addition to the former, our approach with respect to the use of a 12-lead ECG was based on feasibility considerations giving insight into diagnostic information relevant to the detecrion of arrhythmias in regular general practice.

In The Netherlands, most of the patients with complaints possibly caused by an arrhythmia are first seen by their GP, while in some cases the severity of an arrhythmia leads to immediate hospital admission. In our study, the few patients with an acute arrhythmia seen in the hospital, and not by the GP, have not been included in the study. Hence, our results are applicable to patients who consult their GP and not to parients with poorly tolerated arrhythmias or circulatory arrest. For the diagnosis in these pronounced situations, a diagnostic model is less relevant in general practice, since immediate referral is clearly indicated. Because this diagnostic model is based upon a confined primary care population, it is meaningful to test its performance in another, bur similar, population.

In conclusion, patient characteristics, symptoms and medical history can be helpful in diagnosing arrhythmias in general and especially clinically relevant arrhythmias. These data can be used to decide whether it is meaningful to make an ECG recording. Although clinically relevant arrhythmias in younger patients are much less frequent than in older patients, GPs should be alert not to misdiagnose rare arrhythmias in the young, such as the Wolff-Parkinson-White syndrome in which an ECG recording is very sensitive. In older patients with complaints possibly indicating an arrhythmia, GPs should make ECG recordings especially to document the expected arrhythmia and to diagnose possible underlying cardiovascular pathology. As symptoms during consultation are very important for the diagnosis, patients without an arrhythmia during consultation should be asked to alert their GP again when symptoms occur, so that an ECG recording can be made. Probably event recording in general practice is useful in these cases.

\section{REFERENCES}

1. Knomerus $J A$. Interpretation of diagnostic dara an unexplored field in general pracrice. J R Coll Gen Pract 1985: 35: 270-274.

2. Zwwerering $\mathrm{P}$, Knotenerus $A$, Gorgels $T$, Rinkens P. Occurrence of arrhythmias in general practice. Scand J Prim Health Care 1996; 14:244-250. 
3. Frootn I. Froom $\mathbb{P}$. Electrocardiogram abnormalities in primary care parients. J Fam Prace 1984; 18: 223-225.

4. Jones R. Electrocardiographic diagnosis in general pracrice. Practirioner $1984 ; 228: 85-89$.

5. Van Lisdonk EH, Van den Bosch WJHM, Huygen FJA, Lagro-Janssen ALM. Ziekren in de huisartspraktijk [Diseases in general practice]. Utrecht: Bunge, 1990.

6. Lamberts H. In het huis wan de huisars. [In the house of the general practitioner] Leliestad: Meditekst, 1991.

7. Metsemalkers JFM, Hoppener P, Knotnerus JA, Kocken RJJ, Limonard CBG. Computerized health information in the Netherlands: a registration nerworik of family pracrices. Br J Gen Pract $1992 ; 42: 102-106$.

8. Knotmerus JA. The effects of disease verification and refertal on relationship berween symptoms and diseases. Med Decis Making 1987; 7: 139-148.

9. Hurst JW, Morris DC. The history: Symptoms and past events related to cardiovascular disease. In: Schlant RC, Alexander RW, O'Rourke RA, Roberts R, Sonnenblick EH, eds. Hurst's the heart: arteries and veins. New York: Mc Graw-Hill. 8th ed, 1994: 205-216.

10. Wellens HI], Brugada P. Antiarrhythmic therapy. The value of the history of the patient. Eur Heart I 1987; 8 (suppl A): 71-75.

11. Brugada P, Gursoy S, Bruggada J, Andries E. Investigation of palpitations. Lancer 1993; 341 : $1254-1258$

12. Dixon WJ, Brown MB, Engelman L, Jennrich RI. BMDP statistical sofware manual. Universicy of California Press. Berkeley/Los Angeles/Oxford, 1990.

13. Hosmer DW, Lemeshow S. Applied logistic regression. John Wiley \& Sons. New York/ Chichester/Brisbane/Toronto/Singapore, 1989.

14. Kulbertus HE, Leval-Rurten $F$ de, Alber A, Dubois $M$, Petir JM. Electrocardiography changes occurring with advancing atge. In: Wellens HJJ (red). What's new in electrocardiography? Ist ed. The Hague: Nijhof 1981: 300-13.

15. Weber BE, Kapoor WN. Evaluation and outcomes of patients with palpitations. Am J Med 1996; 100: 138-148.

16. Barsky AJ, Cleary PD, Samie MK, Ruskin IN. Panic disorder. palpirarions, and the awareness of cardiac activiry. I Nerv Ment Dis 1994; 182:63-71.

17. Kinlay S, Leitch JW, Neil A, Chapman BL, Hardy DB, Fletcher PJ. Cardiac event reconders yield more diagnoses and are more cost-effective than 48 -hour Holker monitoring in parients with palpitations. A controlled clinical trial. Ann Intern Med 1996; 124: 16-20.

18. DiMarco JP, Philbrick JT. Use of ambulatory elecrrocardiographic (Holter) monitoring. Ann Int Med 1990; $113: 53-68$.

19. Bjerregaard P. Continuous ambularory etectrocardiography in healthy adult subjects over a 24-thour period. Clinical data, and evaluation of instruments for ambulatory electrocardiography. Dan Med Bull 1984; 31:283-97.

20. Barret PA, Perer CT, Swan HJC, Singh BN, Mandel WJ. The frequency and prognostic significance of electrocardiographic abnormalities in clinically normal individuals. Prog Cardiovasc Dis $1981: 23: 299-319$. 
CHAPTER 4

\title{
The diagnostic value of physical signs in arrhythmias
}

\author{
Zwietering PJ, Knotmerus JA, Gorgels APM
}




\section{ABSTRACT}

Objectives. To assess the value of physical signs and symptoms in diagnosing arrhythmias and in identifying patients with important relevant arthythmias in general pracrice.

Desigh. During a twoyear period, all patients with complaints suggesting an arrhythmia, in addition to the medical history, had a siructured physical examination carried our by the general practitioner and a cardiophonic electrocardiogram ECG). Setting. 20 general practices

Subjects. 762 patients, aged 15 years or older consulting their general practitioner. Arrhythmias were documented in $28.3 \%$ of the patients and clinically relewant arrhythmias in $8.8 \%$.

Main outcome measures. Clinical variables: positive and negative predictive values (PV "PV), diagnosric odds ratios with their $95 \%$ confidence intervals (OR $195 \% \mathrm{CI}]$ ); multiple logistic regression models; Receiver Operating Characteristics with the area under the curve (AUC).

Results. In bivariate analysis, a totally irregular pulse was the best predictor of "arrhythmias (PV": 90\%) and clinically relevant arrhythmias" (PV*: 63.3\%). The best performing extensive model in arrhythmias consisted of 5 physical signs: a totally irregular pulse (OR: 13.4), an apical heart rate $<60$ beats per minute (OR: 6.7), varying loudness of the firse heart sound (OR: 5.2), a parrially irregular pulse (OR: 4.7) and a apical heart rate $>100 \mathrm{bpm}$ (OR: 3.2). Suspicious of a cardiovasculat abnormality (OR: 1.9), also contributed to the model. In the best performing model in cinically relewant arthythmias, the above-mentioned findings were included as well as a low blood pressure (OR: 23.1) and a history of arrhythmias (OR: 3.5). Age (OR: 1.04, per year) and palpitations during consultacion (OR: 1.8) were relevant predictors, only in a model with "arrhythmia" as dependent variable in contrast to "clinically retevant arthythmias".

Condwions. Findings from physical examination are important predictors of arrhythmias and their clinical relevance. When data from the physical examinarion are added to patienc characteristics, symproms and medical history findings, the latter become relatively less important for diagnostic prediction. When all information from medical history and physical examination is combined, general practicioners can diagnose arhythmias and assess their severity with a high degree of certainty. These findings can also be useful in the decision to make an ECG recording to evaluate the arthythmia. 


\section{INTRODUCTION}

Arrhythmias can be defined as all cardiac rhythms different from normal sinus rhythm. This definition includes tachycardias, bradycardias and premature beats. Also arthythmias can be classified as paroxysmal and permanent. The clinical significance of arrhythmias depends upon the nature of the arrhythmia, its aetiology, the presence of cardiovascular co-morbidity and the possible consequences of the arrhythmia in daily life.

The incidence and prevalence of arrhythmias depend highly on the population selected and the method of documentation, such as a 12-lead electrocardiogram $(\mathrm{ECG}), 24 \mathrm{~h}-\mathrm{ECG}$, transtelephonic monitoring or electrophysiological testing. In general practice $2-3$ new arrhythmias per 1000 listed patients per year are diagnosed with a standard 12-lead ECG. ${ }^{1-3}$

Cardiology textbooks emphasize the importance of the medical history and the physical examination, and of the diagnostic values of symptoms and physical signs in detecting cardiovascular diseases. However, there is a lack of information on the quantitative aspects in terms of sensitivity, specificity and predictive value with regard to the presentation of arrhythmias. ${ }^{4.5}$ From the general practitioners" view point in the approach to the parient with possible arrhythmia the following steps should be taken: The first step is to determine whether the signs and symptoms in this patient are indeed pointing towards an arrhythmia. This question may be relevant because not infrequently patients mention sensations giving rise to various interpretations, such as palpitations, sweating, shortness of breath, dizziness and fear, which can also indicate the presence of an anxiety disorder. However, anxiety disorders may induce arrhythmias such as sinus tachycardia. The next step is to differentiate between clinically less relevant and more relevant arrhythmias. Finally, the specific arthythmia must be diagnosed.

Recently we reported quantitative information about the value of the medical history, patient characteristics and co-morbidity in arrhythmias. In this study, age and, to a lesser extent, male gender, palpitations and dyspnoea during consultation, and the use of cardiovascular drugs were associated with the presence of arrhythmias. Regarding clinically relevant arrhythmias, the same parameters except gender were important, as well as a history of arrhythmias. The use of central nervous system medication and frequent psychosomatic complaints were negatively associated with the presence of clinically relevant arrhythmias. ${ }^{6}$

By definition, a heart rate or pulse $>100$ beats per minute (bpm) is classified as tachycardia, while a heart rate or pulse $<60 \mathrm{bpm}$ is classified as bradycardia. An irregular heart rate or pulse may be caused by premature beats, atrial fibrillation and sinus arrhythmia. Indicative of atrial fibrillation should be a usually fast, totally irregular pulse, varying loudness of the first heart sound, and beat-to-beat variability in systolic blood pressure (SBP). A varying loudness of the first heart sound and irregular jugular pulsations in regular tachycardias is considered to be correlated with 
ventricular tachycardias, while synchronous expansive jugular pulsations during tachycardias should be linked to atrioventricular nodal and circus movement tachycardias. Finally, a low blood pressure could be caused by low cardiac output in poorly tolerated arrhythmias.

For a definitive diagnosis, an ECG recorded during the arrhythmia is needed. Because of the paroxysmal nature, this is frequently not possible. Therefore, in the diagnostic process and the assessment of the severity of an arrhythmia, the general practitioner must frequently rely on the clinical history, the physical examination and patient characteristics.

Although scientific evidence about the diagnostic value of physical signs in arrhythmias in general practice is lacking, such information is becoming more important because of the increasing incidence of arrhythmias as a result of the ageing of our population. In this study, we evaluate the diagnostic value of the physical examination and its supplementary value to patient characteristics and medical history in arrhythmias, using an ECG taken during the visit of the patient to the general practitioners' office as the gold standard.

\section{PATIENTS AND METHODS}

\section{BACKGROUND}

This study is a research project conducted by the University of Limburg in Maastricht, the Netherlands, and 27 GPs from 20 practices in the region. The study is focused on the occurrence of arrhythmias and the diagnostic value of clinical variables in diagnosing arrhythmias in general practice.

We used a cross-sectional screening design: signs, symptoms, and data from patients" medical records (predictor variables) were compared with the outcome of the ECG diagnosis. Predictor variables and the ECG diagnosis were independently assessed.

Since, in The Netherlands, all inhabitants are listed in a general practice and since -apart from emergencies- referral is only possible via the GP, GPs have a comprehensive view on all presented morbidity.

\section{PATIENTS}

During two years 27 GPs in the Maastricht area, with a total population of nearly 50,000 listed patients, participated in the study. The mean duration of participation of the practices was 22.6 months. All patients consulting their GP because of palpitations, were included. In addition, patients with dyspnoea, dizziness, angina pectoris, fatigue, collapse and orther reasons for encounter were included, when the GP 
considered an arrhythmia as a possible cause of the complaints. Complaints had to be new for the GP or should represent a diagnostic problem. Parients younger than 15 years of age and patients with fever were excluded. In addition, patients were excluded when participation would not be consistent with good dinical practice, since immediate referral was indicated, such as patients with suspected acure myocardial infarction, circulatory arrest, or an otherwise poor circulatory condition.

\section{MEASUREMENTS}

From all patients, a structured medical history was taken and a physical examination was carried out. All data were recorded on standard forms, which were filled out before receiving the interpretation of an ECG. The GP' registration system was used to collect additional medical history data from patients. In all parients, a transtelephonic ECG was sent to the department of cardiology of the local hospital. The transtelephonic ECG recordings were obtained by an ECG modem 3 (Cardio Control BV, Rijswijk, The Netherlands), consisting of a 12-lead ECG taken cluring 36 seconds. Patients who did not have symptoms during consultation were asked to come back for an ECG registration during symproms during the study period. If there was more than one ECG, the ECG during symptoms was used for analysis. The interpretation of the ECGs was done on the department of cardiology of the local hospital. Cardiologists were unaware of the findings from the medical history and physical examination.

\section{ANALYSIS}

\section{DEPENDENT VARIABLE}

The ECG diagnosis, established by a cardiologist was used as dependent variable. Arrhythmias were defined as all rhythms other than sinus rhythm wirh a rate of 60-100 bpm. In the analysis differentiation was made between arrhythmias and no arrhythmias on the ECG. Furthermore, a comparison was made between clinically more relevant arrhythmias on the one hand and innocent or no arrhythmias at the other. The dassification of arrhythmias according to their clinical relevance was prespecified by the research team before the analysis. It was based upon the need for diagnostic work-up by the GP and medical intervention or referral to a cardiologist. Correlations between variables and specific arrhythmias could not be evaluared because of the low incidence of most of the arrhythmias. For such an analysis, a very large population would be necessary to find statistically significant relations. When extrasystoles were present on the ECG in combination with other thythns than sinus rhythm, the leading rhythm was coded and not the extrasystoles. 


\section{MDEPENDENT VARIABLES}

The independent variables were grouped into patient characteristics, medical history data, medication use and symptoms on one hand and physical signs on the other hand. In bivariate analysis, regularity was divided in three groups with the regular thythm as reference group. A heart rate or pulse more than 100 bpm or less than 60 bpm was considered as abnormal and also a blood pressure of $100 / 60 \mathrm{~mm} \mathrm{Hg}$ or less. In the logistic regression model, age was used as a continuous variable. A differentiarion was made between symptoms present during consultation, present by history but not during consultation, and not present.

Some variables were not included in the multiple logistic regression (MLR) analysis together because of their high mutual correlation with each other, such as pulse and heart rate, varying loudness of the systolic blood pressure and beat to beat variability of the first heart sound and separate blood pressure measurements. In the logistic regression analysis, the combined variable of an irregular pulse was also not entered in the model.

\section{BIVARIATE ANALYSIS}

Staristical analyses were performed with BMDP. ${ }^{7}$ In bivariate analysis, the Pearson chi-square test for $2 \times 2$ tables was used. When the expecred frequency in at least one cell was less than 5, the Fisher exact test was used. Diagnostic value was expressed in positive and negative predicrive values and summarized in odds ratios with $95 \%$ confidence intervals.

\section{MULTIPLE LOGISTIC REGRESSION}

Starting from the full models, multiple logistic regression (MLR) with backward elimination of insignificant variables was performed. Selection of the variables entered in the full model was based upon clinical grounds and results of bivariate analysis. Variables with a significance level $p<0.10$ in bivariate analysis were entered. In the MLR, variables were removed when $p>0.05$.

In order to derive a reduced prediction model in diagnosing arrhythmias and to calculate adjusted odds ratios, taking independent variables into consideration simultaneously, a MLR analysis with different subsets of independent variables was performed using "arthythmia" as the dependent variable.

A second analysis was done to obtain a prediction model using "clinically relevant arrhythmia" as outcome variable. Finally, to these models using patient characterisrics, symptoms, and medical history data, a set of findings from physical examination was added, to assess its supplementary diagnostic value.

Significance testing between these models could not be done, because they were not hierarchically built. ${ }^{8}$ Receiver Operating Characteristic (ROC) curves were used 
to express the relation berween sensitivity and specificity with varying cut-off points and to elucidare the surplus value of models with variables from physical examination. The area under the curve (AUC) of the distinct models, which is a measure of the diagnostic power of the different models, was calculated with BMDP.

\section{RESULTS}

A total of 762 patients met the inclusion criteria. Most of the patients were women $(63.2 \%)$ and the majority $(75.9 \%)$ had new complaints. Nearly three quarters of the parients were included because of palpitations. A history of arthyrthmias was found in nearly 10 percent of the patients, while other cardiovascular diseases were rare. Quite some patients were known with anxiery disorders (19\%), and a not negligible part used benzodiazepines (15\%). In nearly one third of the patients an ECG recording was achieved during symptoms (Table 1). Based on the arrhythmias recorded on the ECG during consultation, patients in this population had a prior probability of arrhythmias of $28.3 \%$ and of clinically relevant arrhythmias $8.8 \%$. Table 2 gives an overview of the detected arrhythmias according to their clinical relevance. Nine patients, who had no symptoms during the first consultation came back to the GPs' office during symptoms. Of these, 8 patients initially had a sinus rhythm and one patient had a sinus bradycardia. During symptoms 3 patients had sinus rhythm, 2 patients atrial fibrillation, 2 patients multiple arrial premature beats, 1 patient atrial tachycardia and 1 patient sinus arrhythmia.

\section{DIAGNOSTIC VALUE OF SIGNS IN BIVARIATE ANALYSIS}

Results of bivariate analysis are presented in table 3. Nearly all signs were significant contributors to the occurrence of arrhythmias, except a blood pressure equal or less than $100 / 60 \mathrm{~mm} \mathrm{Hg}$, a systolic blood pressure equal or less than $100 \mathrm{~mm} \mathrm{Hg}$ and jugular pulsations. All variables were significantly associated with the occurrence of clinically relevant arrhythmias. A (totally) irregular pulse and correlated signs such as a beat to beat variability in systolic blood pressure or a varying loudness of the first heart sound were the most dominant predictors of (clinically relevant) arrhythmias. With regard to specific arrhythmias, a totally irregular pulse was found in only $70 \%$ of the patients with atrial fibrillation and also in $15 \%$ of the patients with extrasystoles. Jugular pulsations were seen in 17 parients, of whom only 3 parients had a regular supraventricular tachycardia. 
Table 1. Characreristics of patiens consulting their GP with complaincs posably indicating an arrhythmias $(n=762$, age $16-95$ years, mean age 51 years).

\begin{tabular}{|c|c|c|c|c|c|}
\hline & \multicolumn{2}{|c|}{ Parients } & & \multicolumn{2}{|c|}{ Patienrs } \\
\hline & $\mathbb{N}$ & $a / a$ & & $\mathbb{N}$ & $\%$ \\
\hline \multicolumn{3}{|l|}{ general characteristic } & \multicolumn{3}{|l|}{ medical history } \\
\hline woment & 481 & 63.2 & atrial fibrillation & 18 & 2.4 \\
\hline hame visies & 61 & 8.0 & extrasysroles & 16 & 2.1 \\
\hline new complaint & 557 & 75.9 & paroxysmal SWT** & 8 & 1.0 \\
\hline arhythmia derected & 215 & 28.2 & other arthythmias & 13 & 1.7 \\
\hline known arrhythmia detected & 23 & 3.0 & unspecificd & 15 & 2.0 \\
\hline \multirow[t]{2}{*}{ ECG during symptoms } & \multirow[t]{2}{*}{229} & \multirow[t]{2}{*}{30.9} & total arrhychmias & 70 & 9.2 \\
\hline & & & valwe disease & 16 & 2.1 \\
\hline \multicolumn{6}{|l|}{ reasons for inclusion" } \\
\hline palpitations & 557 & 73.1 & orthostatic hypotension & 14 & 1.8 \\
\hline angina pectoris & 138 & 18.1 & panic disorder & 145 & 19.0 \\
\hline vertigo & 76 & 10.0 & psychiatric disease & 46 & 6.0 \\
\hline dyspnoea & 67 & 8.8 & & & \\
\hline collapse & 22 & 2.9 & medication use & & \\
\hline \multirow[t]{6}{*}{ orher } & \multirow{6}{*}{\multicolumn{2}{|c|}{22}} & betablockers & 49 & 4.6 \\
\hline & & & ninrates & 27 & 3.5 \\
\hline & & & glycosides & 19 & 2.5 \\
\hline & & & calcium entry blockers & 14 & 1.8 \\
\hline & & & anciarrhyrhmics & 10 & 1.3 \\
\hline & & & diuretics & 75 & 9.8 \\
\hline \multirow{2}{*}{\multicolumn{3}{|c|}{$\begin{array}{l}\text { ") Column percentage exceeds } 100 \% \text { because patients } \\
\text { could be included on more than one complainr. } \\
\text { **) Supraventricular rachycardia. }\end{array}$}} & other cardiovascular medication & 41 & 5.4 \\
\hline & & & central nervous system madication & 114 & 15.0 \\
\hline
\end{tabular}

\section{DIAGNOSTIC VALUE OF PATIENT CHARACTERISTICS, SYMPTOMS AND SIGNS IN A LOGISTIC REGRESSION MODEL}

Taking all independent variables into consideration simultaneously, age (OR: 1.04 [per year]; $95 \% \mathrm{Cl}: 1.02-1.05$ ) and palpitations during consultation remained predictors of arthythmias in the logistic model. A history of tiredness (not being present during consultation) was a negative predictor of arrhythmias. For clinically more relevant arthythmias as the dependent variable, a history of palpitations (not being present during consultation) was a negative predictor, and a history of arrhythmias was a positive predictor. All variables of the physical examination were important contributors in the model, except jugular pulsations and a low blood pressure in arrhythmias. 
Table 2. Derected arrlyyth mias in parients consulting their general pracritioner with complaints possibly indicating an arthythmia ( $\mathrm{n}=762$, age 16-95 years, mean age 51 years).

\begin{tabular}{|c|c|c|c|}
\hline dinically more relevant arrhythmias $(n=67)$ & $\mathrm{N}$ & dinically less relevan arrhythmias $(n=148)$ & $N$ \\
\hline antral fibrillation & 47 & extrasystoles & 81 \\
\hline atrial Alutrer & 5 & sinus bradycardia & 33 \\
\hline stpraventricular tachycardia nor specifed & 4 & sinus rachycardia & 25 \\
\hline chaotic atrial rhythm & 3 & sinus arthythmia & 4 \\
\hline AV-nodal tachycardia & 3 & regular atrial mythm & 3 \\
\hline atrial tachycardia & 1 & atrial bigeminy & 2 \\
\hline idioventricular rhythm / sinusarrest & 2 & & \\
\hline ventricular tachycardia & 1 & & \\
\hline circus movement tachycardia (WDW) & 1 & & \\
\hline
\end{tabular}

The predicted probability of an arrhythmia can be estimated according to the formula:

$$
p(x)=\left[1+e^{-g}\right]^{-1(9)}
$$

where $\mathrm{g}=-3.76+0.035 \times$ age(years) $+0.58 \times$ palpitations during consultation $0.64 \times$ tiredness not during consultation $+0.62 \times$ suspicious cardiovascular condition $+1.91 \times$ heart beat $<60 / \mathrm{min}+1.16 \times$ heart beat $>100+2.59 \times$ total irregular thythm + $1.54 \times$ partially irregular rhythm $+1.64 \times$ varying loudness first heart sound.

The predicted probability of a clinically relevant arrhythmia can be calculated in a comparable manner. (Table 4)

\section{ADDED DIAGNOSTIC VALUE OF SIGNS}

The ROC curves of the two prediction models concerning arrhythmias and clinically relevant arrhythmias are shown in figures 1 and 2 . To elucidate the additional value of more extensive diagnostic information, models with patient claracteristics and medical history were extended with a ser of signs.

In predicting arrhythmias, the model with patient characteristics and medical history as independent variables (Figure 1) has already a substantial diagnostic performance ( $A U C=0.77)$. When the model is extended with signs, its predictive value increases ( $\mathrm{AUC}=0.85$ ).

The logistic model for predicting clinically more relevant arrhythmias (Figure 2) had an even better performance. Patient characteristics and medical history already had an AUC of 0.90 . The ultimate model with patient characteristics, medical history and signs had a very good diagnostic performance with an AUC of 0.93 . 


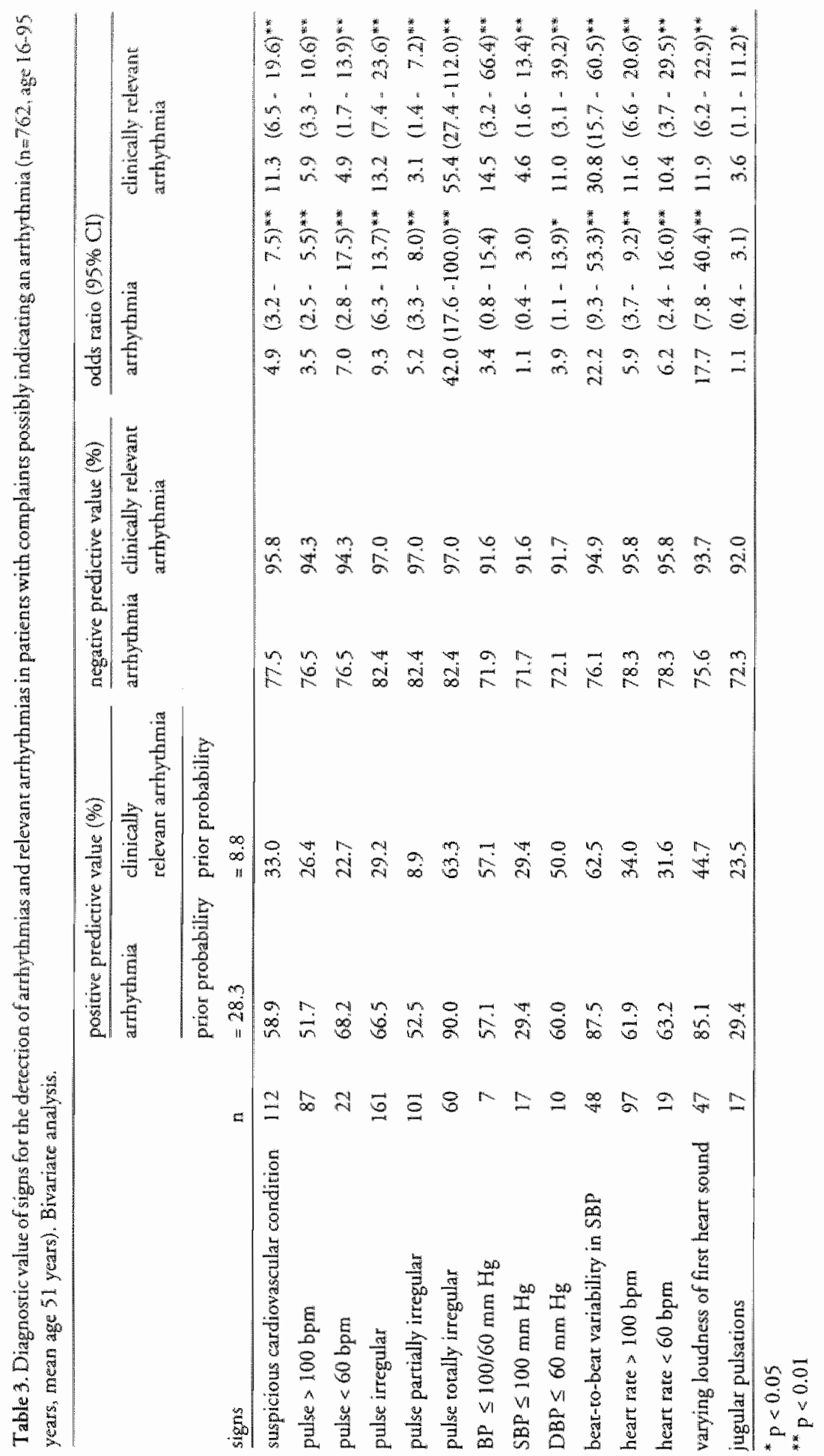




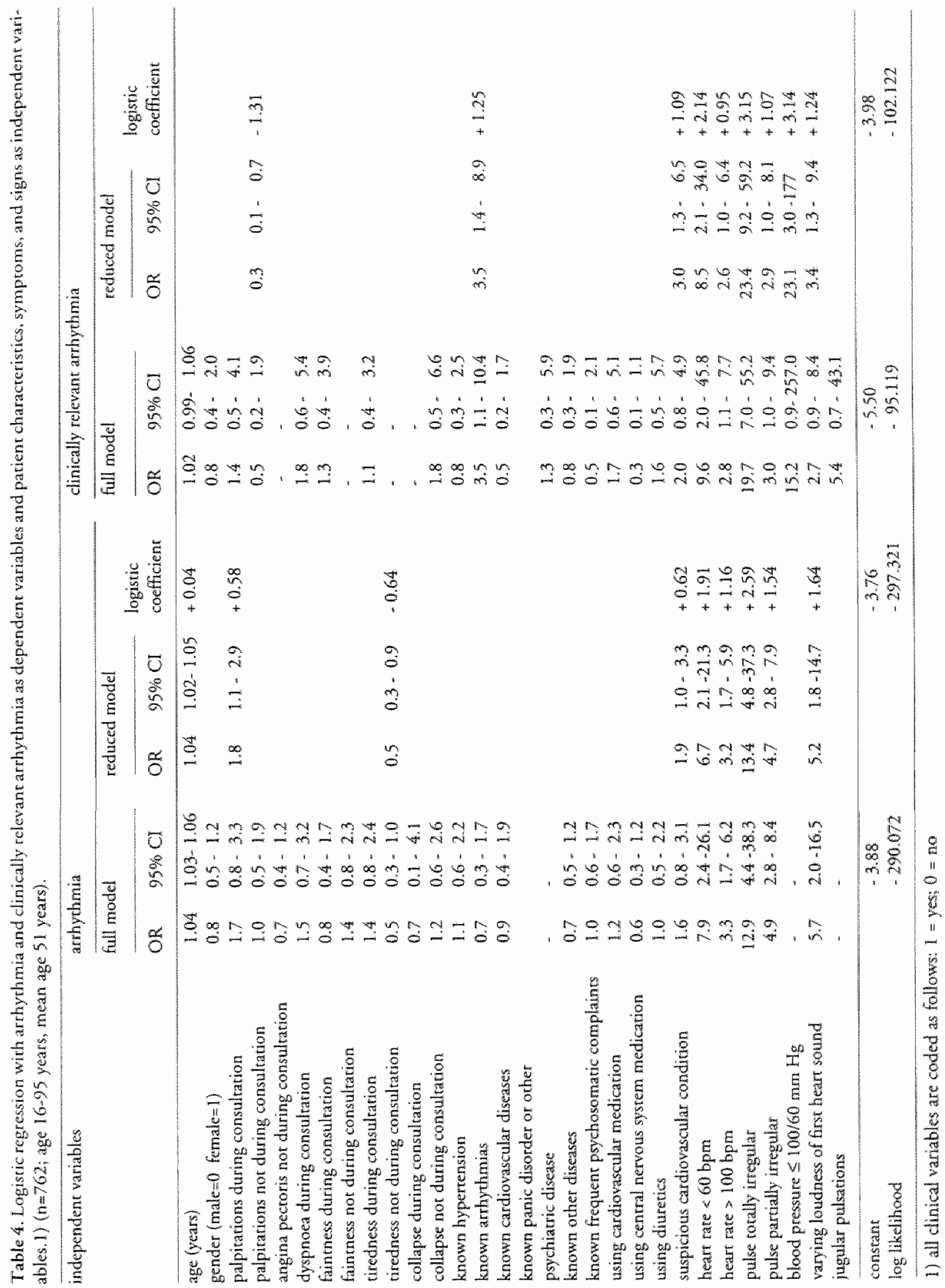




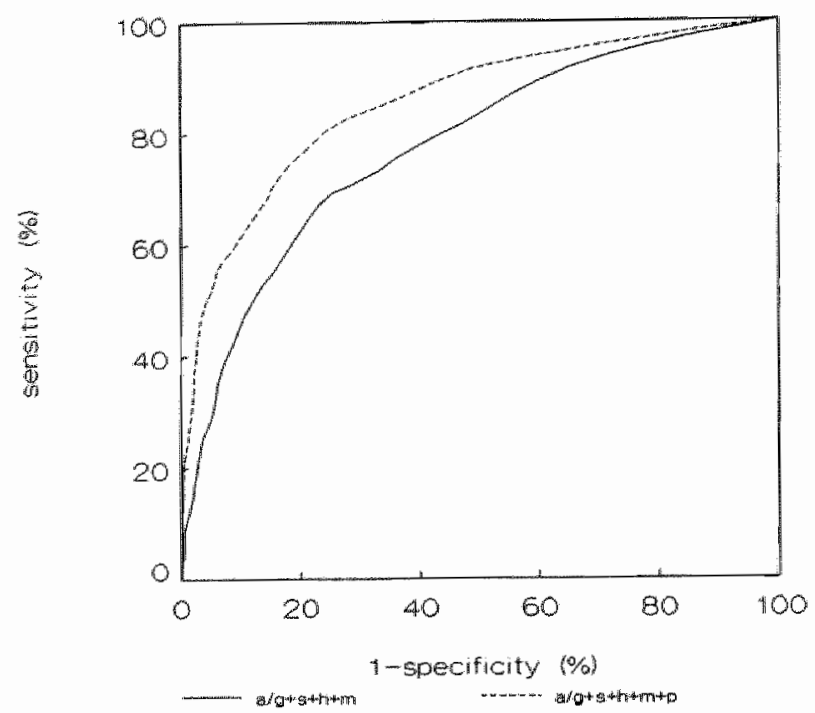

age/gender(a/g), symproms (s), medical history(h) and medicarion(m) AUC $=0.774$

age/gender, symproms, medical history, medication, physical examinattion $(p)$

$A \cup C=0.853$

Figure 1. ROC curve of logistic regression models representing two different subsers of parient characteristics and symproms in predicting arrhythmias and the surplus value of physical examination variables $(n=762$; age $16-95$ years, mean age 51 years).

When the consecutive reduced models, representing the natural increase of clinical information during a consultation are presented together, the gain in diagnostic impact of additional information becomes obvious (Tables 5 and 6). Moreover, some patient characteristics and symptoms, such as gender and dyspnoea during consultation, loose their diagnostic information in more extensive models at the expense of added variables of the physical examination.

\section{DISCUSSION}

In this general practice based study, 762 parients with complaints possibly related to arrhythmias, the diagnostic value of signs associared with arthythmias was assessed. In more than a quarter of the parients arrhythmias and in nearly ten percent clinically relevant arrhythmias were found. In bivariate analysis, a totally irregular pulse and related findings such as variability in SBP and varying loudness of the first heart 


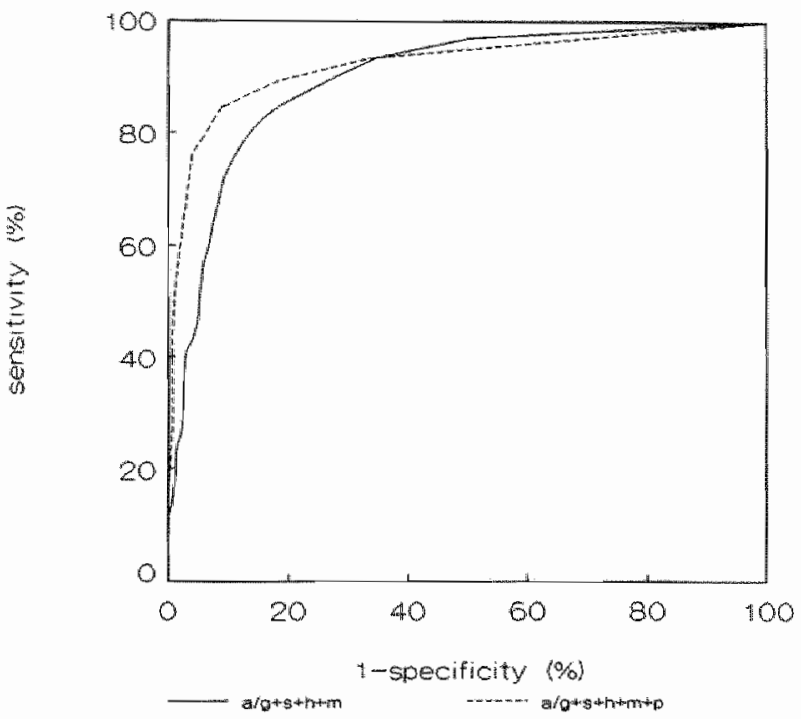

age/gender(a/g), symproms(s), medical history(h) and medication(m) $\mathrm{AUC}=0.905$

age/gender, symptoms, medical history, medication, physical examinat tion(p)

$A U C=0.929$

Figure 2. ROC curve of logistic regression models tepresenting two different subsets of patient characteristics and symptoms in predicting clinically relewant arrhythmias and the surplus value of physical examination variables ( $\mathrm{n}=762$; age $16-95$ years, mean age 51 years).

sound were the best predictors of arrhythmias. For clinically relevant arrhythmias, these were also good predictors as were a low blood pressure and the suspicion of a cardiovascular abnormality. In the logistic regression analysis, it became obvious that signs have such an impact on the prediction of arrhythmias and clinically relevant arrhythmias, that patient characteristics and symptoms become relatively less important after physical signs have been added to these models. In the most comprehensive model, age, palpitations, heart bear, irregularity, varying loudness of the first heart sound and a suspicious cardiovascular condition were positively associated, whereas tiredness was negatively associated with arrhythmias. In a model predicting clinically relevant arrhythmias, a history of palpitations had also a negative predicrive value, while a history of arrhythmias had a positive predictive value. All signs mentioned before, as well as a low blood pressure, which may be due to low cardiac output, were informative diagnostic signs in clinically relevant arrhythmias. In the most extensive models "palpitations during consultation", was only a predictor of arrhythmias and no indicator of clinically important 


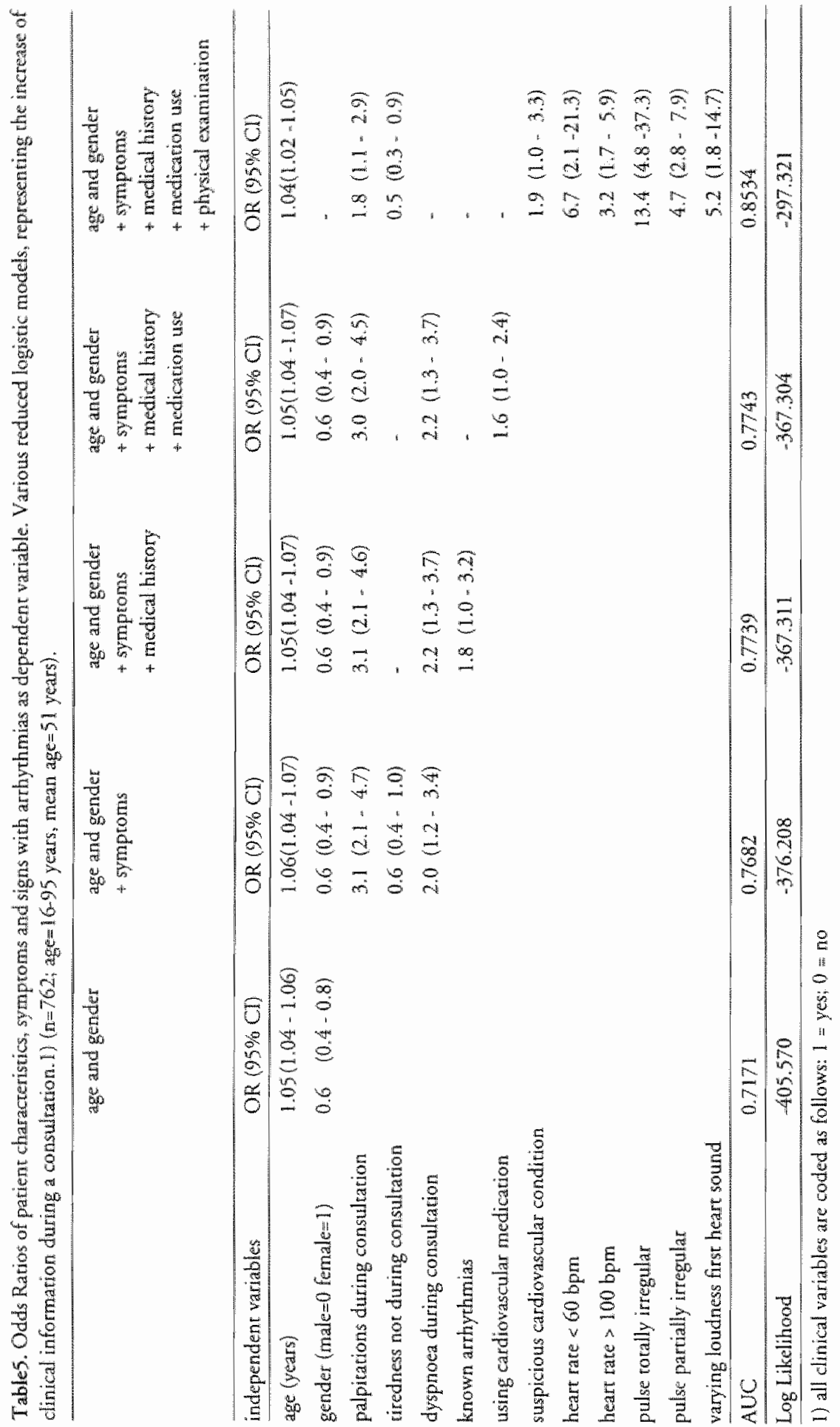




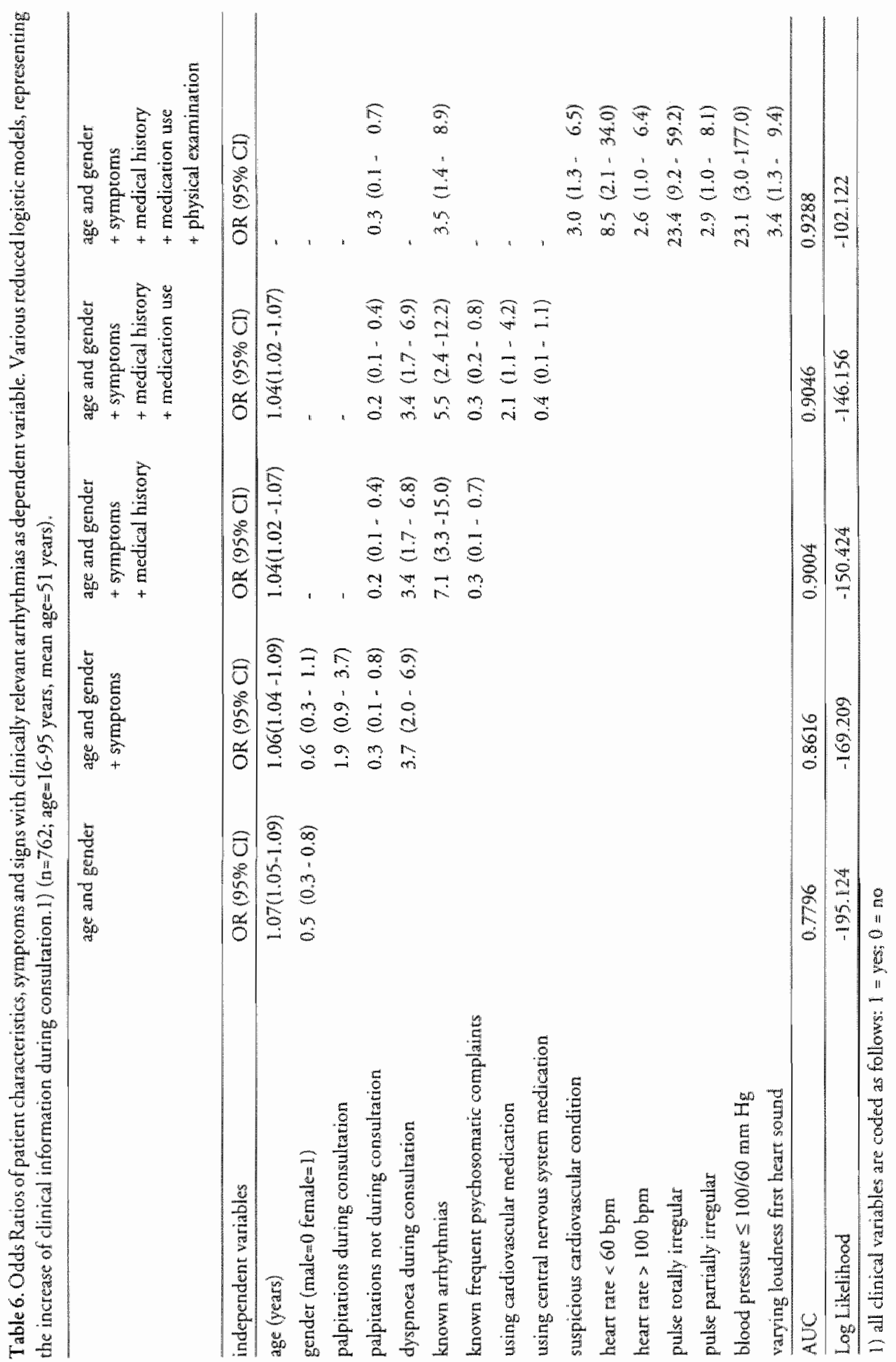


arrhythmias, probably because of the more powerful other variables. A history of palpitarions had a negative odds ratio for clinically relevant arrhythmias, which can be explained by higher diagnostic values of most of the other symproms, resulting in reduction of the diagnostic value of palpitations. In addition, both can be caused by the paroxysmal character of this symptom and therefore its obvious consultation related value with a standard, which was not optimal in the detection of short lasting arrhythmias.

Holter monitoring or event recording would have been attractive because of the paroxysmal character of some arrhythmias. However, we preferred to use the 12-lead ECG because this is the kind of equipment generally used in general practice. In addition, Holter monitoring would have given more false positive arrhythmias with no clinically relevant correlation with signs or symptoms. ${ }^{1011,12}$ Our approach gives insight into the frequency and types of arrhythmias to be detected in general practice.

In The Netherlands, most of the patients with complaints possibly caused by an arrhythmia are first seen by their GP, unless in some cases the severity of an arrhythmia leads to urgent hospital presentation. In our study, the few patients with an acute arrhythmia seen in the hospital, and not by the GP, are not included in the study. Hence, our results are applicable to patients who consult their GP and not to emergency patients with poorly tolerated arrhythmias or circularory arrest. However, for the diagnosis in these pronounced situations, a diagnostic model is less relevant in general practice, since immediate referral is clearly indicated.

In conclusion, patient characteristics, medical history, symptoms, and signs can be very helpful in diagnosing arrhythmias in general and especially clinically relevant arrhythmias. To our knowledge, this is the first reported study in general practice dealing with quantitative information about the value of physical signs, in addition to patient characreristics and symptoms in diagnosing arthythmias. These data can be used to decide whether it is meaningful to make an ECG recording. Although the incidence of clinically relevant arrhythmias in younger patients is much lower than in older patients, GPs should be alert not to misdiagnose rare arrhythmias in the young, such as the Wolff-Parkinson-White syndrome, in which an ECG recording is very sensitive. In older patients with complaints possibly indicating an arrhythmia, GPs should make ECG recordings especially to document the expected arthythmia and to diagnose possible underlying cardiovascular pathology. As symproms during consultation are very important for the diagnosis, parients without an arrhythmia during consultation should be asked to contact their GP again during symptoms, to make an immediate ECG recording. Event recording in general practice may be useful in these cases. 


\section{REFERENCES}

1. Zwietering P. Knottnerus A, Gorgels T, Rinkens P. Occurence of arthythmias in general practice. Scand J Prim Healch Care 1996; 14:244-250.

2. Van Lisdonk EH, Van den Bosch WJHM, Huygen FJA, Lagro-lanssen ALM. Ziekten in de huisartspraktijk (Diseases in general practice). Utrecht: Bunge, 1990.

3. Lamberts $\mathrm{H}$. In het huis van de huisarts (In the house of the general practitioner). Leliestad: Meditelks, 1991.

4. Schlan RC, Alexander RW, O"Rourke RA, Roberts R, Sonnenblick EH, eds. Hurst's the heart an" teries and veins. 8th ed. New York: Mc Graw.Hill, 1994.

5. Zipes DP. Normal and abnormal circulatory function. Specific arthythmias: Diagnosis and treatment. In: Braunwald E, ed. Heart Disease: A rextbook of cardiovascular medicine 4 th ed. Philadelphia: WB Saunders; 1992: 667-718.

6. Zwietering PJ. Knotmerus JA, Rinkens PELM, Kleijne MAWJ Gorgels APM. Arrtyrhmias in general practice: diagnostic value of patient characteristics, medical history and symptoms. Fam Pract $1998: 15: 343-353$.

7. Dixon WJ, Brown MB, Engelman L, Jennrich RI. BMDP staristical software manual. Universiry of California Press. Berkeley/Los Angeles/Oxford, 1990.

8. Kleinbaum DG, Kupper L, Morgenstern H. Esidemiologic Research. Principles and quantitarive merhods. Van Nastrand Reinhold New York, 1982: 426.

9. Hosmer DW, Lemeshow S. Applied logistic regression. John Wiley \& Sons. New York/Chichester/Brisbane/Toronto/Singapore, 1989.

10. DiMarco JP, Philbrick JT. Use of ambulatory electrocardiographic (Holter) moniroring. Ann Int Med 1990; 113: 53-68.

11. Bjerregard P. Continuous ambulatory elecrocardiography in healthy adult subjects over at 24 hour period. Clinical data, and evaluation of instruments for ambulatory electrocardiography. Dan Med Bull 1984; 31:283-97.

12. Barret PA, Peter CT, Swan HJC, Singh BN, Mandel WJ. The frequency and prognostic signifcance of electrocardiographic abnomalines in clinically normat individuals. Prog Cardiovase Dis $1981 ; 23: 299-319$ 
CHAPTER 5

How accurate do general practitioners diagnose arrhythmias presenting as a coincidental finding?

- diagnostic value of patient characteristics, medical history, symptoms and physical signs - 


\section{ABSTRACT}

Backgrownd. Arrlyythmias in general practice are frequently diagnosed by coincidental finding. It is not known whether general practitioners diagnose arrhychmias correcrly, are able to assess their clinical relevance, and can differentiate between arrbythmias and other pathology.

Objectives. To evaluare the accuracy of diagnosing arhythmias in coincidental findings and to assess the walue of symproms and signs (a) in diagnosing arrhythmias in general practice and (b) in identifying clinically relevant arthythmias.

Method. From patients with coincidental findings possibly relaced to an arrhythmia, a structured history and physical examination was taken by the general pracritioner (GP) and a cardiophonic electrocardiogram (ECG) was made during a rwo-year sudy period. These GP's, unaware of the ECG diagnoses, were asked to give a differential diagnosis.

Results. 106 patients were seen with signs possibly related to an arrhythmia. In $61 \%$ of chese, arrhythmias were confirmed by ECG and in $18 \%$ these were classified as clinically relevant. GPs" diagnosis was correcr in $85 \%$ of the cases when an arthythmia was registered by ECG recording. In this population, physical signs (especially a totally irregular pulse and correlated findings) but not patient characteristics, symptoms and medical history findings, were the most accurate predictors of (clinically relewanc) arrhythmias.

In the logistric regression analysis, only an irregular pulse and a history of fainting were positively associated with the presence of arhythmias. In detecting dinically relevant arrhythmias, ireguarity, as well as a heart rate of more than 100 bpm and a history of collapse were important varriables.

Conchasons. In diagnosing arthythmias presenting as a coincidental finding, patient characteristics and medical history find ings are of minor importance. Physical signs are useful to confirm the presence of arthymias and the assessment of clinical relevance. GPs are able to make a correct diagnosis in most of the cases, based on aigns and symproms.

Key words. Arhythmia, medical history taking, physical examination, dingnosis, general practice, predictive value. 


\section{INTRODUCTION}

The diagnostic process in general practice largely depends upon the prior probability of disease and the predictive value of signs and symptoms. ${ }^{1}$ In general practice, an incidence of 2.6 arrhythmias per 1000 listed patients per year was recently reported. ${ }^{2}$ Other studies in primary care patients have focused more on the description of electracardiographic abnormalities than on the diagnosis of arrhythmias. ${ }^{3,4}$ Data from Dutch general practice registration nerworks give incidences of 2-3 arrhythmias per 1000 patient-years for men and $2-5$ for women and period prevalences of 4-8 for men and 8-9 for women per 1000 per year. 5,6 The "Registration Network Family Pracrices" gives a point prevalence of 20 diagnosed arrhythmias per 1000 registered subjects.?

In patients with an irregular, a slow or a fast pulse, as a coincidental finding, when presenting to the GP for another reason, the type and clinical relevance should be considered. In cardiology textbooks, little artention is paid to the predictive value of signs and symptoms in patients with coincidental findings possibly indicating an arrhythmia. ${ }^{8}$ Neither could we find research reports from a non-referred population, paying artention to the quantitative aspects of this relation in terms of sensitivity, specificity and predictive value and using an independent "gold standard".

General practitioners are confronted with findings possibly indicating an arrhythmia when measuring blood pressure and when they palpate the pulse as part of a general physical examination. Recognition of arrhythmias is primarily based on signs and symptoms during history taking and physical examination. Further diagnostic procedures will follow to reassure the patient, if the arrhythmia is considered to be possibly hazardous to the patient, or if the type of arrhythmia needs to be documented. Research data on the diagnostic value of signs and symptoms in arthythmias in general practice become more important because of a growing incidence of arrhythmias as a result of the ageing of our population. Therefore, we studied the value of patient characteristics, medical history, symptoms and signs in diagnosing arrhythmias in general practice and in identifying patients with clinically relevant arrhythmias among patients with coincidental findings possibly indicating an arrhythmia.

\section{METHODS}

\section{PATIENTS AND MEASUREMENTS}

During 2 years, 27 GPs from 20 practices in a (sub) urban population in Limburg, The Netherlands, with a total population of nearly 50,000 patients participated in the study. The mean duration of participation of the practices was 22.6 months. Patients were enrolled when during consultation a pulse or heart beat more than 100 
beats per minute (bpm) or less than $60 \mathrm{bpm}$ was recorded, or when there was an irregular pulse or heart beat or more than 5 extrasystoles per minute. These findings had to be new for the GP or should represent a diagnostic problem. Patients younger than 15 years of age and patients with fever were excluded. In addition, patients were excluded when participation would not be consistent with good practice since immediate referral was indicated, such as patients with an acute myocardial infarction, circulatory atrest, or an otherwise poor circulatory condition. In all patients, a structured medical history was taken and a physical examination was done. GPs recorded signs and symptoms on standardised forms, which were filled out before receiving the interpretation of the ECG. The GPs's registration systems were also used to collecr additional patients' medical history data. General practitioners were asked to make a differential diagnosis before they received the ECG diagnosis. A correcr diagnosis was defined, when the first or the second diagnosis mentioned, was correct. In all patients, a transtelephonic ECG was sent to the department of cardiology of the local hospital. All patients were included in the analysis, irrespective of the availability of an ECG recording when the physical signs pointing to an arrhythmia were noticed. The transtelephonic ECG recordings were obtained by an ECG modem 3 (Cardio Control BV, Rijswijk, The Netherlands), consisting of a 12-lead ECG taken during 36 seconds.

The interpretation of the ECGs was done by a cardiology fellow and confirmed by a senior cardiologist. Both were unaware of the findings from the medical history and physical examination.

\section{DEPENDENT VARIABLES}

As dependent variable the ECG diagnosis was used. Arrhythmias were defined as all rhythms being not a normal rate sinus rhythm. Differentiation was made between arrhythmias (ar) and no arrhythmias at the one hand and clinically relevant arrhythmias (arrel) and innocent or no arrhythmias at the other. The arrhythmias were classified with regard to clinical relevance, specified by the research team before the analysis. It was based upon the need for medical intervention and diagnostic work-up by the GP or by a cardiologist. When extrasystoles were present in combination with another rhythm than a sinus rhythm, the ECG was interpreted as the leading rhythm and no attention was paid to the extrasystoles. Table 1 gives an overview of the detected arrhythmias and their assessed clinical relevance.

\section{INDEPENDENT VARIABLES}

The independent variables were separated into basic patient characteristics, medical history, medication use, symptoms and signs. A differentiation was made between symptoms present during consultation, present but nor during consultation, and not present. 
Table 1. Characteristics of parients with occasional findings possibly caused by arrhythmias $(\mathrm{n}=106)$.

\begin{tabular}{|c|c|c|c|c|c|}
\hline & \multicolumn{2}{|c|}{ Parients } & & \multicolumn{2}{|c|}{ Patints } \\
\hline & $N$ & $\%$ & & $\mathbb{N}$ & $\%$ \\
\hline \multicolumn{3}{|l|}{ general characteristics } & \multicolumn{3}{|l|}{ medical history } \\
\hline wornen & 65 & 61.3 & atrial fibrillation & 4 & 3.8 \\
\hline hoome visits & 12 & 11.3 & extrasystoles & 3 & 2.8 \\
\hline ECG during signs & 77 & 72.6 & not specified & 1 & 1.0 \\
\hline known arrhythmia detected & 3 & 2.8 & rotal arrfyythmias & 8 & 7.5 \\
\hline \multirow[t]{2}{*}{ new finding } & 89 & 84.8 & AV-block & 1 & 1.0 \\
\hline & & & valve disease & 1 & 1.0 \\
\hline reasons for inclusion ${ }^{*}$ & & & myocardial infarction & 4 & 3.8 \\
\hline pulse $>100 \mathrm{bpm}$ & 38 & 35.8 & heart failure & 6 & 5.7 \\
\hline pulse $<60$ bpm & 10 & 9.4 & coronary heart disease & 7 & 6.6 \\
\hline pulse irregular & 37 & 34.9 & hypertension & 43 & 40.6 \\
\hline heart rate > 100 bpm & 8 & 7.5 & & & \\
\hline heart rate $<60 \mathrm{bpm}$ & 2 & 1.9 & medication use & & \\
\hline \multirow[t]{2}{*}{$\geq 5$ extrasystoles/minute } & 14 & 13.2 & betablockers & 13 & 12.3 \\
\hline & & & nitrates & 5 & 4.7 \\
\hline ECG diagnosis & & & glycosides & 5 & 4.7 \\
\hline atrial Alutter & $\mathbb{1}$ & 1.0 & calcium entry blockers & 7 & 6.6 \\
\hline atrial tachycardia & 1 & 1.0 & antiarthythmics (class 1 or 3 ) & 0 & 0.0 \\
\hline atrial fibrillation & 17 & 16.0 & diurerics & 22 & 20.8 \\
\hline clinically relevant arrbychmias & 19 & 17.9 & $A C E$ inhibitors & 10 & 9.4 \\
\hline extrasystoles & 26 & 24.5 & other cardiowascular medication & 13 & 12.3 \\
\hline sinus tachycardia & 11 & 10.4 & & & \\
\hline sinus bradycardia & 7 & 6.6 & & & \\
\hline sinus arrhychmia & 1 & 1.0 & \multirow{2}{*}{\multicolumn{3}{|c|}{$\begin{array}{l}\text { ") Column percentage exceds } 100 \% \text { because patients } \\
\text { could be included on more than one occasional. } \\
\text { finding. }\end{array}$}} \\
\hline regular atrial rhythm & 1 & 1.0 & & & \\
\hline toul arbythmias & 65 & 61.3 & finding. & & \\
\hline
\end{tabular}

\section{STATISTICAL ANALYSIS}

Statistical analyses were performed with BMDP. In bivariate analysis, the Pearson chi-square test was used. When the expected frequency in ar least one cell was less than 5 , the Fisher exact test was used. In calculating the diagnostic value of symptoms, the denominator varied with the subgroup analysed. Diagnostic value was expressed in positive and negative predictive values and summarised in odds ratios with $95 \%$ confidence intervals. 
Variables with a significance level $p<0.10$ in bivariate analysis, were included into a multiple logistic regression analysis. Starting from the full models, multiple logistic regression with backward elimination of insignificant variables was performed for both "arrhythmias" and "climically relevant arrhythmias" as dependent variables, to derive reduced prediction models and to calculate adjusted odds ratios, taking all included variables into consideration simultaneously. Variables were removed when $p>0.05$.

In bivariate analysis, age was divided in two groups (limit 65 years) with the youngest group as reference group. In the logistic regression model, age was entered as a continuous variable.

Receiver Operating Characteristics (ROC) curves, expressing the relation berween sensitivity and specificity of the models for various cur-off points of the predicted posterior probability, were used to elucidate the additional value of models with more variables. The area under the curve (AUC) of the distinct models, which is a measure of the diagnostic power of the different models, was calculated with BMDP.

\section{RESULTS}

A total of 106 patients met the inclusion criteria. Table 1 gives a specification of baseline characteristics. In 77 patients (73\%) an ECG was recorded during signs.

Of the patients included, $89 \%$ was not known with arrhythmia. Eight patients (4 patients with atrial fibrillation, 3 patients with premature beats and one patient with a not specified arrhythmia) allready known with an arrhythmia were included because the generall practitioner had a problem diagnosing the arrhythmia. In 2 patients, known with atrial fibrillation an other arrhythmia was diagnosed: in one patient an atrial tachycardia and in the other patient premarure beats. Of the 3 patients, known with premature beats one had atrial fibrillation and one had a sinus rhythm. In $61 \%$ of the patients the arrhythmia was recorded on ECG and in $18 \%$ clinically relevant arrhythmias. In predicting the type of arrhythmia, the general practitioners mentioned only one possible diagnosis in 71 . $67 \%$ patients. Two and three possible diagnoses were mentioned in $26(25 \%)$ and in $9(8 \%)$ patients, respectively. In $36 \%$ of the patients no arrhythmia was recorded. When excluding patients known with the same arthythmia as the recorded arrhythmia, general practitioners made a correct diagnosis in $50 \%(56 / 103)$ of the patients and in $85 \%(53 / 62)$ of the patients with a documented arrhythmia (Table 2). 


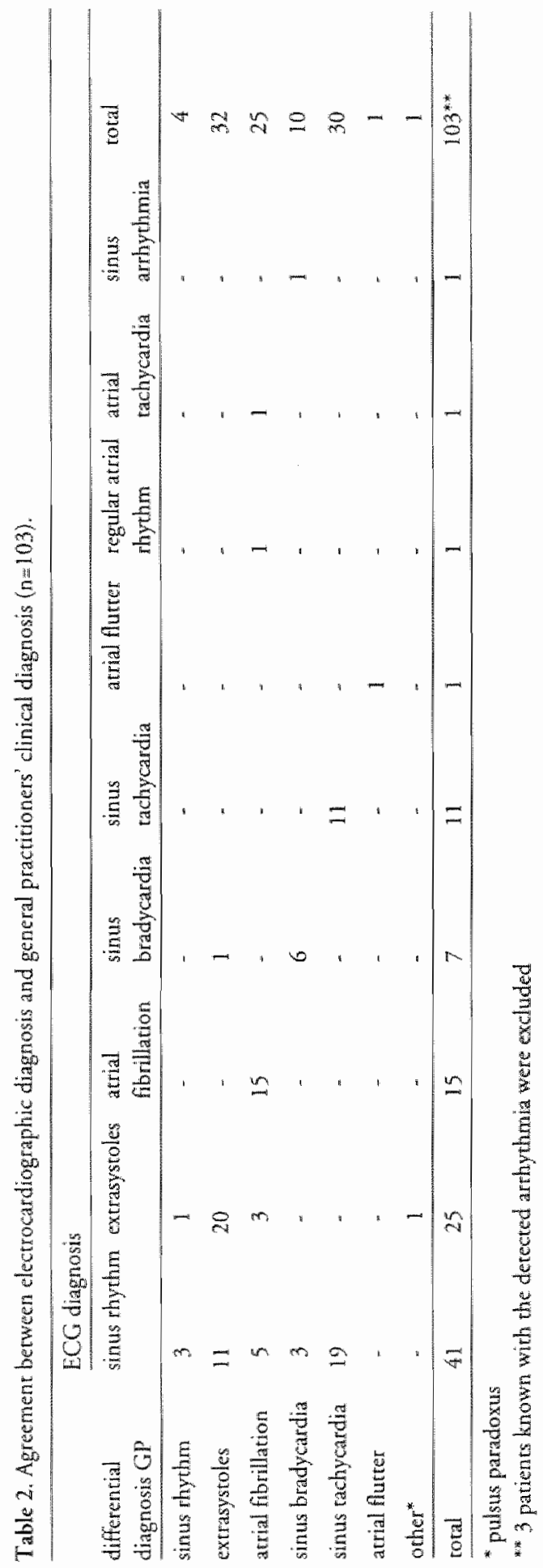




\section{DIAGNOSTIC VALUE OF PATIENT CHARACTERISTICS IN BIVARIATE ANALYSIS}

Results of bivariate analysis are presented in table 3. Using the age group 15-64 years as reference group, higher age was a significant determinant of the occurrence of arthythmias and clinically relevant arthythmias $\left(\mathrm{OR}_{\mathrm{ar}}=2.6, \mathrm{OR}\right.$ arrel $\left.=3.3\right)$. The absolute number of arrhythmias in women was higher than in men, while the percentage arrhythmias detected in men and in women was nearly the same. Arrhythmia in the past $\left(O R_{\text {arrefl}}=5.5\right)$ was significantly associated with clinically relevant arrhythmia, while a history of cardiovascular disease $\left(O R_{a r}=4.1, O R_{a r r e l}=5.2\right)$ was an important factor conrributing to the probability of both arhythmias and relevant arrhythmias. Other known conditions or medication use did not contribute to the diagnosis of arrhythmias or clinically relevant arrhythmias.

\section{DIAGNOSTIC VALUE OF SYMPTOMS IN BIVARIATE ANALYSIS}

Fainting not present during consultation $\left(\mathrm{OR}_{\mathrm{ar}}=3.8\right)$, was the only symptom positively correlated with the derection of arrhythmias (Table 3). In all (4) patients with a history of collapse an arrhythmia was detected ( 3 patients had atrial fibrillation and one patient had sinus tachycardia). Collapse ( $O R_{\text {arrel }}=16.1$ ), whether or not during consultation, had the highest positive predictive value for clinically relevant arrhythmias. Dyspnoea $\left(O R_{\text {arrel }}=2.8\right)$, especially during consultation $\left(O R_{\text {arrel }}=3.2\right)$, also was a significant predictor of clinically relevant arrhythmias. Neither palpitations, nor angina, fatigue or other symptoms supported the diagnosis of arrhythmias in this patient group.

\section{DIAGNOSTIC VALUE OF SIGNS IN BIVARIATE ANALYSIS}

Irregularity was positively associated with the occurrence of arthythmias and clinically welevant arrhythmias (Table 4). A totally irregular pulse (OR $\mathrm{Ar}_{\mathrm{ar}}=10.5, \mathrm{OR}$ arel $=48.8$ ) and correlated signs such as a beat to bear variability in systolic blood pressure or a varying loudness of the first heart sound, were the most prominent predictors of (clinically relevant) arrhythmias. A suspected cardiovascular condition was positively correlated with the detection of both arthythmias and clinically relevant arrhythmias. A heart rate of more then $100 \mathrm{bpm}$ was only associated $\left(O \mathrm{R}_{\text {arrel }}=2.9\right)$ with the presence of clinically relevant arrhythmias. No significant correlation was found between pulse, heart rate, a low blood pressure or jugular pulsations and arrhythmias. 


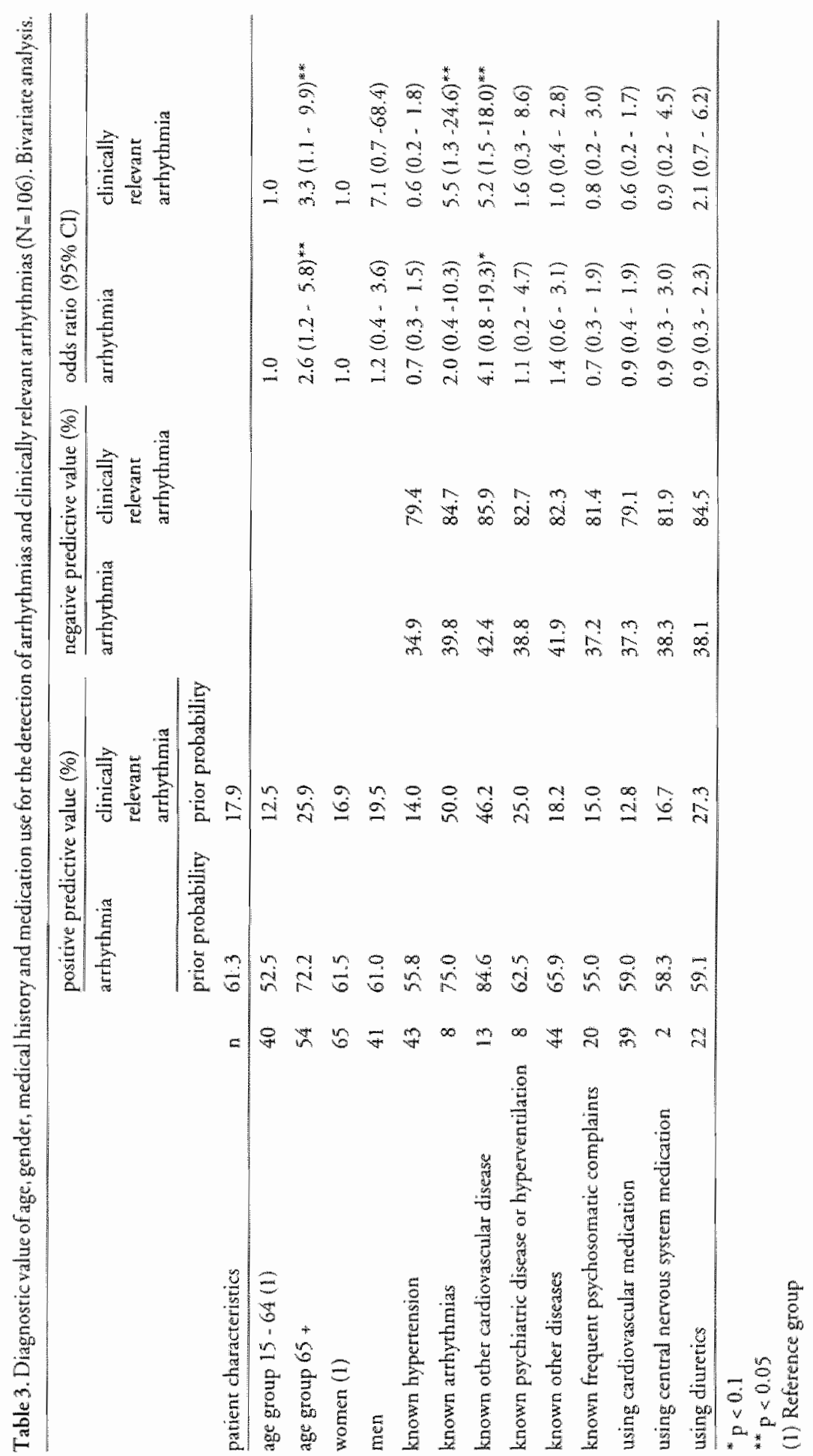




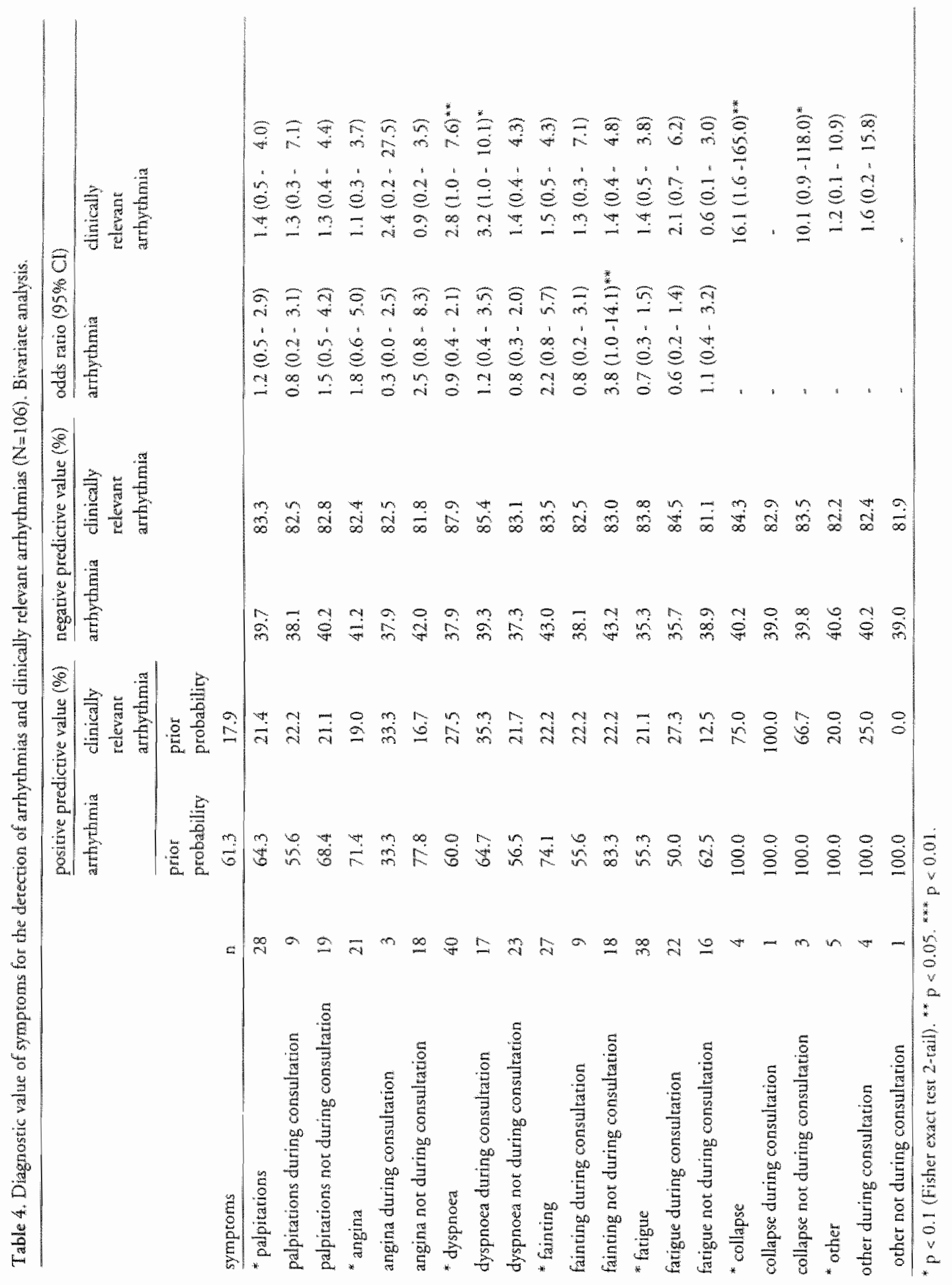




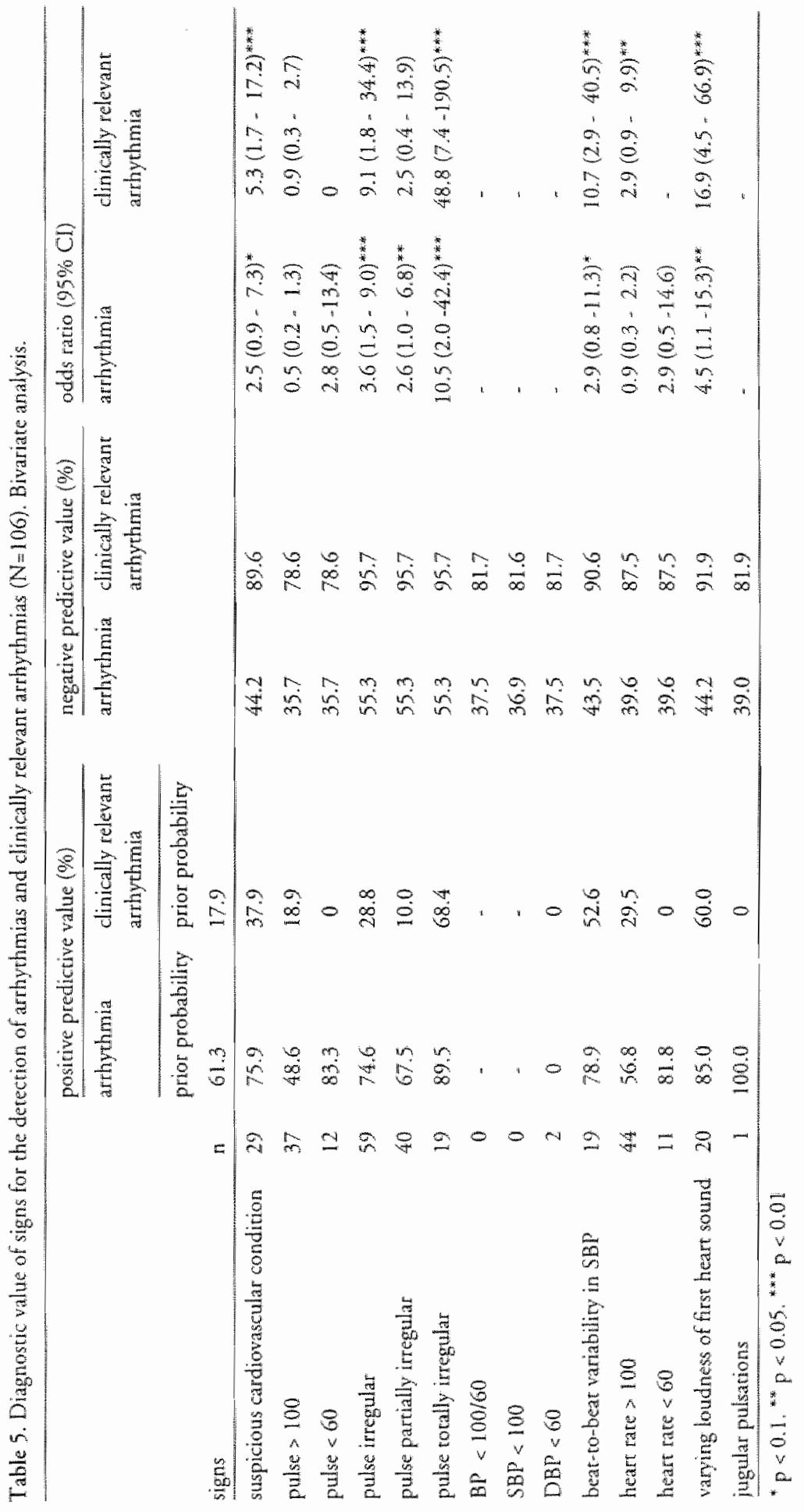


Table 6. Reduced logistic regression models with arhychmia and clinically relewan armythmia as dependenr wariables, and patient characteristics, signs and symptoms as independent varables $(a=106)$.

\begin{tabular}{|c|c|c|c|c|c|c|}
\hline \multirow[b]{2}{*}{ independent wariables ${ }^{* *}$ ) } & \multicolumn{3}{|c|}{$\begin{array}{l}\text { arthythmia } \\
\text { reduced model }\end{array}$} & \multicolumn{3}{|c|}{$\begin{array}{l}\text { clinically relevan arrlythmia } \\
\text { reduced model }\end{array}$} \\
\hline & OR & $95 \% \mathrm{CI}$ & $\begin{array}{l}\text { regression } \\
\text { coefficient }\end{array}$ & OR & $95 \% \mathrm{Cl}$ & $\begin{array}{l}\text { regression } \\
\text { coeficten }\end{array}$ \\
\hline fainting not during consultation & 4.5 & $1.1-17.8$ & 1.49 & & & \\
\hline collapse & & & & 25.6 & $1.4-482$ & 3.24 \\
\hline pulse partially itregular & 2.6 & $1.0-6.5$ & 0.95 & 18.1 & $1.5-215$ & 2.90 \\
\hline pulse totally irregular & 12.3 & $2.4-61.6$ & 2.51 & 457.0 & $27.7-7560$ & 6.13 \\
\hline hearc bear $\times 100 \mathrm{bpm}$ & & & & 24.2 & $2.7-220$ & 3.19 \\
\hline Constant & & 0.46 & & & -6.20 & \\
\hline log likelihood & & -60.760 & & & -22.121 & \\
\hline
\end{tabular}

4) all variables are coded as follows: $1=$ yes; $0=$ no.

*) variables are entered in the logistic regression model when $\mathrm{p}<0.1$ in bivariate analysis (See: table 2,3 and 4 ).

\section{DHAGNOSTIC VALUE OF PATIENT CHARACTERISTICS, SYMPTOMS AND SIGNS IN LOGISTIC REGRESSION}

Taking all independent variables with a significant correlation with (clinically relevant) arrhythmias in bivariate analysis into consideration simultaneously, a history of fainting not during consultation $\left(O R_{a r}=4.5\right)$ and a partially $\left(\mathrm{OR}_{\mathrm{ar}}=2.6\right)$ or totally $\left(O R_{a r}=12.3\right)$ irregular pulse were important determinants in diagnosing arrhythmias (Table 5). For clinically relevant arrhythmias as the dependent variable, syncope $\left(O R_{\text {arrel }}=25.6\right)$, a hearrbeat of $>100 \mathrm{bpm}\left(O R_{\text {arrel }}=24.2\right)$ and a partially $\left(O R_{\text {arrel }}=18.1\right)$ or a totally irregular $\left(O R_{\text {arrel }}=457\right)$ pullse were positive predictors.

The predicted probability of an arrhythmia can be estimated according to the formula:

$$
p=\left[1+e^{-y}\right]^{-1(10)}
$$

where, based on the reduced model (Table 5): $y=-0.46+1.5 \times$ fainting $+0.95 \times$ partially irregular pulse $+2.51 \times$ totally irregular pulse.

For relevant arrhythmias $y=-6.20+3.24 \times$ syncopet $3.19 \times$ heartbeat $>100+2.90 x$ parrially irregular pulse $+6.13 \times$ totally irregular pulse.

Using these multivariable models, the predicted probability of an arrhythmia in patients with coincidental findings suggesting an arrhythmia can be estimated. 


\section{RECEIVER OPERATING CHARACTERISTICS OF PATIENT CHARACTERISTICS AND SYMPTOMS IN A LOGISTIC REGRESSION}

The relation between sensitivity and specificity for various cut-off points in various prediction models, with different subsets of independent variables is shown in figures 1 and 2. For the model with arrhythmias as dependent variable, the $A U C=0.729$. Regarding the logistic model for detecting clinically relevant arrhythmias, the $\mathrm{AUC}=0.931$.

\section{DISCUSSION}

To our knowledge, this is the first study done in primary care, yielding quantitative information about the value of patient characteristics, symptoms and signs for diagnosing arrhythmias in patients with coincidental findings, possibly related to arrhythmias. Because we were also interested in the accuracy of GP' diagnoses, we formulated broad inclusion criteria to detect all new arrhythmias in patients, also in patients already known with an arrhythmia when there was a new diagnostic problem. This "indicated population", is the population in which GPs are clinically interested in the diagnostic value of symptoms with regard to arrhythmias.

In more than $60 \%$ of the patients arrhythmias were registered. In nearly $18 \%$ a clinically relevant arrhythmia could be found. Higher age, and to a lesser degree a history of cardiovascular disease or arrhythmia are significantly related to the presence of arrhythmias. Symptoms related to haemodynamic compromise, such as dyspnoea and collapse, are associated with the presence of clinically relevant arrhythmias. However, collapse was found in only few patients. Nearly all signs were significantly related to (clinically relevant) arrhythmias. No relation was found between a fast or slow pulse and arrhythmias, possibly caused by the relatively large amoun of extrasystoles in the normal pulse rate range. In the multiple logistic models, especially a totaily irregular pulse was a very good predictor of arrhythmias and their clinically relevance.

Correlations between the independent variables and specific arrhythmias could not be evaluated because of the low frequency of most of the arrhythmias. On the other hand, the ECG is not an ideal gold standard because it may be recorded at a time the arrhythmia has stopped, an other arrhythmia may be present and single paroxysmal arrhythmias are less likely to be recorded than chronic recurrent.

Although atrial fibrillation is likely to be the most frequent arrhythmia, a very large source population would be necessary to evaluate possible relations with specific infrequent arrhythmias. Holter monitoring or event recording could seem more attractive because of the paroxysmal character of some arrhythmias. However, Holter monitoring is a moderate diagnostic test in palpitations, which occur infrequently. 11,12,13 Most studies about the diagnostic yield of Holver monitoring are 


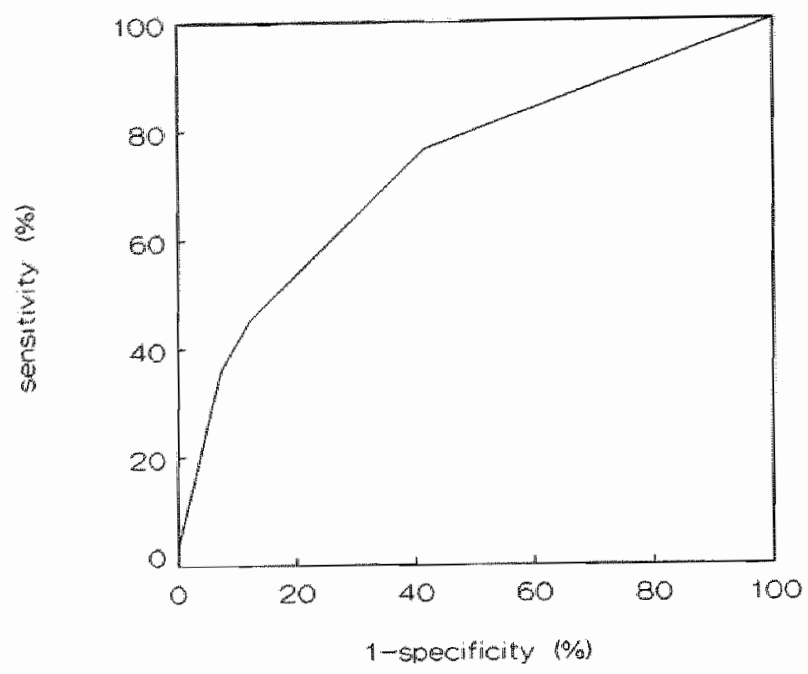

$A \cup C=0,729$

Figure 1. ROC curve of a logistic regression model of symptoms and signs in predicting arrhythmias $(n=106)$.

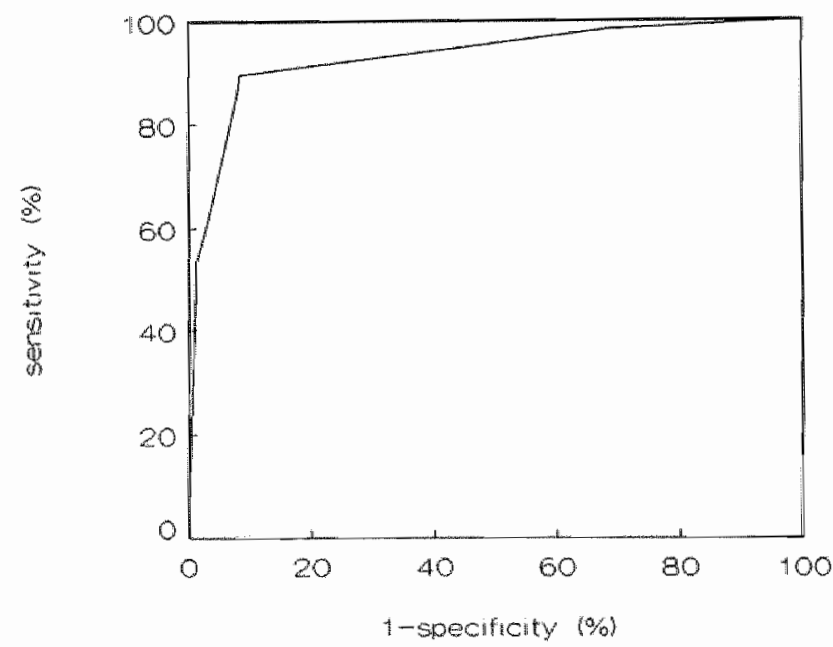

$\mathrm{AUC}=0.931$

Figure 2. ROC curve of a logistic regression model of symptoms and signs in predicting clinically relevant arrhythnias $(n=106)$. 
performed in selected populations and there is a considerable inter- and intra-reader variability and intra-patient day-to-day variability. Arrhythmias may also occur in asymptomatic persons, which would have given more false positive arrhythmias with no clinically relevant correlation to signs or symptoms, especially in a nearly unselected general practice population. ${ }^{13: 4}$ Event recording as another option, is no adequate standard in long lasting symptoms, such as fainring and tiredness. In at recent study, only $17 \%$ of the patients with palpitations were eligible for event recording. ${ }^{11}$

Finally, the 12-lead ECG is the kind of equipment used in regular general practice. Our approach with respect to the use of a 12 -lead ECG was based on these principal and feasibility considerations. It gives insight into the diagnostic value of clinical correlates and the frequency and types of arrhythmias to be detected in general practice. The frequent diagnosis of atrial fibrillation based on a coincidental finding is of importance. The patient does not present this arthythmia on the main complaint to the GP either because he is unaware of it or it does not bother him. Still this is a potentially dangerous arrhythmia, leading possibly to thrombo-embolic events, heart failure and increased mortality risk. This study suggests that the GP is well capable of detecting this arrhythmia allowing measures to prevent these complications in relatively asymptomatic patients.

In The Netherlands, most of the patients with signs possibly relared to an arrhythmia, are first seen by the GP, while in some cases the severity of an arrhythmia leads to immediate hospital admission. In our study, the few patients with an acure arrhythmia seen in the hospital, and not by the GP, are not included in the study. Hence, our results are applicable to patients who consult their GP and not to patients with poorly tolerated arrhythmias or circulatory arrest. For the diagnosis in these pronounced situations, a derailed diagnostic model based on symptons and signs is less relevant in general practice, since immediate referral is clearly indicared. Because this diagnostic model is based upon a confined primary care population, it is meaningful to test its performance in another but similar primary care population.

In conclusion, patient characteristics, symptoms and medical history can be helpful in diagnosing arrhythmias in general and especially clinically relevant arrhythmias in patients with coincidental findings, suggesting an arrhythmia. These dara can be used to decide whether it is meaningful to make an ECG recording. Although clinically relevant arrhythmias in younger patients are much less frequent than in older patients, GPS should be alert not to misdiagnose rare arrhythmias in the young, such as the Wolff-Parkinson-White syndrome in which an ECG recording is very sensitive. In older patients with occasional findings possibly indicating an arrhythmia, GPs should make ECG recordings especially to document the expected arrhythmia and to diagnose possible underlying cardiovascular parhology. Because physical signs during consultation are very important for the diagnosis, GPs should have the opportunity to make an ECG recording at the moment signs are registered. 


\section{ACKNOWLEDGEMENTS}

This study was supported by grant no 900-715-153 of the Netherlands Organisation of Scientific Research.

\section{REEERENCES}

1. Knottnerus JA. Interprexation of diagnostic data: an unexplored feld in general practice. I R Coll Gen Prace 1985: 35:270-274.

2. Zwietering P. Knotrnerus A, Gorgets T, Rinkens P. Occurrence of arrhythmias in general practice. Scand I Prim Health Care 1996: 14:244-250.

3. Froom I, Froom P. Electrocardiogram abrormalities in primary care patients. I Fam Pracr 1984; 1.8: $223-225$.

4. Jones R. Electrocardiographic diagnosis in general practice. Practitioner 1984; 228: 85-89.

5. Van Lisdonk EH, Van den Bosch WHM, Huygen FIA, Lagro-Janssen ALM. Ziekten in de huisartsprakrijk [Diseases in general practice]. Utreche: Bungē, 1990.

6. Lambers $H$. In thet huis wan de huisarts. [In the house of the general practirioner] Leiliestad: Meditekst. 1991.

7. Mersemakers JFM, Hoppener P, Knotnerus JA, Kocken RJI, Limonard CBG. Compurerized health information in the Netherlands: a registration network of family practices. $\mathrm{Br} J$ Gen Pract 1992: 42: 102-106.

8. Hurs JW, Morris DC. The history: Symptoms and past events related to cardiovascular disease. In: Scliant RC, Alexander RW, O'Rourke RA, Roberts R, Sonnenblick EH, eds. Hurst's the heart: arteries and veins. New York: Mc Graw-Hill, 8th ed, 1994: 205-216.

9. Dixon WJ, Brown MB, Engelman $L_{x}$ Jennrich RI. BMDP statistical software manual. Universiry of California Press. Berkeley/Los Angeles/Oxford, 1990.

10. Hosmer DW, Lemeshow S. Applied logistic regression. John Wiley \& Sons. New York/ Chichester/Brisband/Toronto/Singapone, 1989.

11. Kinlay S, Leith JW, Neil A, Chapman BL, Hardy DB, Fletcher PJ. Cardiac event recorders yield more diagnoses and are more cost-effective than 48 -hour Holter monitoring in patients with palpiarions. A controlled dinical rral. Ann Intern Med 1996; 124: 16-20,

12. DiMarco JP, Philbrick JT. Use of ambulatory electrocandiographic (Hollen) monitoring. Ann Int Med 1990; 13:53-68.

13. Herregard P. Continuous ambulatory electrocardiography in heathy adult subjects ower a 24thour period. Clinical data, and evaluation of instruments for ambulatory electrocardiography. Dan Med Bull 1984; $31: 283-97$.

14. Barrer PA, Peter CT, Swan HJC. Singh BN, Mandel WJ. The frequency and prognostic significance of electrocardiographic abnormalicies in clinically normal individuals. Prog Cardiovasc Dis 1981; 23: 299-319. 
CHAPTER 6

\title{
Atrial fibrillation in general practice \\ - diagnostic value of signs and symptoms -
}

\author{
Zwietering PJ, Knotmerus JA, Gorgels APM
}




\section{ABSTRACT}

Objectives. To assess the value of patient characreristics, medical history and physical examination in diagnosing arrial fubrillation in patients in general practice.

Mathods. During a two year period, a structured medical history and physical examination was carried out in all parients registered in 20 general practices with new complaints suggesting an arrhychmia. Relevant data of medical records were collected and a cardiophonic electrocardiogram (ECG) was made. For dara analysis bivarate and multiple logistic regression analysis were performed.

Results. Age was a powerful predictor of atrial fibrillation with prevalences of $4.5 \%$ (13/288) in the age group 45-64 years and $12.4 \%(23 / 185)$ in pacients 65 years or older. A history of other arrhyrhmias $(\mathrm{OR}=3.7[1.7-8.3])$, hypertension (OR=3.0 [1.6.6.0]) and in a lesser degree cardiovascular disease were significant predictors, as well as the use of diurerics and orher cardiovascullar medication, and symptoms such as dyspnoea $(\mathrm{OR}=7.0(3.5-13.8)$ ), dizziness $(\mathrm{OR}=3.4[1.6-7.1])$, palpitations $(\mathrm{OR}=2.6$ $[1.4-5.0]$ ) and to a lesser degree, farigue and collapse. A totally irregular pulse was the best diagnostic predictor of atrial fibrillation $\left(\mathrm{PV}^{+*}=49 \%\right.$ ), with an odds ratio of 94 [34.9-249].

In the logistic regression model, age, palpitations and dyspnoea, a totally or partially irregular pulse and a varying loudness of the first heart sound remaned significant contributors. An AUC or 0.93 was calculared in the ultmate logistic model, induding all significant dinicall variables.

Conchusion. Atrial filwillation as a new arrhythmia is a frequent event in general practice. Diagnosing this arrhythmia in general practice, based on simple features from the dinical history and physical examination, can be done with a high degree of certainty.

Key words. Arrhythmias, atrial fibriliation. diagnosis, medical-history-raking, physical examination, predictive value of tests. 


\section{INTRODUCTION}

Atrial fibrillation (AF) is a common arthythma in general practice next to extrasystoles. $1,2,3,4$ In the adult popularion the overall prevalence is $0.4 \%-0,9 \%, 5,6,7$

The prevalence of AF rises sharply with age and is estimated to be $6 \%$ in patients older than 65 years and increases to $10 \%$ in those aged 80 years and over, $1,5,8,9,10$ Men have a grearer risk of developing AF than women. However, because of the larger number of older women, the absolute number AF patients among women and men is rearly the same. $1,5,10,11,12$ Identification of patients with $A F$ is important because of its association with an increased risk of ischaemic stroke and TIA. ${ }^{3}$ In the literature, the average incidence of ischaemic stroke or TIA in patients with non-rheumatic AF varies among subpopulations from 5\%-12\% per year, which is about five times that of patients with sinus rhythm. 14,15,16 Patients with paroxysmal $\mathrm{AF}$ and chronic AF have a similar risk of stroke. ${ }^{14}$ Eventually, AF is strongly associated with increased risk of congestive heart failure and increased mortality. ${ }^{6,17}$ Interruption of AV conduction and regularisation of ventricular rate by pacing have been shown to improve ventricular function. ${ }^{18}$ Coumarin based therapy and therapy with aspirin have recently been shown to reduce the occurrence of stroke and mortality. ${ }^{14}$ A recent study in general pracrice, however, did not show any advantage of warfarin over aspirin. ${ }^{19}$ Only half of the patients with AF, eligible for antithrombotic therapy, is treated with warfarin. ${ }^{20}$ Although antithrombotic therapy in parients with $\mathrm{AF}$ in general practice is still subject of debate, particularly focused on the risk of haemorrhage in very elderly patients, detection of AF is important because of the efficacy of antithrombotic therapy in high risk groups. 21,22

In general practice, the diagnostic process is primarily based on the prior probability, the medical history and the physical examination. ${ }^{23}$ Cardiology textbooks emphasize the importance of medical history, physical examination and of applying predicrive values of symptoms and physical signs in diagnosing cardiovascular disease. 24.25 Recently, a study was published about the diagnostic value of medical history in arthythmias in general practice. ${ }^{26}$ Howewer, no data are available related to the diagnostic process in terms of sensitivity, specificity and predictive value in AF presenting in an unselected population. Moreover, technological developments in cardiology appear to have reduced the attention paid to the medical history and physical examination in medical literature and in clinical practice. In general practice nevertheless, early recognition of AF remains dependent upon appropriate interpretarion of signs and symptoms, with which the parient presents.

Many symptoms, such as palpitations, fatigue, dyspnoea, dizziness, syncope, limited exercise performance and other symptoms can indicate the presence of AF. 24,25

Parient characteristics, such as age are also important because of the age related occurrence of AF. Sometimes patients with AF without symptoms are detected inci- 
dentally during general physical examination or measuring blood pressure revealing a rapid irregular rhythm.

A wide variety of cardiovascular diseases, such as congestive heart failure, hypertension, valve discase, coronary heart disease and myocardial infarction can also be an important factor in the aetiology of AF. ${ }^{1,11}$ Non-cardiovascular aetiologies of AF include diabetes mellitus, thyrotoxicosis, and lung diseases. ${ }^{27}$ Howewer, in popularion based studies no association was found between COPD and AF. 6,11

Diagnostic procedures, such as an ECG recording may follow when information obtained from medical history and physical examination is not conclusive in determining the type of arrhythmia or co-existing cardiovascular pathology. While valid scientific information about the diagnostic value of signs and symptoms in AF in general practice is not available, such information becomes more important because of the increasing incidence of AF in our ageing population. Therefore, we studied the diagnostic value of patient characteristics, medical history and physical examination in diagnosing $\mathrm{AF}$ in general practice.

\section{METHODS}

\section{PATIENT SELECTION}

During two years, 27 Dutch GPs from 20 practices in the Maastricht area, with a total population of nearly 50,000 listed patients participated in the study. All patients consulting their GP because of palpitations were included. In addition, patients with dyspnoea, dizziness, angina pectoris, fatigue, collapse and other complaints (i.e. reasons for encounter) were included, when the GP considered an arrhythmia as a possible cause of the complaints. Complaints had to be new for the GP or should represent a diagnostic problem. In all patients, a structured medical history was taken and a physical examination was carried out and recorded on standard forms, which were filled our before receiving the interpretation of an electrocardiogram (ECG). 'The GPs' registration system was used to collect additional parients' medical history data. In all patients, a transtelephonic ECG was sent to the deparment of cardiology of the local hospital. Patients who did not have symptoms during consultation were asked to come back for an ECG registration during symptoms through out the study period. If there was more than one ECG, the ECG during symptoms was used for analysis. The transtelephonic ECG recordings were obtained by an ECG modem 3 (Cardio Control BV, Rijswijk, The Netherlands), consisting of a 12 -lead ECG taken during 36 seconds. The interpretation of the ECGs was done at the Department of Cardiology of the Maastricht University hospital. Cardiologists were unaware of the findings from the medical history and physical examination. 
Patients younger than 15 years of age and patients with fever were excluded. In addition, patients were excluded when participation would not be consistent with good clinical practice, since immediate referral was indicated, such as patients with an acute myocardial infarction, circulatory arrest, or an otherwise poor circularory condition.

\section{DEPENDENT AND INDEPENDENT VARIABLES}

The ECG diagnosis, established by a cardiologist was used as dependent variable. AF was diagnosed based on international criteria. ${ }^{28}$

The independent variables can be separated into patient characteristics, medical history and medication use and symptoms on one hand and physical signs on the other. This was done because the diagnostic value of the former can be used during a consultation by telephone, when no information about signs is available. Besides, the interference between these sets of variables could be evaluated. Finally, symptoms were subdivided as to wherher they were present or not during consultation.

\section{STATISTICAL ANALYSIS}

Statistical analyses were performed with BMDP. ${ }^{29}$ In bivariate analysis, the Pearson chi-square test for $2 \times 2$ tables was used. When the expected frequency in at least one cell was less than 5 , the Fisher exact test was used. Diagnostic value was expressed in positive and negative predictive values $(\mathrm{PV}, \mathrm{PV}-)$ and summarized in odds ratios with $95 \%$ confidence intervals (OR [95\% CI]), with two differently defined reference groups: the total group of patients without atrial fibrillation (AF-) and patients with sinus rhythm only (SR), respectively. Symptoms were subdivided, as to whether they were present or not during consultation. The variable regularity was split up into three groups with the regular rhythm as reference group. A heart rate or pulse more than 100 beats/minute and a blood pressure of $100 / 60 \mathrm{~mm} \mathrm{Hg}$ or less were considered as abnormal.

Variables with a significance level $p<0.10$ in bivariate analysis were entered into multiple logistic regression analysis. In the logistic regression model, age was used as a continuous variable. Some variables from the medical history, such as valve disease, heart failure and coronary heart disease were considered together because of the small numbers. Only symptoms present during consultation were entered in the model. Some variables were not included in the logistic regression analysis together because of their high correlation with another, such as pulse and heart rate, varying loudness of the systolic blood pressure and beat to bear variability of the first heart sound, and separate blood pressure measurements (DBP or SBP). 
In the logistic regression analysis, "irregular pulse' was split up into "partially' and 'totally irregular'. Selection of the variables entered in the full model was based upon clinical grounds and results of bivariate analysis. Starting from the full models, multiple logistic regression with backward elimination of insignificant variables was performed with $\mathrm{AF}$ as dependent variable, to derive reduced prediction models and to calculate adjusted odds ratios, taking independent variables into consideration simultaneously. Parients having no AF were used as reference group. Variables were removed when p> 0.05 . Regression analysis was carried out with different subsets of independent variables: a model with patient characteristics was gradually extended with medical history data, medication use, symptoms and findings by physical examination, respectively. The performance of the models was compared with the likelihood ratio test. ${ }^{30}$ Receiver Operating Characteristics (ROC) curves were used to express the relation between sensitivity and specificity for various cut-off points and to elucidate the surplus value of more extensive models. For the distinct models, the area under the curve (AUC) which is a measure of the diagnostic power of the different models, was calculated with BMDP.

\section{RESULTS}

\section{CHARACTERISTICS OF THE STUDY POPULATION}

A total of 754 patients met the inclusion criteria. Eight patients, who after all were already known with AF, were excluded. In 546 patients $(63 \%)$ sinus thythm was recorded, new AF was diagnosed in 39 patients (5\%) and other arrhythmias in 169 patients $(22 \%)$. Table 1 gives a specification of age and gender of all enrolled patients, patients with AF and patients with other arrhythmias. In the whole study group most parients were women (63\%). Mean (SD) age was 51.3 (16.4), and 66.3 (13.3) for the subgroup with AF $(n=39)$. A medical history of hypertension was found in $18 \%$ of the patients. Nearly $10 \%$ was known with arrhythmias. Cardiovascullar disease was relatively rare (8\%): 43 patients were known with coronary heart disease and 18 parients had a history of a myocardial infarction. Valvular heart disease was present in 15 patients (2\%), while 19 patients $(2.5 \%)$ suffered from heart failure. Only 16 parients were known with diabetes mellitus and 8 parients had hyperthyroidism. Many patients (22\%) were known with anxiety disorders, such as the hyperventilation syndrome, and a substantial part of the patients (15\%) used benzodiazepines. Diuretics (10\%) and other cardiovascular medication (18\%) were mainly used for the treatment of hypertension and heart failure. 
Table 1. Atrial fibrillation by age and gender, in patients, with presenting symproms possibly caused by arrhythmias $(n=754)$.

\begin{tabular}{|c|c|c|c|c|c|c|c|}
\hline \multirow[b]{2}{*}{ age group } & \multicolumn{2}{|c|}{$\begin{array}{l}\text { patiemts with atrial } \\
\text { fibrillarion }\end{array}$} & \multicolumn{2}{|c|}{$\begin{array}{l}\text { parients with other } \\
\text { arrhyrhmias }\end{array}$} & \multicolumn{2}{|c|}{$\begin{array}{l}\text { patients with } \\
\text { sinus rhythm }\end{array}$} & \multirow[t]{2}{*}{ total } \\
\hline & men & women & men & women & mea & women & \\
\hline $15-24$ & 0 & 0 & 2 & 1 & 12 & 20 & 35 \\
\hline $25-34$ & 1 & 0 & 7 & 8 & 31. & 64 & 111 \\
\hline $35-44$ & 2 & 0 & $11^{*}$ & $10^{*}$ & 38 & 74 & $136^{*}$ \\
\hline $45-54$ & 1 & 2 & 9 & 19 & 52 & 76 & 159 \\
\hline $55 \times 64$ & 7 & 3 & 13 & 15 & 23 & 66 & 128 \\
\hline $65-74$ & 5 & 8 & 21 & 29 & 23 & 45 & 131 \\
\hline $75-84$ & 3 & 4 & 8 & 13 & 6 & 14 & 48 \\
\hline $85-94$ & 0 & 3 & 1 & 0 & $a$ & 2 & 6 \\
\hline mean age (y & 61.2 & 71.2 & 57.4 & 58.9 & 47.3 & 48.5 & 51.3 \\
\hline toral & 19 & 20 & 73 & 95 & 185 & 361 & 754 \\
\hline
\end{tabular}

* in one patient gender was not retrievable

\section{DIAGNOSTIC VALUE OF PATIENT CHARACTERISTICS AND MEDICAL HISTORY}

Results of bivariate analysis are presented in table 2. Depending on the reference group chosen (AF-/SR), patients had a prior probability of AF of $5.2 \%$ and $6.7 \%$, respectively. Age was a powerful predictor of $\mathrm{AF}$ with predictive values ranging from $4.5 \%$ (AF-) to $5.7 \%$ (SR) in the age group $45-64$ years and $12.4 \%$ (AF-) to $20.4 \%$ $(\mathrm{SR})$ in the age group 65 years and older. Although AF was more frequently seen among men, gender was not significantly correlated with AF. A history of hypertension $\left(\mathrm{OR}_{\mathrm{SR}}: 3.4, \mathrm{OR}_{\mathrm{AF}-\mathrm{s}}\right.$ 3.0), other arrhythmias $\left(\mathrm{OR}_{\mathrm{SR}}: 4.6, \mathrm{OR}_{\mathrm{AF}}: 3.7\right)$, known valvular disease $\left(\mathrm{OR}_{\mathrm{SR}}: 6.4, \mathrm{OR}_{\mathrm{AF}}: 4.9\right)$ and heart failure (OR $\left.\mathrm{SR}: 13.2, \mathrm{OR}_{\mathrm{AF}:}: 7.3\right)$ were significant predictors of AF, while the relation between $\mathrm{AF}$ and the combined variable of cardiovascular disease was less pronounced. The use of diuretics and other cardiovascular medication was also correlated with the occurrence of $\mathrm{AF}$. A history of diabetes mellitus or thyrotoxicosis was no predictor of AF.

\section{DIAGNOSTIC VALUE OF SYMPTOMS (TABLE 3)}

Symptoms present during consultation such as dyspnoea $\left(\mathrm{OR}_{\mathrm{SR}}: 9.3, \mathrm{OR}_{\mathrm{AF}}: 7.0\right)$, dizziness $\left(\mathrm{OR}_{\mathrm{SR}}: 4.4, \mathrm{OR}_{\mathrm{AF}}: 3.4\right)$, palpitations $\left(\mathrm{OR}_{\mathrm{SR}}: 3.5, \mathrm{OR}_{\mathrm{AF}}: 2.6\right)$ and to a lesser degree, fatigue and collapse also were associated with the incidence of AF. "Palpirations not present during consultation" was negatively correlated with the occurrence of AF. 


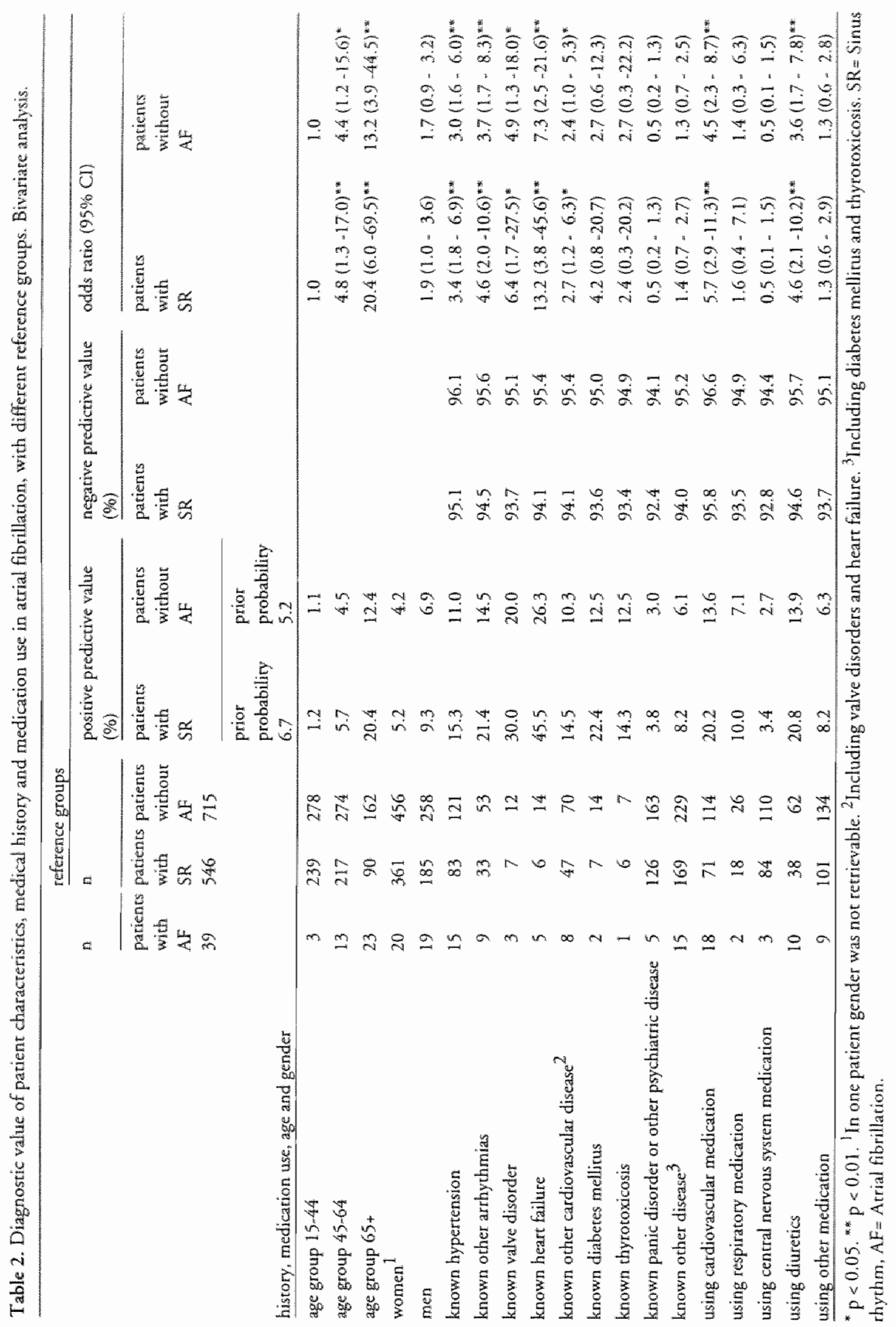




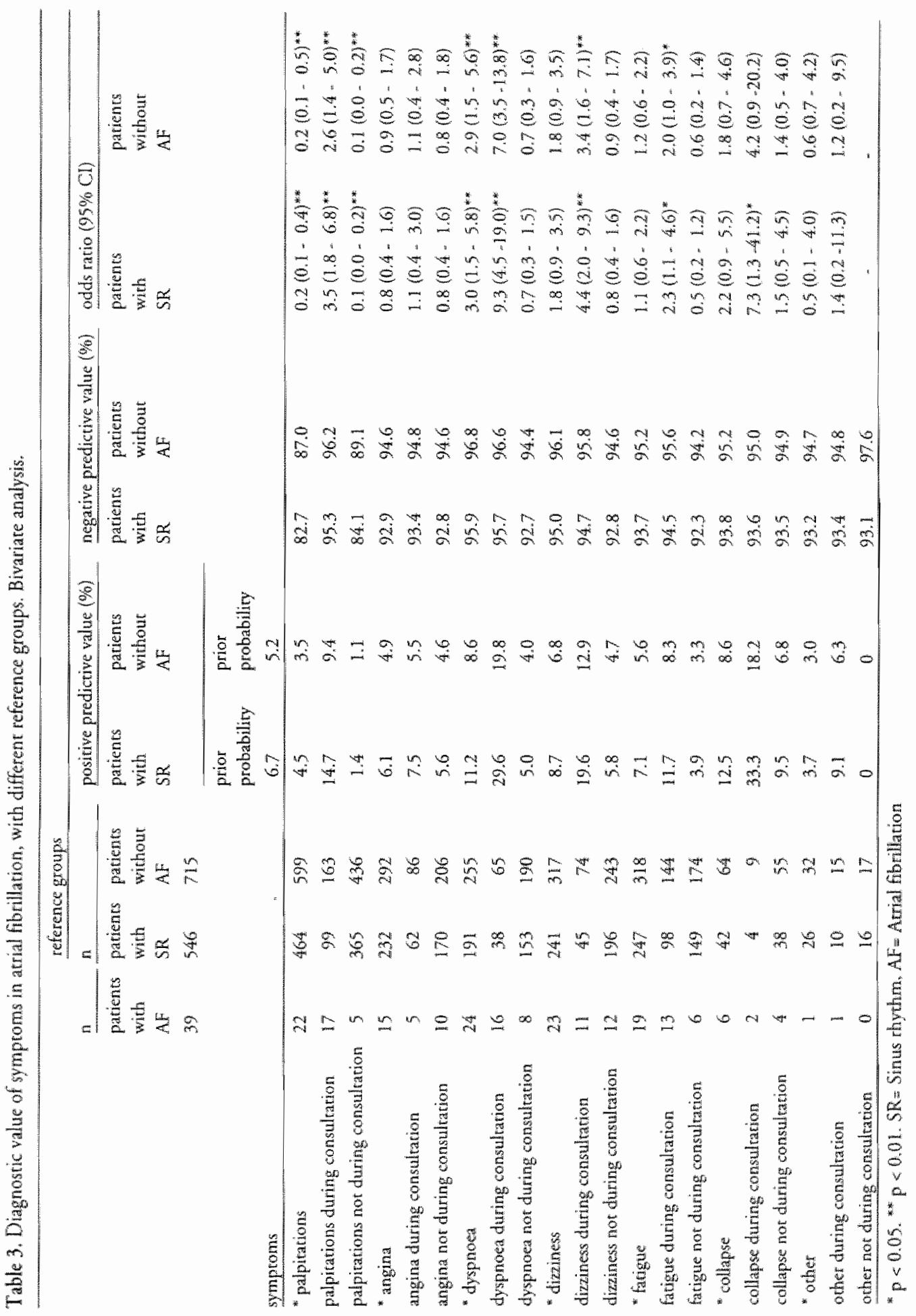


Signs had high predictive values for diagnosing AF. A totally irregular pulse was the best predictor of AF (PV' ${ }_{S R}: 81 \%$., $\mathrm{PV}^{+}{ }_{\mathrm{AF}-}: 49 \%$ ), with odds ratios ranging from 94 [34.9-249] to 354 [107-1173], with AF- and SR as reference groups, respectively. Phenomena highly related to an irregular pulse such as beat-to-beat variability in systolic blood pressure (SBP) and a varying loudness of the first heart sound also had extremely high odds ratios. A suspicious cardiovascular condition assessed by the general practitioner and, less remarkably, a heart rate and pulse rate greater than 100 beats per minute (bpm) and a partially irregular pulse were also significantly associated with $\mathrm{AF}$ (Table 4).

\section{LOGISTIC REGRESSION ANALYSIS}

When different reduced modells representing the natural increase of clinical information are figured together, the gain in clinical diagnostic certainty of additional information becomes obvious (Table 5). In all models, with patients without AF as reference group, age, palpitations and dyspnoea during consultation were significant contributors. Some clinical variables, such as a history of hypertension and the use of cardiovascular medication, loose their diagnostic information in more extensive models in favour of added 'physical examination' variables. A totally irregular pulse (OR 28.9), as well as a partially irregular pulse (OR 4.8) and a varying loudness of the first heart sound (OR 3.3) were important predictors of AF, although their odds ratios have decreased after adjustment of covariables.

The predicted probability of AF can be calculated according to the formula:

$$
p=\left[1+e^{-y}\right]^{-1(31)}
$$

where $y=-7.235+0.03859 \times$ age(years) $+0.843 \times$ palpitations during consultation + $1.380 \times$ dyspnoea during consultation $+3.364 \times$ total irregular thythm $+1.576 \times$ partially irregular thythm +1.207 xvarying loudness first heart sound.

Using this most extensive multivariate model the predicted probability of AF can be calculated. For example, a 50 year old woman, consulting her GP with palpitations, dyspnoea during consultation, a total irregular rhythm and a varying loudness of the first heart sound, has a probability of $82 \%$ to have AF. A woman of 80 years old with similar characreristics but with a partially irregular rhythm instead of a totally irregular rhythm has a chance of $70 \%$ to have $\mathrm{AF}$.

\section{PREDICTED VERSUS OBSERVED PROBABILITY}

The predicted probability of AF in different categories can be compared with the observed probability (prevalence) employing the most extensive multivariate model. 


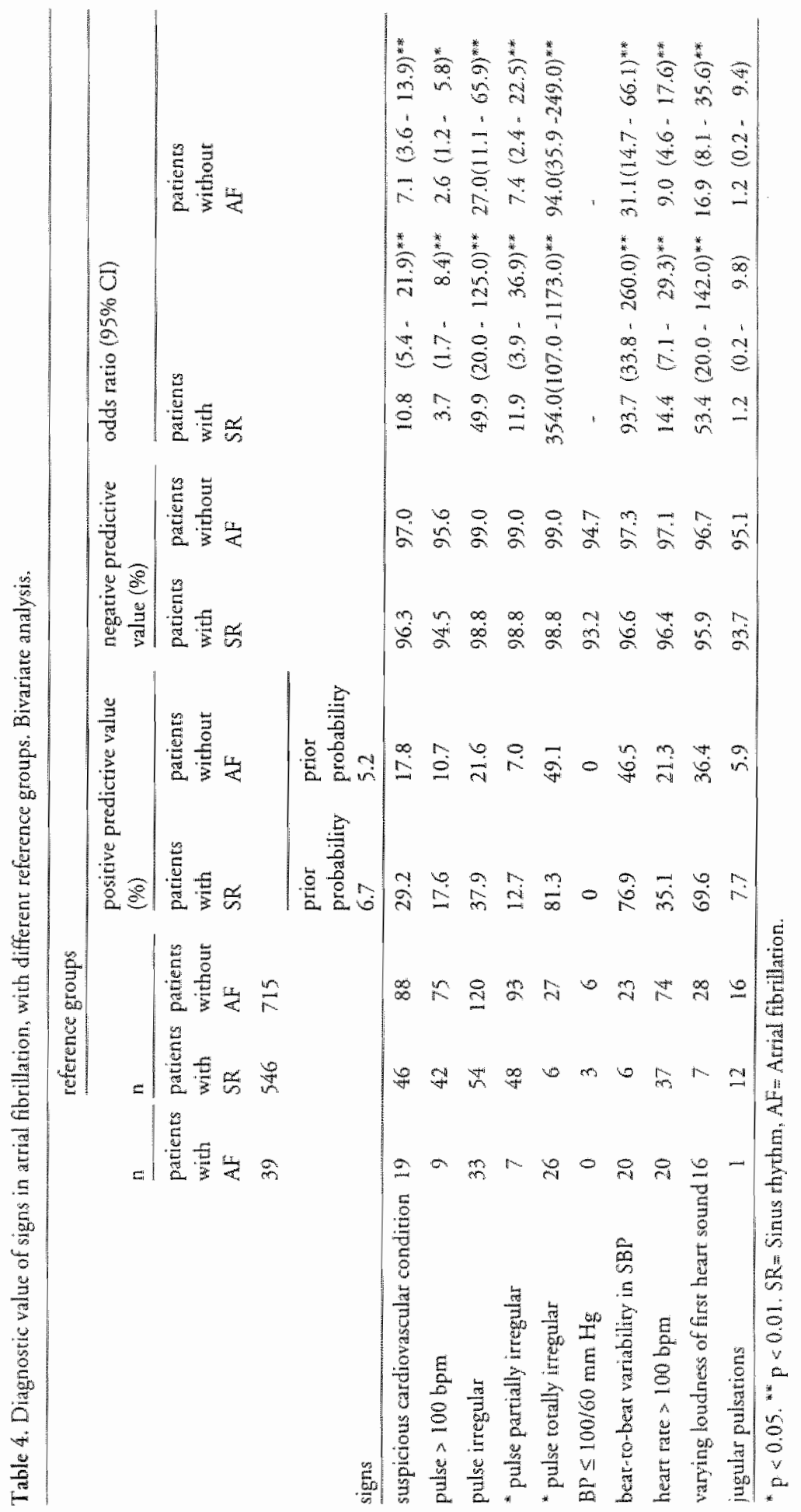




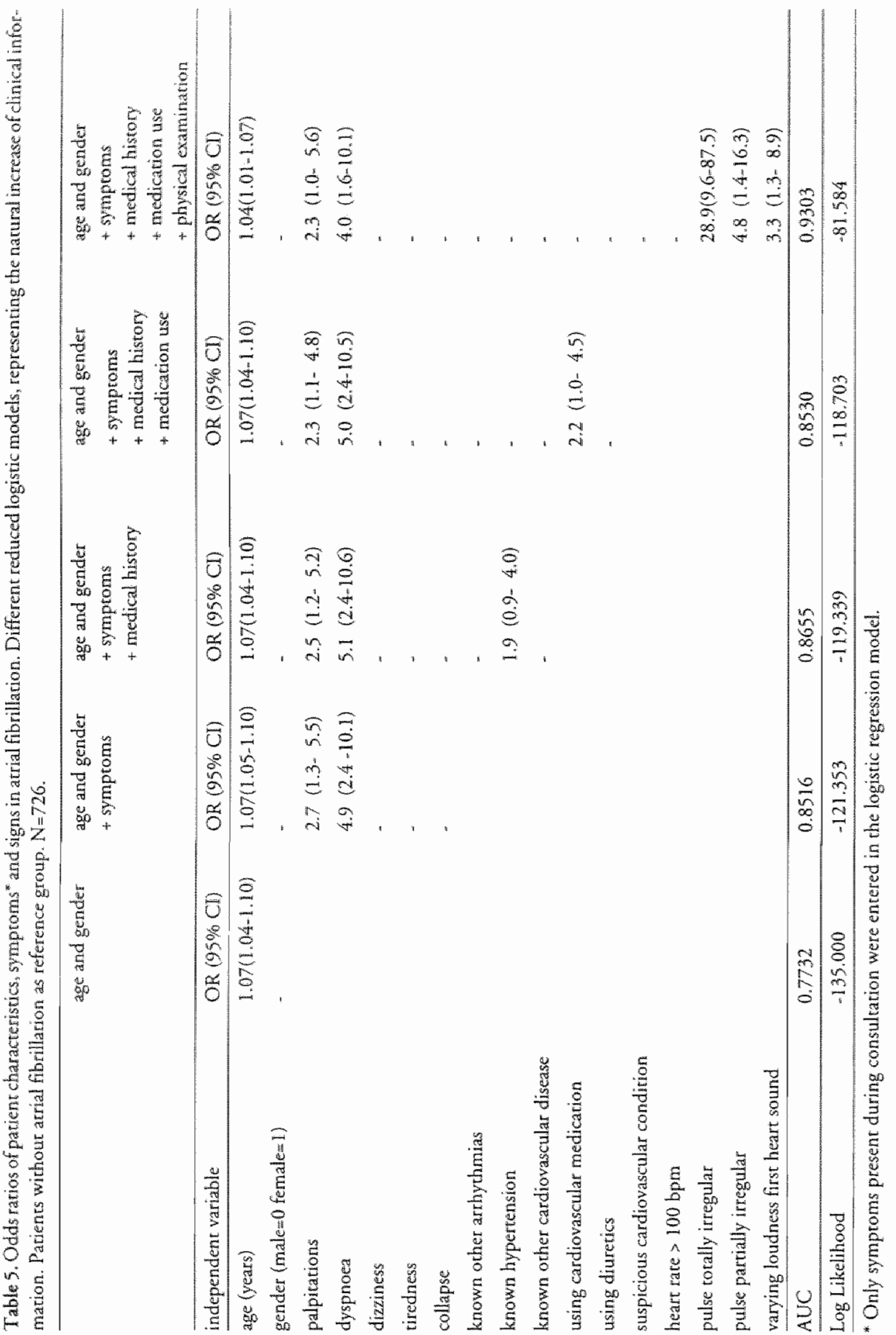


Table 6. Predicted versus observed probability of atrial fibrillation based on the most comprehensive logistic model.

\begin{tabular}{lcc}
\hline predicted probability & observed probability & n \\
$0 \leq 10 \%$ & $1.2 \%$ & 653 \\
$10 \leq 20 \%$ & $14.3 \%$ & 21 \\
$20 \leq 40 \%$ & $47.4 \%$ & 19 \\
$40 \leq 60 \%$ & $37.5 \%$ & 16 \\
$60 \leq 80 \%$ & $61.5 \%$ & 13 \\
$80 \leq 100 \%$ & $100.0 \%$ & 4 \\
\hline
\end{tabular}

In most of the categories there is good agreement berween the observed and the predicted probability. In two categories, there is only a small overestimation and underestimation of the percentage of AF (Table 6).

\section{RECEIVER OPERATING CURVES OF THE LOGISTIC REGRESSION MODEL}

The relation between sensitivity and specificity of the four models ar various cut-off points is shown in figure 1. To elucidate the surplus value of more extensive diagnostic information, a model with only age and gender is presented, and in addition models extended with medical history data, symptoms and signs. The AUC of the various models can be seen as representing the diagnostic power. The model with age and gender has already a substantial diagnostic performance $(A \cup C=0.77)$ in detecting AF. In the model extended with symptoms ( $A U C=0.85$ ), the predictive vallue was significantly $\left(\mathrm{p}<10^{-3}\right)$ better, while the model with medical history findings ( $A U C=0.87)$ was not better than the former $(p=0.258)$. The model with signs eventually (AUC $=0.93$ ) was much better than the previous ones $\left(\mathrm{p}<10^{-5}\right)$.

\section{DISCUSSION}

Age, a history of hypertension or arrhythmias, and the use of cardiovascular medication or diuretics are highly correlated with the presence of AF. Dyspnoea, palpitations, dizziness, fatigue and collapse are meaningful symptoms of AF. "Palpitations not being present during consultation" had an odds ratio smaller than 1.0. This can be explained by higher diagnostic value of most of the other symptoms, resulting in reducing the diagnostic value of palpitations as compared to those other symptoms. Secondly, it can be caused by the paroxysmal character of palpitations and therefore its obvious consultation related value with a standard which was not optimal in the detection of short lasting arrhythmias. If Holter monitoring or event recording had 


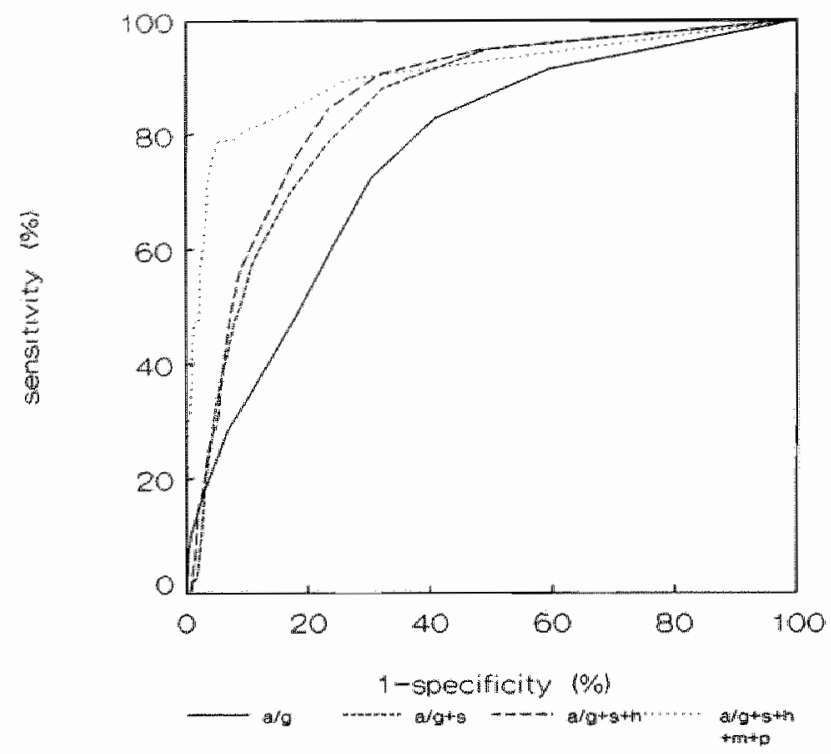

AUC

age and gender (a/g)

age/gender and symptoms $(a / g+s)$

age/gender, symptoms and medical history ( $(\mathrm{a} / \mathrm{g}+\mathrm{s}+\mathrm{h})$

age/gender, symptoms, medical history, medication use

and physical examination $(a / g+s+h+m+p)$

Figure 1. ROC curves and AUCS of logistic models based on patient characteristics, symptoms and signs in predicting atrial fibrillation. Models of increasing comprehensiveness.

been used 'palpitations not being present during consultation' might have had an odds ratio larger than 1.0.

As expected the diagnostic values of symptoms were higher in case of patients with sinus rhythm as the reference group. In this case, the results reflect the specific diagnostic values of signs and symptoms of AF versus sinus rhythm. However, predictive values of signs and symptoms in case of "patients without $A F^{x}$ as reference group may be of more clinical relevance because in daily practice they can be used to differentiare berween AF and "orher or no arrhythmias'. Findings from physical examination, such as a tachycardia or a suspicious cardiovascular condition are important predictors of AF. An irregular pulse, a partially irregular pulse, and associated phenomena such as a varying loudness of the first heart sound and a beat to beat variability in SBP have extremely high predictive values in diagnosing AF. A partially irregular pulse in some patients with AF, probably caused by medication use, is also found in other studies. ${ }^{32}$ When data from the physical examination are added to 
parient characteristics, symptoms and medical history findings, the latter becomes less important. With knowledge of the patients' past history and a well-taken medical history and physical examination, clinicians can predicr AF with a high degtee of certainty. Although also according to literature the above mentioned symptoms and signs can be related to the presence of AF, to our knowledge, this is the first reported study performed in general practice giving quantitative information about the value of signs in addition to patient characteristics and symptoms in diagnosing AF.

In our study we used broad inclusion criteria. As a result a wide speccrum of diagnostic outcomes is warranted. It is exactly this 'indicated population' (that is, the patient population for which diagnosing AF might be considered to be indicated) in which we are interested concerning the value of signs and symproms in general practice. This makes the results from this study are widely clinically applicable in primary care.

In patients without signs or symptoms during consultation, AF may not be detected because of its paroxysmal character. Holter monitoring or event recording seems more attractive than usual ECG recording in this situation. However, Holter monitoring is also not very useful in intermittent palpitarions, which occur infrequently. 33,34 Besides, most studies about the diagnostic yield of Holter monitoring have been executed in selected populations and there is a considerable inter- and intra-reader variability and intra-patient day-to-day variability. Furthermore, especially in a primary care population with a low prior probability and less developed clinical pictures of clinically relevant arrhythmias, Holter registration might result in finding asymptomatic arrhythmias. ${ }^{33,35}$ Event recording is not an adequate standard for long-lasting symptoms such as faintness and tiredness. Also, in a recent study only one third of the patients with palpitations were eligible for event recording. ${ }^{36}$ Moreover, the 12-lead ECG is the kind of equipment used in regular general practice. Therefore our approach gives insight into diagnostic information relevant to the detection of arrhythmias in regular general practice. Another method to be used as a gold standard, is to do a follow-up study and to document arrhythmias during a longer period.

In The Netherlands, nearly all patients with complaints possibly caused by AF are first seen by their GP. In some cases the severity of AF or associated co-morbidity leads to urgent hospital presentarion. Therefore, a few patients with acute AF may have been seen in the hospital and not by the GP and may not have been included in the study. Hence, our results are applicable to patients who consult their GP and not to patients with poorly tolerated, clinically severe AF. However, for the diagnosis in these pronounced and obvious situations a diagnostic model is less relevant in general practice, since immediate referral is clearly indicated.

In conclusion, patient characteristics, medical history, symproms and signs can be helpful in diagnosing AF. Detecting patients with AF becomes more relevant considering the growing evidence of the preventive effecriveness of antithrombotic 
therapy. In patients with signs and symptoms suggesting AF, GPs should make ECG recordings especially to document the arrhythmia and to diagnose possible underlying or associated cardiovascular pathology. Because symptoms during consultation are very important for the diagnosis, patients without an arrhythmia during consultation should be asked to contact their GP again during symptoms, to make an immediate ECG recording. Event recording in general practice may be useful in these cases.

\section{REFERENCES}

1. Langenberg $M$, Hellemons BSP, Van Ree JW, et al. Atrial fibrillation in elderly patients: prevalence and comorbidity in general practice. Br Med ] 1996; 313: 1534.

2. Lip GYH, Golding DJ, Nazir M, Beevers DG, Child DL, Fletcher RI. A survey of arrial fibrillation in general practice: the West Birmingham Atrial Fibrillation Project. Br J Gen Pract $1997 ; 47$ : $285-289$.

3. Wheeldon NM, Tayler DI, Anagnostou E, Cook D, Wales C, Oalkley. Screening for atrial fibrillation in primary care. Heart 1998;79:50-55.

4. Zwietering P. Knotmerus A, Gorgels T, Rinkens P. Occurrence of arrhythmias in general practice. Scand I Prim Health Care 1996; 14:244-250.

5. Feinberg WM, Blackshear JL, Laupacis $A$, Kronmal R. Hart RG. Prevalence, age distriburion, and gender of patients with atrial fibrillation. Arch Intern Med; 155: 469-473.

6. Onundarson PT, Thorgeirsson G, Jonmundsson E, Sigfusson N, Hardarson T. Chronic atrial fibrillation-epidemiologic fearures and 14 year follow-up: a case control study. Eur Heart J 1987; 8 : $521-7$.

7. Ostrander JD, Brandt RL, Kjelsberg MO, Epstein FH. Electrocardiographic findings among the adult population of a total natural community, Tecumseh, Michigan. Circulation 1965; 31 : 888-98.

8. Hill J, Mortan EM. Killeen PD. Study of the prevalence of atrial fibrillarion in general practice patients over 65 years of age. J R Coll Gen prace 1987;37: 172-173.

9. Kannel WB, Abbott RD, Savage DD, MCNamara PM. Epidemiologic features of chronic atrial fibrillation. The Fumingham Study. New Engl I Med 1982;306:1018-22.

10. Wolf PA, Abbort RD, Kannel WB. Atrial fibrillarion: a major contributor ro stroke in the elderly. The Framingham Srudy. Arch Intern Med 1987; 147: 1561-4.

11. Benjamin EI, Lexy D, Vaziri SM, D'Agostino RB, Belanger AJ, Wolf PA. Independent risk factors for arrial fibrillation in a population-based cohort. The Framingham Heart Study. JAMA 1994; 271(11): $840-4$

12. Kannel WB, Abbott RD, Savage DD, McNamara PM. Coronary heart disease and atrial fibrillation: The Framingham Study. Am Heart J 1983;106:389-396.

13. Wolf PA, Abbott RD, Kannel WB. Atrial fibrillation as an independent risk factor for stroke: The Framingham study. Stroke 1991:22: 983-988. 
14. Arrial fibrillation investigators. Risk factors for stroke and efficacy of antithrombotic treatment in atrial fibrillation: analysis of pooled data from randomized controlled mials. Arch Intern Mad 1994: $154: 1449-1457$.

15. Kopecky SL, Gersh BJ, McGoon MD, et al. The natural history of lone arrial fibrillation: a population based study over three decades. N Engl J Med 1987; 317:669-674.

16. The Stroke Prevention in Atrial Fibrillation Invesrigators. Predictors of thromboembolism in arrial fibrillation: $\mathbb{I}$. Clinical features of patients at risk. Ann Intern Med 1992;116:1-5.

17. Benjamin E], Wolf PA. D'Agostino RB, Silbersharz H, Kannel WB, Levy D. Impact of arrial fibrilation on the risk of death. The Framingham Sudy. Circulation 1998;98:946-952.

18. Rodriguez LM, Smeets LRM, Xie B, et al. Improvement in left ventricular function by ablation of atrioventricular nodal conduction in selected patients with lone atrial fibrillation. Am y Cardiol $1993 ; 72: 1137-1141$.

19. Hellemons-Boode $B$, Langenberg-Ledeboer $M$. Observations on arrial fibrillation in primary care (thesis). Maastriche, 1998.

20. Sudlow M, Rodgers H, Kenny RA. Thomson R. Population based study of use of anticoagulants among patients with arral fibrillation in the community. Be Med J 1997;314:1529-1530.

21. Albers GW. Atrial fibrillation and stroke. Three new studies, three remaining questions. Arch Intern Med 1994: 154: 1443-1448.

22. Sweeney KS, Pereira Gray D, Steele R, Evans P. Use of Warfarin in non-rheumatic arrial fibrillation: a commentary from general practice. Br J Gen Pract 1995;45:153-158.

23. Knotunerus JA. Interpretation of diagnostic dara: an unexplored field in general practice. I R Coll. Gen Pract 1985; 35: 270-274.

24. Schlant RC, Alexander RW, O'Rourke RA, Roberts R, Somenblick EH, eds. Hurse's the heart: atreries and veins. 8th ed. New York: Mc Graw-Hill, 1994.

25. Zipes DP. Normal and abnormal circulatory function. Specific arrhythmias: Diagnosis and treatment. In: Braunwald $\mathbb{E}$, ed. Heart Disease: $A$ textbook of cardiovascular medicine. 4th ed. Philadelphia: WBB Saunders; 1992: 667-718.

26. Zwietering PJ. Knomerus JA, Rinkens PELM, Kleijne MAWJ Gorgels APM. Arrhythrmins in general pracrice: diagnostic value of patient characterisrics, medical history and symptoms. Fam Pact $1998 ; 15: 343-353$.

27. Davidson E, Weinberger I, Rotenberg Z. Fuchs I. Atrial fibrillation. Cause and time of onset. Arch Intern Med 1989; $149: 457-459$.

28. Dolgin $M$ (ed). Nomenclature and criteria for diagnosis of diseases of the heart and great vessels. 9th ed: Boston: Little, Brown and Compary; 1994: 187.

29. Dixon WI, Brown MB. Engelman L, Jennrich RI. BMDP statistical sofware manual. University of California Press. Berkeley/Los Angeles/Ox ford, 1990.

30. Hosmer DW, Lemeshow S. Applied lagistic regression. John Wilcy \& Sons. New York/ Chichester/Brisbane/Toronto/Singapore, 1989.

31. Kleinbaum DG, Kupper L, Morgenstern H. Epidemiologic Research. Principles and quantivative methods. Van Nostand Reinhold New York, 1982: 426. 
32. Schile B, Hellemons-Boode BSP, Zwietering PJ. Palparie van de pols bij atrumfibrilleren wergeteken met het ECG. [Pulse palpation in atrial fibrillation compared to ECG diagnosis] Huisares Wer 1997; 40:95-97.

33. Bjerregaard P. Continuous ambulatory electrocardiography in healthy adult subjects over a 24-hour period. Clinical data and evaluation of instruments for ambulatory electrocardiography. Dan Med Bull 1984:31: $283-97$.

34. Coumel P. Diagnostic and prognostic walues and limitations of Holter monitoring. Eur Heart ] 1989; 10S: 19-30.

35. Bartet PA, Peter CT, Swan HJC, Singh BN, Mandel WJ. The frequency and prognostic signifcance of electrocardiographic abnormalities in clinically normal individuals. Prog Cardiovase Dis $1981 ; 23: 299-319$.

36. Kinlay S, Leirch JW, Neil A, Chapman BL, Hardy DB, Fletcher PJ. Cardiac event recorders yield more diagnoses and are more cost-effective than 48-hour Holter monitoring in patients with palpitations. A controlled clinical trial. Ann Intern Med 1996; 124: 16-20. 


\section{CHAPTER 7}

\section{General discussion}

\section{INTRODUCTION}

Aims of the study were to investigate the occurrence of arrhythmias and to assess the value of patient characterisrics, medical history findings, symptoms and signs in diagnosing arrhythmias in general practice. Because of the low prevalence of most arrhythmias, we made a differentiation between the absence of arrhythmias on one side and the presence of arthythmias or clinically rellevant armythmias on the other. The diagnostic value of clinical variables in one specific clinically relevant arthythmia, in this case atrial fibrillation, could be evaluated because of its relatively frequent occurrence. In this chapter, the main findings of the study will be presented and discussed, as well as the strengths and limitations of the methodology. Finally, we will focus on implications of our results for general practice and give some recommendarions for future research.

\section{MAIN FINDINGS}

During two years, 868 patients with complaints possibly related to arthythmias were seen in 20 general practices, with a total population of nearly 50,000 listed patients. In $75 \%$ of the cases, a new symptom or a coincidental finding was the reason for including parients; in the remainder the GP had a new diagnostic problem in a parient known to have an arrhythmia. Most of the patients $(n=762)$ were enrolled because of specific symptoms, the remaining $(n=106)$ because of coincidental findings. GPs succeeded in making an ECG recording while they had specific symptoms or signs in $36 \%$ of the cases. Most of the included patients (63\%) were women. An arrhythmia was documented on ECG in nearly one third of the cases. An overall incidence of 2-3 arrhythmias per 1000 listed patients per year was seen by the GP. An arthythmia was detected in $48 \%$ of the patients who bad specific symptoms during the ECG, and in 19\% without symptoms at the time of the recording. Of the patients who were included because of coincidental findings, an arrhythmia was found in $81 \%$ with signs during recording and in $7 \%$ without signs. The majority of the patients $(64 \%)$ were included because of palpitations. An arrhythmia was found in $61 \%$ of the patients who were included because of occasional findings and in $28 \%$ of the patients who were included because of symptoms. 
In patients included for symptoms (n=762), in more than a quarter arthythmias were registered. In nearly ten percent a chinically relevant arthythmia could be found. In logistic models, age especially was a good predictor in diagnosing arrhythmias and their clinical relevance. Relatively more arrhythmias and clinically relevant arrhythmias were found in men, but gender was no independent predictor of the dinical relevance of the arthythmia in the logistic model. Dyspnoea during consultavion, possibly caused by haemodynamic instability, had a high odds ratio both in arthythmias and in clinically relevant arrtythmias. Although in more than a quarter of patients with palpitations an arrhythmia could be detected, palpitations in general and not during consultation had negative odds ratios for both arthythmias and assessing their clinical relevance, in contrast to palpitations during consultation.

Physical signs in patients included for symptoms $(n=762)$ had very high odds ratios. In bivariate analysis, a totally irregular pulse and related findings such as variability in SBP and varying loudness of the first heart sound were the best predictors of arrhythmias. In clinically relevant arrhythmias, these were also good predictors, as well as a low blood pressure and a suspicious cardiovascular condition. In the logistic regression analysis it became obvious that signs have such an impact on the prediction of arthythmias and clinically relevant arrhythmias, that patient characteristics and symproms become less important after signs have been added to this model. In the most comprehensive model, age, palpitations, heart beat, irregularity, varying loudness of the first heart sound and a suspicious cardiovascular condition were posirively associated with arrhythmias. In a model with clinically relevant arrhythmias, palpitations in the past were negatively associated, while a history of arrhythmias in the past was positively associated. with the presence of these. All signs mentioned before, as well as a low blood pressure were informative diagnostic signs in clinically relevant arthythmias. In the most extensive models, "palpitations during consultation" was only a predictor of arrhythmias and no indicator of clinically important arthythmias, probably because of the more powerfull other variables. A history of palpitations had a negative odds ratio for clinically relevant arrhythmias

In more than $60 \%$ of parients included on coincidental findings $(n=106)$ arthythmias were registered. In nearly $18 \%$ a dinically relevant arthythmia could be found. Of the recorded arthythmias $(n=62)$ GPs considered a correct diagnosis in $85 \%$ of the cases. Leawing patients known with the same arrhythmia as the recorded arthythmia out of consideration, general practitioners mentioned a correct diagnosis in $50 \%$ of the patients. Age, and to a lesser degree a history of cardiovascular disease or arrhythmia are significantly related to the presence of arrhythmias. Symptoms related to haemodynanic imbalance, such as dyspnoea and collapse are associated with the presence of clinically relevant arrhythmias. However, collapse was found in a few patients. Nearly all signs were significantly related to (clinically relevant) arrhythmias. No relation was found between a fast or slow pulse and arrhythmias. In the multiple logistic models, especially a totally irregular pulse was a very good predictor in diagnosing arhychmias and their clinically relevance. 
Of 762 patients included for symptoms, eight patients were already known with AF. Of the remainder, in 546 patients (63\%) sinus rhythm was recorded, new AF was diagnosed in 39 patients $(5 \%)$ and other arrhythmias in 169 parients $(22 \%)$. Most patients were women (63\%). Mean (SD) age was 51.3 (16.4), and 66.3 (13.3) for the subgroup with AF. Age, a history of hypertension or arrhythmias, and the use of cardiovascular medication or diuretics are highly correlated with the presence of AF. Dyspnoea, palpitations, dizziness, farigue and collapse are meaningful symptoms of AF. Palpitations not being present during consultation had an odds ratio smaller than 1.0. Findings from physical examination, such as a tachycardia or a suspicious cardiovascular condirion are important predictors of AF. An irregular pulse, a partially irregular pulse, and associated phenomena such as a varying loudness of the furst heart sound and a beat to beat variability in SBP have extremely high predictive values in diagnosing AF. Employing the most extensive multivariable model, we found good agreement berween the observed and the predicted probability of AF.

\section{STRENGTH AND LIMITATIONS OF THE METHODOLOGY}

The incidence found in this study was based on patients who consulted their GP because of symptoms or with coincidental findings pointing to an arrhychmia. It is likely that the population-based incidence of arrhythmias such as extrasystoles and atrial fibrillation is larger because arrhythmias may be asymptomatic or do nor bother the patient. Although GPs were strongly encouraged to include all consecutive patients, we had no formal check whether all patienrs consulting their GP and meeting the inclusion criteria, were included in the study.

In patients with complaints without signs or symptoms during consultation, arrhythmias may not be detected, because of its paroxysmal character. "Therefore, parients were asked to consult their GP again during their specific symptoms. Ten patients, in which initially no arrhythmia was recorded, consulted their GP for a second time; in three of them a clinically relevant arrhythmia, in 4 patients a clinically less relevant arrhythmia and in 3 patients a sinus rhythm was recorded. We also asked the GPs to make an ECG recording during the consultation when signs or symptoms pointing to an arrhythmia were present. Nevertheless, pracrice based circumstances could have caused a time delay berween the ECG recording and signs and symptoms and consequently an underestimation of arrhythmias. The correct diagnosis of GPs in only 50 percent of patients included for coincidental findings can also be caused by this time delay between GP's diagnosis and ECG recording. Holter monitoring or event recording seems more attractive than the usual ECG recording. However, Holter monitoring has a low yield in intermittent palpitations, which occur infrequently. Besides, most studies about the diagnostic yisld of Holter monitoring have been executed in selected populations and there is a considerable inter-and intra-reader variability and intra-patient day-ro-day wariability. Further- 
more, especially in a primary care population with a low prior probability and less developed clinical pictures of clinically relevant arrhythmias, Holter registration might result in detecting asymptomatic arrhythmias. Event recording is not an adequate standard for long-lasting symproms such as fainting and tiredness. Also, in a recent study only one third of the parients with palpitations were eligible for event recording. Moreover, the 12 -lead ECG is the kind of equipment used in regular general practice. Therefore, our approach gives insight into diagnostic information relevant to the detection of arrhythmias in regular general practice.

In The Netherlands, nearly all patients with complaints possibly caused by arrhythmias are first seen by their GP. In some cases the severity of the arrhythmia or associated co-morbidity leads to urgent hospital presentation. Therefore, a few patients with acute arrhythmias may have been seen in the hospital and not by the GP and may not have been included in the study. Hence, our results are applicable to patients who consult their GP and not to patients with poorly tolerated, clinically severe armythmias. However, for the diagnosis in these pronounced and obvious situations a diagnostic model is less relevant in general practice, since immediate referral is clearly indicared.

Initially, we considered to correlations between signs and symptoms on the one hand and specific arrhythmias on the other. Because of the low incidence of some arrhythmias, we decided to categorize arrhythmias according to their clinical relevance. In general practice this is a suitable subdivision, for deciding whether a diagnostic work-up, such as an ECG recording is necessary. Nevertheless, with regard to atrial fibrillation, which was the most frequent dinically relevant arrhythmia, we were able to examine the predictive value of signs and symptoms. The symptoms (predictor variables) and the ECG diagnosis were independently assessed. In the analysis differentiation was made as to whether specific symptoms were present during consultation and ECG recording or not. Dyspnoea was the most informative symptom in diagnosing arrhythmias, clinically relevant arrhythmias and atrial fibrillation, while palpitations, collapse, dizziness and fatigue were especially correlated with the detection of (dinically relevant) arrhythmias when the symptom was present during consultation. This can be caused by the fact that our standard was not optimal in short lasting symptoms. However, a lot of arrhythmias were also documented in patients not having the specific symptom during consultation, which can be due to a chronic arrhythmia with varying symptomatology. Palpitations in general had an odds ratio smaller than 1, probably caused by the large number of patients known with an anxiety disorder. In the analysis of diagnostic values of symptoms in atrial fibrillation two reference groups were used. "Patients with sinus rhythm" as reference group gives insight in the predictive values of symptoms in atrial fibrillation, specifically. On the other hand "patients without atrial fibrillation" as reference group gives more clinically relevant information in diagnosing atrial fibrillation in a population with symptoms suggesting an arrhythmia. Nearly all signs had high predictive values in diagnosing arrhythmias. Notable is the fact that, 
in a not negligible part of the parients with atrial fibrillation, no totally irregular pulse was observed, which implicates that this sign is not fully specific in diagnosing atrial fibrillation or that the thythm was not sufficiently long observed by the physician. The probability that the diagnostic value of predictor variables in arrhythmias and clinically relevant arrhythmias is mainly based on atrial fibrillation can be rejected because nearly all variables remained significant when parients with atrial fibrillation were excluded (data not in this dissertation).

\section{FINDINGS IN RELATION TO LITERATURE}

The figure of 2-3 new arrhythmias per 1000 listed parients per year seen by the GPs in our study, is in accordance with the figures from existing registration networks. ${ }^{1.2}$ The large percentage of patients known to have hyperventilation or a history of psychosocial and psychiatric morbidiry was striking. This is in accordance with orher studies in which there was an apparent association between a history of psychiatric illness and palpitations. $3,4,5$ The highly positive correlation berween the occurrence of arrhythmias and age, especially atrial fibrillation and extrasystoles, is in accordance with the literature. ${ }^{6-9}$

The correlation between a history of hypertension, arrhythmias in the past and cardiovascular disease on the one hand and the occurrence of arrhythmias fits with results of other studies. ${ }^{10-16}$ Quantitarive data about the correlation of signs and symptoms and arrhythmias in unselected populations are lacking. According to literature ${ }^{17,18}$, most of the symptoms and signs indicating the presence of arrhythmias were also found to be related to arrhythmias in our study. Especially symptoms indicating haemodynamic imbalance, such as dyspnoea, dizziness and collapse were highly correlated with the presence of arrhythmias and serious arrhythmias. Palpitations however, were only correlated to the documentation of arrhythmias when present during consultation. All physical signs indicating arrhythmias, described in literature were also indicators of arrhythmias in our study. Although a totally irregular pulse was the most dominant predictor of atrial fibrillation, a partially irregular pulse was correlated, not only to clinically less relevant arrhythmias (premature beats), but also to documented atrial fibrillation.

\section{CONCLUSIONS AND IMPLICATIONS FOR GENERAL PRACTICE}

Based on a well-taken history (medical history, symptoms and medication use), GPs can diagnose arrhythmias and clinically relevant arrhythmias with a high degree of certainty. This finding can be used in consultations and during attendance hours to decide whether a patient must visit the practice or parients can be reassured. In patients with palpitations, known with anxiety disorders few arrhythmias will be 
present. When history data and findings from physical examination are considered together, a more reliable estimation can be made whether an arthythmia is present. Symptoms indicating a clinically relevant arrhythmia are mainly based upon haemodynamic imbalance, such as dyspnoea, dizziness and (near) syncope. While nearly all physical signs, known to be related to arrhythmias, can indicate innocent arrhythmias as well as clinically relevant arthythmias, it is recommended to combine all clinical wariables and to make a further differential diagnosis with the specific arrhythmias. When a clinically relevant arrhythmia is considered, an ECG recording is indicated during symproms and patients should be asked to visit the practice.

Especially in paroxysmal arthythmias, ECG facilities in the direct surroundings of the patient, like in a general practice, seem important. Probably, the availability of event recorders by way of a diagnostic coordinating centre is another possibility. Interpretation of ECG's can be done by GPs or cardiologists (e.g. after faxing the ECG recording).

In patients with poorly tolerated arrhythmias, it is obvious that immediate referral to a cardiologist is warranted and an extensive clinical evaluation by the GP is not necessary.

\section{RECOMMENDATIONS FOR FUTURE RESEARCH}

This study raises new questions for further research. A follow up study of our study population could indicate whether arrhythmias or other arthythmia related events might be recorded at a later stage in patients with specific symptoms in which no arrhythmia was documented in this study. The determinants of such later occurring arrhythmias could be evaluated. This may have also implications with regard to the predicrive values of clinical variables.

Because we could not evaluate the predictive value of signs and symptoms in case of most of the specific (clinically relevant) arthythmias a study with a larger popularion, a longer follow-up period or in a more selected source population is relevant. Because of the quite similar symptomatology of anxiecy disorders and arthythmias, research can be done to idenrify clinical variables to differentiate between these. Because this diagnostic study is based upon a confined primary care population, it is meaningful to test the external validity of our diagnostic models in another, but similar population. Also, a study can be done to evaluate the diagnostic value of event recorders with or without communication facilities in general practice.

\section{REFERENCES}

1. Lamberts H. In het huis van de huisarts (In the house of the general practitioner). Leliestad: Meditekst, 1991. 
2. Metsemakers JFM, Hoppener P, Knotmerus JA, Kocken RI, Limonard CBG. Computerized health information in the Netherlands: a regisration nework of family practices. Br I Gen Practice 1992:42:102-6.

3. Barsky A). Palpitarions, cardiac awareness and panic disorder. An I Med 1992,92(1A Suppl: 31 S-34S.

4. Knudson MP. The natural history of palpiations in a familly practice. I Fam Prat $1987 ; 2,4: 357-60$.

5. Lochen M, Snaprud T, Zhang W, Rasmussen K. Arrhythmias in subjects without a hisrory of palpirations: The Tromso Srudy. Eur Hear J 1994; 15: 345-3495.

6. Kulbertus $H E_{2}$ Lewal-Ruten $\mathbb{F}$ de, Albert A, Dubois $M$, Petic $\mathbb{M} M$. Electrocardiography changes oc curring with adwancing age. In: Wellens HJ], ediror. What's new in electrocardiography? Ist ed. The Hague: Nijhof 1981:300-13.

7. Kannel WB, Abtott RD, Savage DD, MCNamara PM. Epidemiologic features of chronic atrial fibrillation. The Framingham Study. New Engl I Med 1982;306:1018-22.

8. De Bacquer D, Martins Pereira LS, De Backer G, De Henauw S, Kornitzer M. Prevalences and correlates of ECG abnormalities in the adult Belgian population. J Electrocandiol 1995:28:1-11.

9. Bethge KP, Bethge D, Meiners $G$, Lichtlen PR. Incidence and prognostic significance of ventricular arrhychmias in individuals without detectable heart disease. Eur Fleart J 1983;4:338-46.

10. Bjerregaard P. Continuous ambulatory electracardiography in healthy adult subjects over a 24-hour period. Clinical data, and evaluation of instruments for ambulatory electrocardiography. Dan Med Bull 1,984;31:283-97.

11. Langenberg M, Hellemoms BSP, Van Ree JW, et al. Atrial fibrillation in elderly patients: prevalence and comorbidicy in general practice. Br Med J 1996; 313: 1534 .

12. Lip GYH, Golding DJ, Nazir M, Beevers DG, Child DL, Flercher RI. A survey of atrial fibrillation in general practice: the West Birmingham Atrial Fibrillation Projecr. Br J Gen Pract 1997; 47: 285-289.

13. Benjamin EJ, Levy D, Vaziri SM, D'Agostino RB, Belanger AJ, WolEPA. Independent risk factors for atrial fibrillation in a population-based cohort. The Framingham Heart Study. JAMA 1994; 272(11): $840-4$.

14. Green MS, Jucha E, Luz J, Cocos M, Nurynberg M, Rosenberg N. Prevalence and correlares of ventricular premature beats detected by ambulatory electrocardiography in working populations. J Epidemiol 1988;127:955-68.

15. Hinkle LE, Carver ST, Stevens M. The frequency of asymptomatic disturbances of cardiac rlythm and conduction in middle-aged man. Am J Cardiol 1969;24:629-650.

16. Kelleher PW, Imperial ES, Burnet P. Mitchell R. Ventricular ectopy during prolonged ambulatory electrocardiographic monitoring in elderly hypertensive subjects. J Am Geriar Soc 1990; 38: 201.204.

17. Schlant RC, Alexander RW, O'Rourke RA, Roberts R, Sonnenblick EH, eds. Hurst's the heart; arreries and veins. $8 \mathrm{ch}$ ed. New York: Mc Graw-Hill, 1994.

18. Braunwald E, ed. Heart Disease: A textbook of cardiovascular medicine. 4th ed. Philadelphia: W/B Saunders; 1992. 



\section{CHAPTER 8}

\section{Summary}

This thesis addresses the occurrence of arrhythmias and a quantitative description of the diagnostic value of patient characteristics, medical history findings, symproms and signs in diagnosing arrhythmias in general practice. During a two-year period, all patients with complaints or physical findings suggesting an arrhythmia, were enrolled in the study. A total of 868 patients, registered in 20 general practices, met the inclusion criteria.

Chapter 1 presents a general overview of arrhythmias and their clinical diagnoses.

Chapter 2 deals with the occurrence of arrhythmias. An overall incidence of 2.6 (SD 1.6) arrhythmias per 1000 listed patients per year, was calculated. An arrhythmia was documented in $32 \%$ of the patients. Depending on the inclusion criteria, in $48-80 \%$ of the parients who were included because of coincidental findings and in $18-59 \%$ of the patients who were included because of symptoms, an arrhythmia was detected. In nearly half of the patients, who were suspected by the GP of having an arrhythmia based on symproms possibly caused by haemodynamic imbalance, e.g. vertigo, dyspnoea, fatigue and collapse, an arrhythmia was documented. Although the total incidence of arrhythmias in women was higher, the percentage of arrhythmias found in men was higher. The occurrence of arrhythmias increased significantly with age. Half of the arrhythmias were found in patients 55-74 years of age. Severe arrhythmias were infrequent in this general practice population. Most of the detected arrhythmias were not previously known in these parients, including some severe arrhythmias.

Chapter 3 focuses on the predicuive value of symptoms in diagnosing arrhythmias in a sub-population of 762 patients included on complaints and in identifying clinically relevant arrhythmias. In $28.3 \%$ of the patients arrhythmias were detected and $8.8 \%$ were clinically relevant. Several patient characteristics, symptoms and medical history findings have high predictive values in diagnosing arrhythmias.

In bivariate analysis, age, gender, arrhythmias in the past, cardiovascular disease, and hypertension were important factors contributing to the probability of both arrhythmias and clinically relevant arrhythmias. The use of cardiovascular drugs and diuretics was also positively associated with the occurrence of arrhythmias and clinically relevant arrhythmias. Collapse and dyspnoea were symptoms with the highest positive predictive values for arrhythmias Palpitations were only positively associated with the presence of arrhythmias and clinically relevant arrhythmias when present during ECG-recording, in contrast to this symptom in general.

In the logistic regression analysis, age and, to a lesser extent, male gender, palpitacions and dyspnoea during consultation and the use of cardiovascular drugs were associared with the presence of arrhythmias. In detecting clinically relevant 
arrhythmias, the same parameters except gender were important, as well as a history of arrhythmias. The use of central nervous system medication and frequent psychosomatic complains were negatively associated with the presence of clinically relevant arrhythmias.

Chapter 4 describes the value of physical signs in addition to patient characteristics and the medical history in 762 patients included on complaints.

In bivariate analysis, nearly all known signs from literature were significant contributors to the occurrence of arthythmias and clinically relevant arrhythmias. A (totally) irregular pulse and correlated signs like a beat-to-beat variability in systolic blood pressure or a varying loudness of the first heart sound were the most dominant predictors of (clinically relevant) arrhythmias.

In logistic regression, the best performing extensive model with 'arrhythmias' as independent variable consisted of 5 physical signs: a totally irregular pulse, a heart rate $<60$ beats per minute, varying loudness of the first heart sound, a partially irregular pulse and a heart rate $>100$ beats per minute. A suspicious cardiovascular condition also contributed well to the model.

In the best performing model with "clinically relevant arrhythmias" as independent variable, the above-mentioned signs were included as well as a low blood pressure and a history of arrhythmias. In addition to signs, age and "palpitations during consultation" only were relevant predictors in a model with "arrhythmia" as dependent variable in contrast to "clinically relevant arthythmias". When data from the physical examination were added to patient characteristics, symptoms and medical history findings, the latter become relatively less important for diagnostic prediction.

Chapter 5 deals with the diagnostic value of patient characteristics, symptoms and signs in 106 patients included on coincidental findings, suggesting an arthythmia. Besides, the accuracy of diagnosing arrhythmias based on medical history taking and physical examination is evaluated. In $61 \%$ of the patients arrhythmias were detected and in 18\% clinically relevant arrhythmias. GPs considered a correct diagnosis in $85 \%$ of the cases when an arrhythmia was registered by ECG recording. In this indicated population, patient characteristics, symptoms and medical history findings scarcely contributed in diagnosing (clinically relevant) arrhythmias. Only age, a history of arrhythmias or cardiovascular disease, dyspnoea, collapse and dizziness were significantly correlated to (clinically) relevant arrhythmias. Physical signs, especially a totally irregular pulse and correlated findings were the most dominant predictors of (clinical relevant) arrhythmias.

In the logistic regression analysis, only an irregular pulse and a history of dizziness were positively associated with the presence of arrhythmias. In detecting clinically relevant arrhythmias, irregularity as well as a heart rate of more than 100 bears per minute and a history of collapse, were important variables.

In chapter 6 the diagnostic value of patiene characteristics and clinical variables wirh respect to atrial fibrillation is presented, concerning a subgroup of 754 patients 
without a history of atrial fibrillation and included on complaints. In 39 patients atrial fibrillation was documented. In this population, age was a powerful predictor of atrial fibrillation with prevalences of $4.5 \%$ in the age group 45-64 years and $12.4 \%$ in patients 65 years or older. A history of other arrhythmias, hypertension and in a lesser degree cardiovascular disease were significant predicrors, as well as the use of diuretics and other cardiovascular medication, and symptoms such as dyspnoea, dizziness, palpitations and in a lesser degree, farigue and collapse. A totally irregular pulse was the best diagnostic predictor of atrial fibrillation. However, also a partially irregular pulse was significantly associared with the presence of atrial fibrillation.

In a logistic regression model, age, palpitations and dyspnoea, a totally and partially irregular pulse and a varying loudness of the first heart sound, remained significant contributors. An AUC of 0.93 was calculated in the ultimare logistic model, including all significant clinical variables. Employing the multivariate model, a good agreement is found between the observed and the predicted probability of atrial fibrillation.

In chapter 7 the main results of this study are discussed in relation to our objectives. Also the strength and the limitations of our study are summarised. Finally, some implications for general practice and further research are formulated. 



\section{Samenvatting}

In dit proefschrift worden de resultaten beschreven van een onderzoek naar het vóórkomen van hartritmestoornissen in de huisartspraktijk. Daarnaast wordt een kwantitatieve beschrijving gegeven van de diagnostische waarde van patientkenmerken, medische voorgeschiedenis, klachten en symptomen bij de diagnostiek van hartritmestoornissen. Gedurende twee jaar werden patiënten met klachten en/of bevindingen, mogelijk gerelateerd aan een rirmestoornis, opgenomen in de studie. In totaal werden 868 patiënten uit 20 huisartspraktijken geïncludeerd.

Hoofdstuk 1 is een algemene introductie over het onderwerp hartritmestoornissen en de klinische diagnostiek hiervan.

Hoofdstuk 2 beschrijft her vóorkomen van rirmestoornissen. Een incidentie van 2.6 (SD 1.6) per 1000 patiëntjaren werd vastgesteld. Een ritmestoornis werd gevonden bij 32\% van de geincludeerde patiënten. Afhankelijk van het inclusiecriterium werd bij $48-80 \%$ van de patiënten met toevalsbevindingen bij lichamelijk onderzoek en bij 18-59\% van de patiënten met klachten een hartritmestoornis vastgesteld op het elektrocardiogram. In bijna de helft van de patiënten, geïncludeerd op klachten wijzend op een gestoorde haemodynamiek, zoals collaps, duizeligheid, kortademigheid en moeheid, werd een ritmestoornis vastgesteld. Alhoewel er een hogere totale incidentie van ritmestoornissen bij vrouwen gevonden werd, was het percentage mannen met een ritmestoornis in de onderzoekspopulatie hoger. De incidentie van ritmestoornissen bleek significant toe te nemen met de leeftijd. Bijna de helft van de ritmestoornissen werd vastgesteld bij patiënten van 55 tor 74 jaar. Ernstige ritmestoornissen werden weinig gevonden in deze huisartsgeneeskundige populatie. Het merendeel van de patiënten waarbij een (ernstige) ritmestoornis werd gedetecteerd, was hiermee niet bekend.

Hoofdstuk 3 gaat in op de voorspellende waarde van klachten bij de diagnostick van (klinisch relevante) ritmestoornissen in een subpopulatie van 762 patiënten, geïncludeerd op klachten. Bij 28.3\% van de patiënten werd een ritmestoornis vastgesteld en $8.8 \%$ was klinisch relevant. Meerdere patiëntkenmerken, gegevens uit de voorgeschiedenis en anamnestische gegevens hadden een hoge voorspellende waarde met betrekking tot de aanwezigheid van ritmestoornissen. Bij bivariate analyse bleken met name een ritmestoornis, hypertensie of cardiovasculaire ziekte in de voorgeschiedenis en leeftijd en geslacht goede voorspellers te zijn van (klinisch relevante) ritmestoornissen. Het gebruik van diuretica en cardiovasculaire medicatie was ook significant gecorreleerd aan het vaststellen van ritmestoornissen. Van de anamnestische gegevens hadden collaps en kortademigheid de hoogste voorspellende waarde voor de diagnostiek van ritmestoornissen en de klinische relevantie. Een 
positief verband tussen hartkloppingen en ritmestoornissen werd alleen gevonden indien her ECG rijdens de hartkloppingen kon worden gemaakr.

In de logistische regressie-analyse werd en significante samenhang gevonden tussen de detectic van ritmestoomissen en leeftijd, mannelijk geslacht, het gebruik van cardiovasculaire medicatie en hartkloppingen of kortademigheid tijdens het consult. Klinisch relevante ritmestoornissen waren positief gecorreleerd met leefrijd, een voorgeschiedenis van rirmestoornissen, het gebruik van cardiovasculaire medicatie en kortademigheid tijdens het consult. Een voorgeschiedenis van frequente psychosomatische klachten, palpitaties waarvan de patiënt geen last had rijdens het consult en her gebruik van benzodiazepines pleitten tegen de aanwezigheid van klinisch relevante ritmestoornissen.

In hoofdstuk 4 wordr aandacht geschonken aan de meerwaarde van fysisch diagnostische gegevens boven op de waarde van patiëntkenmerken en anamnestische gegevens bij 762 patiënten. Bij bivariare analyse bleken vrijwel alle in de literatuur vermelde fysisch diagnostische gegevens te wijzen op de aanwezigheid van (klinisch relevante) ritmestoornissen. Een (totaal) irregulaire pols en gerelateerde symptomen zoals een wisselende waarde van de systolische bloeddruk en een wisselende luidheid van de eerste hartoon waren de meest uitgesproken voorspellers van zowel ritmestoornissen alsook de klinische relevantie hierwan.

Bij de logistische regressie bevatte het best voorspellende model voor ritmestoornissen de vijf wolgende fysisch diagnostische variabelen: een totaal irregulaire pols, een hartfrequentie< $60 \mathrm{slagen} / \mathrm{min}$, een wisselende luidheid van de eerste harttoon, een niet volledig irregulaire pols en een hartfrequentie> $100 \mathrm{slagen} / \mathrm{min}$. Daarnaast leverde ook het "niet pluis gevoel" van de huisarts inzake de cardiovasculaire roestand van de patiënt een bijdrage aan het model.

In her beste model betreffende de voorspelling van klinisch relevante ritmestoornissen waren naast bovengenoemde fysisch diagnostische gegevens tevens een lage bloeddruk en een voorgeschiedenis van ritmestoornissen opgenomen. Leeftijd en hartkloppingen tijdens het consult droegen wel bij aan het model betreffende ritmestoornissen, doch niet aan de voorspelling van klinische relevantie. Wanneer gegevens van het lichamelijk onderzoek werden toegevoegd aan een model met patiëntkenmerken, medische voorgeschiedenis en anamnestische gegevens, werden laarstgenoemde variabelen minder belangrijk met betrekking rot de predictie van (klinisch relevante) ritmestoornissen.

In Hoofdstuk 5 wordt de diagnostische waarde van pariëntkenmerken, klachten en symptomen beschreven bij 106 patiënten, die geinncludeerd waren op toevalsbevindingen, mogelijk gerelateerd aan een rimestoornis. Daarnaast werd nagegaan in hoeverre de huisarts in staat was een correcte diagnose te stellen op basis van voorgeschiedenis, de anamnese en het lichamelijk onderzoek. Bij $61 \%$ van de patiënten werd een ritmestoornis op het ECG gediagnostiseerd en bij 18\% een klinisch relevante rimestoornis. In $85 \%$ stelden de huisartsen een correcte diagnose. In deze subpopulatie leverden gegevens uit de voorgeschiedenis, patiëntkenmerken en 
anamnestische gegevens slechts een kleine bijdrage aan de diagnostiek wan ritmestoornissen. Alleen leeftijd, een voorgeschiedenis van ritmestoornissen, dyspnoe, collaps en duizeligheid waren significante voorspellers van (klinisch relevante) ritmestoornissen. Fysisch diagnostische bevindingen, met name een totaal irregulaire pols en daaraan gecorreleerde bevindingen, waren de meest uirgesproken voorspetlers van (klinisch relevante) ritmestoornissen. Bij de logistische regressie waren alleen duizeligheid en een irregulaire pols gerelateerd aan de aanwezigheid van ritmestoornissen. Voor de vaststelling van klinisch relevante ritmestoornissen waren met name collaps, irregulariteit en een hartfrequentie> 100/min van belang.

Hoofdstuk 6 gaat over de diagnostische waarde van patiëntkenmerken en klinische variabelen voor de diagnostiek van atriumfibrilleren in een subpopulatie van 754 pariënten, geïncludeerd op klachten, die van tevoren niet bekend waren met arriumfibrilleren. Bij 39 patiënten werd atriumfibrilleren gedocumenteerd op het ECG. In deze populatie bleek leeftijd een belangrijke voorspeller te zijn van atriumfibrilleren met prevalenties wan $4.5 \%$ in de leefrijdsgroep $45-64$ jaar en $12.4 \%$ bij patiënten van 65 jaar en ouder. Een voorgeschiedenis van andere ritmestoornissen, hypertensie en cardiale aandoeningen was significant gecorteleerd aan de waststelling van atriumfibrilleren, evenals het gebruik van diuretica en cardiale medicarie. Van de symptomen waren met name dyspnoe, duizeligheid, hartkloppingen en in mindere mate moeheid en collaps goede voorspellers. Een totaal irregulaire pols was de beste woorspeller van atriumfibrilleren, alhoewel ook een nier geheel irregulaire pols hiermee was geassocieerd.

Leeftijd, hartkloppingen, dyspnoe, een irregulaire pols en een wisselende luidheid van de eerste harttoon leverden een significante bijdrage aan het logistisch regressiemodel. In het uiteindelijke model met alle significante variabelen werd een AUC van 0.93 gevonden. Gebruik makend van dit model werd een goede overeenstemming gevonden tussen vastgesteld en voorspeld atriumfibrilleren.

In Hoofdstuk 7 worden de belangrijkste resultaten van de studie vergeleken met onze vraagstellingen. Daarnaast worden de sterke kanten en de beperkingen van de studie beschreven. Tenslotte wordt ingegaan op de mogelijke implicaties van deze studie voor de dagelijkse praktijk en verder onderzoek. 


\section{Dankwoord}

Aan dit proefschrift hebben een groot aantal personen hun bijdragen geleverd. Op de eerste plaats They Lemmens, de initiator van zovele onderzoeksprojecten binnen onze vakgroep. Hij is ook de grondlegger van dit onderzoek geweest. Helaas is hij veel te vroeg gestorven. De herinnering aan zijn enthousiasme voor het onderwerp hartritmestoornissen kwam ik nog vaak tegen in de fel rode onderstrepingen in allerhande tijdschriftartikelen. Annie, They heeft veel betekend voor mij, her onderzoek en de vakgroep.

André Knottnerus, zonder jouw begeleiding was ik er nooit in geslaagd het proefschrift af te ronden. Je welbewuste, subtiele sturing naar de eindstreep had ik nodig. $V$ an je scherpzinnige opmerkingen en je analytisch vermogen heb ik veel geleerd. Ik verwonderde me elke keer weer over her feit dar je, ondanks je vele andere activiteiten, toch elke keer weer de essenties van het project paraat had. Ik heb genoten van je spel met de Nederlandse taal. Je hebt me veel handvatten gegeven om door te kunnen gaan met wetenschappelijk onderzoek.

Ton Gorgels, je hebt me wegwijs gemaakt in het onderwerp ritmestoornissen. Zonder jouw inhoudelijke inbreng zou het project niet uitgevoerd hebben kunnen worden. Met name je transmurale denkwijze zou een uitgangspunt kunnen zijn voor verdere samenwerking.

Paula Rinkens, ik denk met plezier terug aan de tijd dat we intensief samenwerkten aan het project. Je hebt op een nier te evenaren wijze codeboeken samengesteld, de data ingevoerd en de eerste analyses verricht. In de periode dat ik zelf de analyses moest doen heb ik kunnen bouwen op een zeer goed opgebouwd bestand, waarin ik geen enkele four ben tegen gekomen.

Miep Kleijne, naast het feit dat je de meeste ECG's hebt beoordeeld, was je een maatje in het ziekenhuis. Het is jammer dat je je zover weg hebt gevestigd als cardio$\operatorname{loog}$.

Arnold Kester, bedankt voor de statistische adviezen die ik even russendoor bij je kon komen halen.

Fons Kessels, je maakte een prachtig programma om ROC-curves uit te printen.

Deze studie had niet kunnen plaatsvinden zonder de vrijwel belangeloze medewerking van de volgende huisartsen: HMA Aussems, WCM Bakker, GHMI Beusmans, P Castermans, GMHJ Costongs, WHR Croughs, HPT Derkx, AWM van Dongen, ThJ van Erp. H Habets, WJCM Heiligers, MJM Huijnen, LLJM Keijsers, ThFWA Krebber, JAPM Kuijpers, JFM Metsemakers, RRBC Pinckers, WMF Ritzen, JRAY van Rooy, MJAM van Sint Fiet, AFM Smits, CI'L. Straus, JAJM Swaans, WPM Vierhout, BHM Warnier, RVC van Well en hun assistentes. Jullie includeerden de patiënten, namen een gestructureerde anamnese af en makkten de ECG's. Ik hoop dat dit her onderzoeksproject ook een bijdrage heeft geleverd aan 
jullie interesse in ritmestoornissen. Ik denk met plezier terug aan de vele geanimeerde praktrikbezoeken.

Pie Castermans, jij was de meest betrokken huisarts bij het project. Ik vind het jammer dat her registratieproject nooit is afgerond. Wellicht iets voor na je pensioen?

Vanzelfsprekend wil ik ook de patiënten bedanken, die mee hebben gedaan aan het onderzoek.

Henriette, Boris en Peter jullie waren student-assistent van het eerste uur. Ik hoop dat jullie er iets van geleerd hebben en iets van jullie inspanningen in dit proefschrift terug zien.

De medewerkers van de ECG-afdeling van het AZM en van het transmuraal diagnostisch centrum wil ik bedanken voor de administratieve verwerking van de overgezonden ECG's.

En vanzelfsprekend wil ik "de gang" bedanken. Op de eerste plaats de toen nog "jonge honden": Jelle Stoffers, Geert-Jan Dinant, Piet Portegijs, Michiel Cornel, Victor Kaiser en George Wolfs. Samen hebben we met veel plezier de HOIO opleiding gevolgd. In de kennel was er nog veel saamhorigheid. Helaas zijn onze persoonlijke contacten door onze drukke werkzaamheden verwaterd.

Marjan van den Akker, jij gaf mij de nodige ondersteuning om mijn bloeddruk op peil te houden.

Vic Dubois, door jouw enthousiasme voor onderwijs ben ik bij de vakgroep komen werken. Ik denk nog vaak terug aan de plezierige tijd toen ik als jong broekje bij de huisartsopleiding kwam werken. Yvonne van Leeuwen (maatje), ik hoop dat ik meer tijd krijg om binnen het onderwijs aan palliatieve zorg te kunnen besteden en wellicht kom ik ooit nog eens terug waar ik begonnen ben. Paul Ram, ik heb je de vuurdoop gegeven toen je als opleider bij de huisartsopleiding kwam werken. De wisseling van opleider was een ware cultuuromslag. Jacques van Thiel, er zit een kaftje omheen.

Sjoerd Hobma en Hennie Lantman, mijn huidige kamergenoten, het sfeertje moeten we zo houden. Ik ben blij dat we kunnen roeien met de computers die we hebben.

Jos op ' $t$ Root, ik heb je in veel functies binnen de vakgroep meegemaakt. Ik neem mijn perje af voor de manier waarop je het onderwijs binnen onze vakgroep gestructureerd hebt.

Beppie Hellemons en Machteld Langenberg, in het begin liepen het PATAF en HRS onderzoek nog parallel onder de bezielende leiding van They. Ik hoop dat we in de toekomst ook op een plezierige manier samen met Jelle. Trudy van der Weijden en de overige leden van de hart-vaat club ons onderzoek kunnen voortzetten.

Ine Siegelaer, er zijn mensen die je wel en niet mogen. Er zijn mensen die je mag en die je nier mag. Ik mag je. Frits Ruijters, bedankt voor je hulp bij klusjes tussendoor. 
Frans van der Horst, je betrokkenheid bij de mens achter de collega, heeeft mij altijd gecharmeerd.

Jan van Ree, het is precies 10 jaar geleden dat ik samen mer They op jouw afscheid in Nijmegen was. Een moment om even bij stil te staan.

Harry Crebolder, onder jouw leiding is de vakgroep weer een hechtere dub geworden. Ik hoop dar het je lukt het academisch netwerk de functie re geven, die het verdient.

Mijn huidige collega's bij het LEGO-project, Riet Drop, Paul Lemmens, 'Truus van Uijen, Ellen de Goeij en niet te vergeten Truus Custers will ik bedanken voor de pretrige samenwerking die we hebben opgebouwd, ondanks het feit dat ik een vreemde eend in de bijt ben.

Job Metsemakers en Jean Muris, mijn huidige collega's in de praktijk. Ik hoop dat het ons lukt van onze praktijk een echte academische praktijk te maken en onderwijs, onderzoek en gezondheidszorg goed op elkaar af te stemmen. Yvonne Welzen, Marie-Louise Smeets en Marieke Janssens, onze huidige praktijkassistentes. Jullie hebben nier veel gemerkt van mijn onderzoek. De structurering die jullie me in de praktijk boden was echter een voorwaarde om in Maastricht te kunnen werken.

Theo en Annie Zwietering wil ik bedanken voor de mogelijkheid die zij mij boden om geneeskunde te studeren. $\mathrm{Pa}$, bedankt voor her programma, dat je geschreven hebt om de kans op ritmestoornissen te berekenen. Ma, je zal het allemaal niet zo goed meer begrijpen, maar het warme thuis, waar jij zo van houdt, is toch de basis geweest van waar ik verder heb kunnen bouwen aan mijn toekomst.

Last, but not least, Janine, Anne, Jeroen en Sander. Ik wil jullie bedanken voor het geduld en het feit dat jullie me de ruimte gaven ook op zaterdag aan het boekje te werken, naast de toch al schaarse tijd voor het gezin. Jullie weten nu dat de dikte van het boekje niet in verhouding staat tot de tijd die er is ingestoken. 



\section{Curriculum vitae}

Paul Zwietering werd op 12 oktober 1956 geboren te Sittard. In 1977 behaalde hij zijn eindexamen B aan de scholengemeenschap St. Michiel te Geleen. In datzelfde jaar begon hij met zijn studie geneeskunde te Maastricht. Tijdens zijn studic was hij van 1978-1980 bestuurslid van de studentenvereniging KOKO, warvan één jaar als voorzitter. Daarnaast was hij van 1980-1982 lid van de universiteitsraad. Naast universitaire functies was hij van 1980 tot 1981 lid van het bestuur Stichting Studenten Huisvesting te Maastricht en lid van het algemeen bestuur Stichting Studenten Gezondheidszorg te Utrecht. In 1983 was hij lid van de gezondheidszorgcommissie van de faculteit der geneeskunde. In dat zelfde jaar behaalde hij zijn artsdiploma. Van 1983-1985 werkte hij als beleidmedewerker bij het inderdertijd op te richten Revalidatie Informatie Centrum te Hoensbroek. In 1985 startte hij met de huisartsopleiding te Maastricht, huisartsopleider R Wittgen te Waalre. In 1986 werd hij ingeschreven in het huisartsen register. In dat jaar werd hij bij de huisartsopleiding in Maastricht aangesteld in het kader van de ontwikkeling van onderwijsprogramma's hart- en vaatziekten. Van 1987 tot 1991 was hij partrime werkzaam als huisarts in gezondheidscentrum "de Maar" in Kerkrade. In juli 1991 werd de geacademiseerde huisartspraktijk van JAPM Kuijpers overgenomen en in associatie voortgezet met JFM Metsemakers. In oktober 1993 trad JWM. Muris tot de maatschap toe. In 1988 werd in het kader van "de stimuleringsregeling huisartsgeneeskunde" van NWO, gestart met her onderzoek waarvan in dit proefschrift verslag wordt gedaan. Vanaf 1992 heeft hij naast zijn werkzaamheden als huisarts een vast dienstverband bij de capaciteitsgroep huisartsgeneeskunde van de Universiteit Maastricht. Momenteel is hij betrokken bij het practisch medisch onderwijs in de Huisartspraktijk (PMOH) als begeleider. Tevens is hij opleider in het kader van het PMOH en de huisartsopleiding. Binnen het onderzock is hij betrokken bij meerdere onderzoeken op het gebied van hart-en vaatziekten, waarbij momenteel de de meeste tijd besteed wordt an het project "Leefwijze en Gezondheid" (LEGO). 



\section{Appendix}

Artsenformulier

\section{Onderzoek diagnostiek \\ van hartritmestoornissen}

Rijksuniversiteit Limburg 


\section{CARDIOFONIELIJN (043-) 437105}

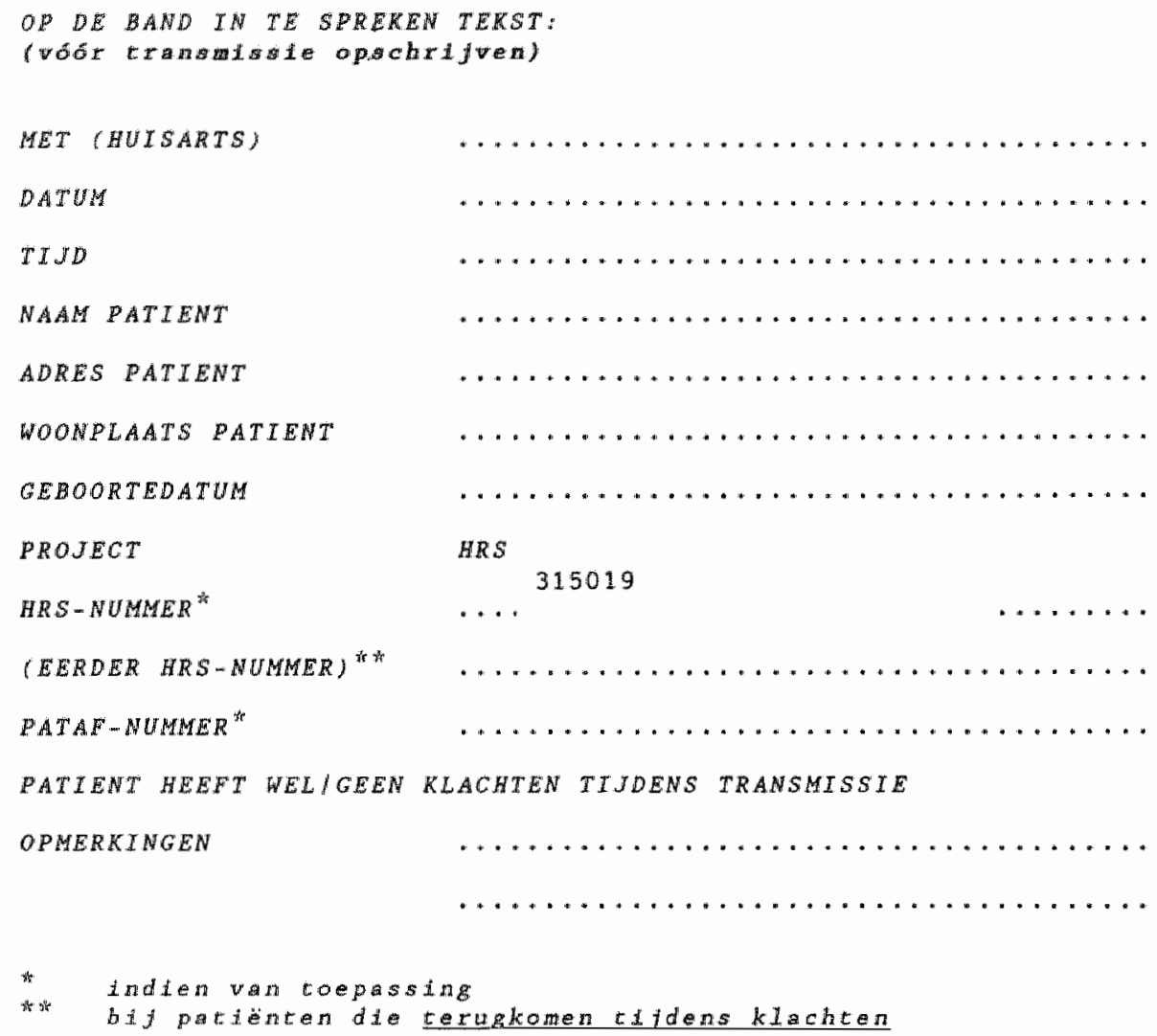

NOODZAAK DIRECTE CONSULTATIE CARDIOLOOG:

$(043-) 862219$

$\mathrm{CCU} / \mathrm{AZM}$

OF:

(043 -) 866666 SEIN 1526 ASSISTENT CARDIOLOGIE 


\section{Toelichting}

Deze gegevens zijn uitdrukkelijk bedoeld om na te gaan op welke wijze de patient in de studie is terechigekomen.

1. Indien een patiënt spontaan (een) klacthtein) wermeldt op basis waarwan hij/zil aan de ingangscriteria voldoet, hoeft $u$ alleen betreffende criteri(a) una aan te kruisen.

\section{voorbeeld 1}

$\$$ duizeligheid + overweging HRS

O moeheid + overweging HRS

ingangsklacht

dr

0

ingangsklacht

2

$\mathbb{x}$
Anamuestisch

o

0

aramnestisch

0

pijn op de borst + overweging HRS

2. Indien u bij toeval (dus niet gestuurd door de anamnese) bij het lichmmelijk onderzoek een (of meer) van de genoende ritmes vindt, kruist u slechts betreffende toevalsbevinding(en) aan.

voorbeeld 3

$O$ anders + owerweging HRS

namelijk:...........

Xtoevalsbevinding bij

lichamelijk onderzoek: ingangsklacht

anamnestisch

o

o polsfrequentie $>100 /$ minuut

0 polsfrequentie $<60 /$ minuut

$\not$ onregelmatige pols

Donregelmatige hartactie

$O$ hartfrequentie $>100 /$ minum

0 hartfrequentie $<60$ /minuut

$0 \geq 5$ extrasystolen per min.

3. Indien de patient zich met geheel andere klachten op het spreekuur presenteen en tijdens de anamnese bevestigi last te hebben van klachten zoals geformuleerd in de ingangscriteria, kruist u betreffende klacht aan.

\section{woorbeeld 4}

$O$ hartkloppingen

pijn op de borsi + overweging HRS

ingangskinacht

anamnestisch

0

o

Indien de patiènt derhalve aan een ingangscriterium voldoet, wordt hij/zij opge-

nomen in de studie en hoeft u de andere criteria niet meer nat te lopen.

Eventuele klachien komen aan de orde bij de anamnese. 


\section{INGANGSCAITERIA}

L. Va weilk(e) ingangeriteri(a)um is de patien in het onderzock gekomen?

ingangagengeht

O hitrkloppingen

Opijn op de borst averweging HRS

O kortademigheid + overweging HRS

O duixeligheld +overwheging HRS

O moeheid + overueging HRS

O vallen + overweging HRS

O andars + owerweging HRS mamelijk

O toevalsbevinding bij lichamelijk onderzoek: o

o

o

o

o

o

o

O polifirequentic $>100 /$ minuut

O polsfrequentie < 60/minutut

O onregelmatige pols

O onregelmatige hartactie

$O$ hartfrequentie $>100 /$ mimut

$O$ hartfrequentie $<60 /$ minut

$\mathrm{O} \geq 5$ extrasystolen per min. anamnestisich

O

o

0

0

O

o

o

II. O nieuwe klacht bevinding

O oude klacht/bevinding, nieuw diagnostisch probleem

O oude klachuthar klachten tijidens consult

III. O consult

O visilte

O spoedvisisite

IV. Indien u ecn ingangacriterium bebt arangekruist met ${ }^{*}+$ owerweging HIRS" ${ }^{*}$ wat wats dan uw overweging?

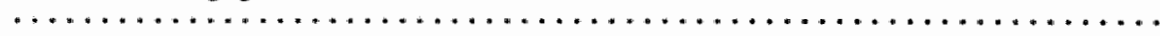

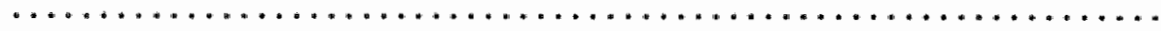




\section{ANAMNESE}

1. Heeft patieñ lasi van: (s., $\psi_{n}$ alle antwoonden aankiruisen)

- Harkloppingen?

- Piju op de borst?

ja, nu ja, gehad nee

- Kortademigheid?

$0 \quad 0 \quad 0$

$0 \quad 0$

- Duizeligheid?

$0 \quad 0 \quad 0$

- Moeheid?

0

$0 \quad 0$

- Syncope?

- Andere klachten op basis waarvan

0

0

u een ritmestoornis overweegi"?

namelijis.

$\mathrm{O}$

O 0

$0 \quad 0$

2. Treden de klachten van de patient in bepalde combinatie op? (\$.y. alle antworden aankruisen)

- hartkloppingen

ja nee nuidet

pijn op de borst

$0 \quad 0$

- kortademigheid

0

0

- duizeligheid

O

- mocheid.

O

- (flauw) vallen

a

- angst

- transpireren

0

0

0

- tintelingen in de vinger's of mond

0

0

0

0

- andere klachten, namelijk

o

0

0

0

0

0

0

o

0

c)

0

0

0

0

$\mathrm{O}$

$\ldots \ldots \ldots \ldots \ldots \ldots \ldots \ldots \ldots$

\section{HARTKLOPPINGEN}

INDIEN PATEENT GEEN LAST HEEFT VAN HARTKLOPPINGEN, KUNT U DOOROAAN NAAR VRAAG 14

3. Ervaiart patient tijolens harkkloppingen cen snelle hartslag?
O jaz
Onee
O niet duidelijk

4. Hoe boog schat patient de hartfrequentie tjjdens harthloppingen'?
$0<60 /$ min
$060-100 / \mathrm{min}$
$0>100 / \mathrm{min}$
O niet duidelijk

5. Ervaart patiènt tijdens hartkloppüngen een regulair rĭtne?
O ja
O nee
O niet duidelijk 


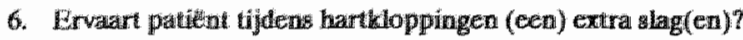
Oja
O the
O nüet duideligk

7. Ervaart patient tijdens hartkloppingen weleens een extra lange pauze tussen twee hartslagen?
Oja
Onee
O niet duidelijk

8. Ervaiart patient (na zo'n pauze) een extra sterke slag?
O ja
Onee
O niet duidelijk

9. Treden de hartkloppingen intermitterend (aanvalsgewijs) op?
$\mathrm{Oja}$
Onee
O niet duidelijk

10. Ervaart patient een plotseling begin van de hartkloppingen, van het ene op het andere moment?
O ja
Onee
O niet duidelijk

11. Ervaart patient een plotseling einde van de bartkloppingen, van het ene op het andere moment?
O ja
O nee
O niet duidelijk

12. Kan patient de hartkloppingen zelf be eindigen? (Meer antwoorden mogelijk)
Ja, doom"
$O$ afleiding te zoeken
$O$ rustig tidem te halcn
$O$ koud water te drinken
Ote persen
O anders, namelijk
.
Onee, patient heeft er geen invloed op
$O$ niet duidelijk
O spontane bedindiging

13. Moet patidint na de barkkloppingen meestal meteen urinerem?
O ja
Onew
O niet duidelijk 


\section{GROENE KAARTGEGEVENS}

14. Gebruikt patiennt medicijnen?

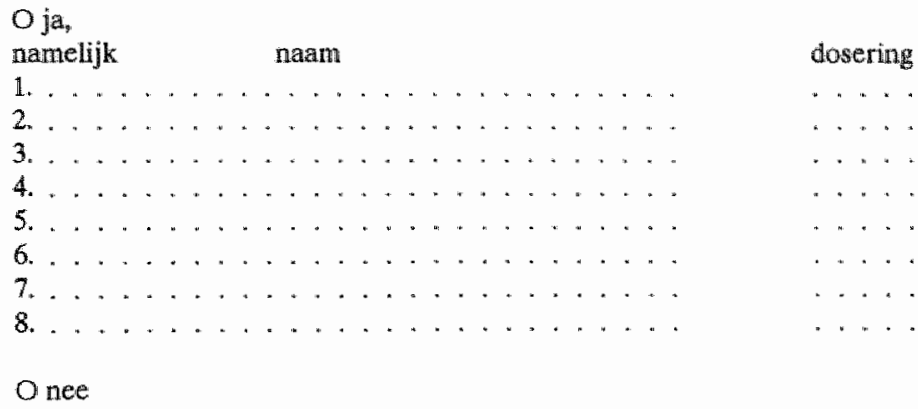

15. Is patiënt bekend met: (s.v.p. alle antwoorden aankruisen)

\begin{tabular}{|c|c|c|}
\hline - coronaìrlijiden & Oja & Onee \\
\hline - myocardinfarct & O ja & Onee \\
\hline - klepgebreken & $\mathrm{Oja}$ & O nee \\
\hline - hypertensie & 0 ja & Onee \\
\hline - ritmestoornissen & $\begin{array}{l}\text { o ja } \\
\text { namelijk. }\end{array}$ & Onee \\
\hline - decompensatio cordis & $\mathrm{O} \mathrm{ja}$ & Onee \\
\hline - AV-block & Oja & Onee \\
\hline - CARA & oja & Onee \\
\hline $\begin{array}{l}\text { orthostatische hypo- } \\
\text { tensie }\end{array}$ & $\mathrm{O}$ ja & Onee \\
\hline - ooraandoeningen & $\begin{array}{l}\text { O ja }{ }_{*} \\
\text { namelijk..... }\end{array}$ & Onee \\
\hline $\begin{array}{l}\text { - neurologische aan- } \\
\text { doeningen }\end{array}$ & $\begin{array}{l}\text { O ja, } \\
\text { namelijk..... }\end{array}$ & O nee \\
\hline - diabetes mellitus & O ja & Onee. \\
\hline $\begin{array}{l}\text { psychiatrische aandoe- } \\
\text { ningen }\end{array}$ & O ja & Onee \\
\hline - hyperventilatie & $0 \mathrm{ja}$ & Once \\
\hline - andere aandoen & $\begin{array}{l}\text { O ja, } \\
\text { namelijk }\end{array}$ & nee \\
\hline
\end{tabular}

16. Hebt u bij deze patient vaker bet gevoel: "oh jee, daar heb je hem of haar weer"?
O ja
Onee

17. Heeft patiênt vaak door $\mathrm{v}$ als psychnomatisch geduide klachten?
O ja
O nee 


\section{LICHAMELIJK ONDERZOEK}

18. Heef patient voonoemde klachten tijdems het bichamelijk onderzoek? (s.w.p. alle antwoorden aankruisen)

$\begin{array}{lll}\text { - hartkloppingen } & \text { O ja } & \text { O nee } \\ \text { - pijn op de borst } & \text { O ja } & \text { O nee } \\ \text { - kortademigheid } & \text { O ja } & \text { O nee } \\ \text { - duizeligheid } & \text { O ja } & \text { Onee } \\ \text { - moeheid } & \text { O ja } & \text { O nee } \\ \text { - vallen } & \text { O ja } & \text { O nee } \\ \text { - anders, namelijk: } & 0 \text { ja } & \text { Onee }\end{array}$

19. Hoe is op het eerste gezicht de cardiale toestand van de patiënt?
Opluis
Oniet pluis

20. Polsfrequentie?

„.../ $/$ min.

21. Ritme irregulair
ja, namelijk:
O nee
O niet duidelijk
$O$ totaal irregulair
O extra slag(en)
O compensatoire pauze(s)

22. Bloeddruk?

$\ldots / \ldots \mathrm{mm} \mathrm{Hg}$

23. Wisselende waarde van de bloeddruk van slag tot slag?
O ja
Onee
O niet duidelijk

24. Hartfrequentie? $\ldots /$ min.

25. Wisselende luidheid van de eerste harttoon?
O ja
Onee
Oniet duideliik 
26. Inspectie wan de halswenen?
O geen pulsaties
O kikkerfenomeen
O canon waves
O niet duidelijk

27. Effect van sinus-carotis-massage op een tijdens het onderzoek anawerige tachycardie?
Ogeen effect
O termineren tachycardie
$O$ tijdelijke verlangzaming
$O$ niet verricht, i.v.m. contra-indicatie
$O$ niet verricht, om andere redenen

28. Andere relevante bevindingen bij bet lichamelijk onderzoek?

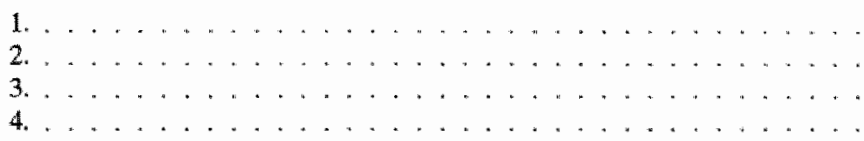

\section{OORZAAK VAN DE KLACHTEN}

29. Is er naar uw mening op basis yan anamnese en/of lichamelijk onderzoek sprake van een bartritmestoornis?
O ja
Onee $\quad$ niet duidelijk
ga door naar vraag 31

30. Welke bartritmestoornis overweegt u?

Meer mogelijkheden kunnen worden aangegeven; in volgorde van waarschijnlijkheid numumerem $(\mathbb{1}=$ meest waarschijnlijk; $10=$ mist waarschijolijk $)$.

extrasystole sinustachycardie chronisch atriumfibrilleren paroxysmaal atriumfibrilleren AV nodale tachycardie cirkeltachycardie/WPW ventriculaire tachycardie tachycardie eci bradycardie anders, te weten. 
31. Wethe cardilate oorzaak vinut u wasarshijnlijk?

(2. W.p. alle antwoonder aanliruisen)

\begin{tabular}{|c|c|c|}
\hline 1. ischaemie & Oja & 0 twijfel \\
\hline $\begin{array}{l}\text { 2. decompensatio } \\
\text { cordis }\end{array}$ & $\mathrm{Oja}$ & O twilfel \\
\hline 3. hypertensie & Oja & O twillel \\
\hline 4. kleplijden & $\begin{array}{l}\text { O ja, } \\
\text { namelijk }\end{array}$ & $\begin{array}{l}\text { O twijfel } \\
\ldots \ldots \ldots\end{array}$ \\
\hline $\begin{array}{l}\text { 5. electrolyten- } \\
\text { stoornissen }\end{array}$ & O ja & O twijfel \\
\hline 6. anders & $\begin{array}{l}\text { O ja } \\
\text { namelijk }\end{array}$ & $O$ twijfel \\
\hline
\end{tabular}

32. Welke extra-cardiale oorzaak vindt w waxtrschijnilijk? (s.v.p. alle antwoordten aankruisen)

$\begin{array}{llll}\text { 1. hyperthyreoidie } & \text { O ja } & \text { O twijfel } & \text { O nee } \\ \text { 2. ontsteking } & \text { O ja } & \text { O twijfel } & \text { O nee } \\ \text { 3. anaemie } & \text { O ja } & \text { O twijfel } & \text { O nee } \\ \text { 4. medicatie } & \text { O ja, } & \text { O twijfel } & \text { O nee } \\ & \text { namelijk................ } & \\ \text { 5. nicotine } & \text { O ja } & \text { O twijfel } & \text { O nee } \\ \text { 6. alcohol } & \text { O ja } & \text { O twijfel } & \text { O nee } \\ \text { 7. koffie } & \text { O ja } & \text { O twijfel } & \text { O nee } \\ \text { 8. psychogeen } & \text { O ja } & \text { O twijfel } & \text { O nee } \\ \text { 9. idiopatisch } & \text { O ja } & \text { O twijfel } & \text { O nee } \\ \text { (e.c.i) } & & & \\ \text { 10. anders } & \text { O ja, } & \text { O twijfel } & \text { O nee }\end{array}$

33. Overweegt $u$ andere diagnosen ter verklaring wan de klachten?

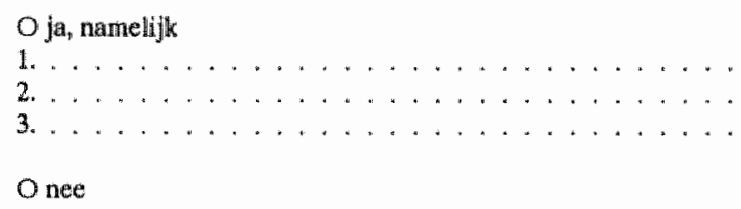

Drie mogelijkheden kunnen worden aangegeven; in volgorde van waanschijniijkheid ( $1=$ meest waarschijolijk; $3=$ minst waarschijnlijk).

\section{FUNCTIONEREN VAN DE PATIENT}

34. Hoe beoordeelt $\mathrm{g}$ het lichamelijk functioneren wan de patient?
O zeer goed
0 goed
O natig.
Oslecht
zeer slecht 
35. Hoe beoordeelt $\underline{u}$ het psychisch functioneren wan de patient?
O zeer goed
$O$ goed
$O$ matig
O slecht
O zeer slecht

36. Hoe beoordeelt u de gezondheid van de patient?
O zeer goed
$O$ goed
O matig
O slecht
O zeer slecht

37. Hoe ernstig acht u de klachten/aandoening van de patient?
$O$ zeer ernstig
O ernstig
$O$ matig ernstig
$O$ niet ernstig
$O$ helemaal niet ernstig

38. Hoeveel hinder beeft de patient volgens $\mathrm{u}$ van zijn/haar klachten/aandoening?
$O$ zeer veel hinder
$O$ veel hinder
$O$ matige hinder
$O$ weinig/een beetje hinder
O geen hinder 


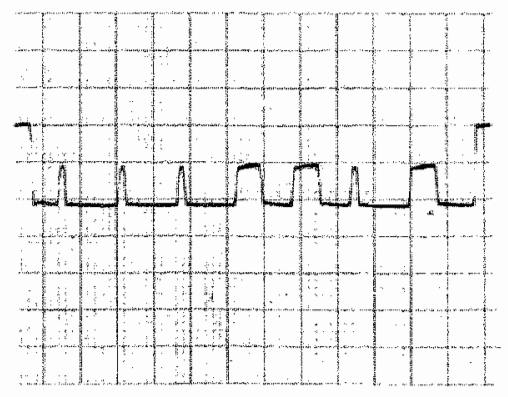

\title{
AFDELING ELECTROCARDIOGRAFIE
}

\section{OP DE BAND INGESPROKEN TEKST:}

\author{
MET (DOKTER) \\ DATUM \\ TIID \\ NAAM PATIENT \\ GEBOORTEDATUM \\ PROJECT \\ HRS-NUMMER \\ PATAF-NUMMER \\ OMERKTNGEN
}

HRS/ PATAF / GEZONDHEIDSZORG *

31.3009 Klachten tijdens opname (registratie) .....

* DE INGESPROKEN PROJECTEN OMCIRKELEN

BEOORDELING ECG:

UTTGETYPF" D.D.*

Atriumfibrilleren 150 per min. $(170-120)$

Intermediaire stand elektrigche hartas.

Abmormale sT-megmenter.

Abromal $\mathrm{EG}$ cat. 3. 

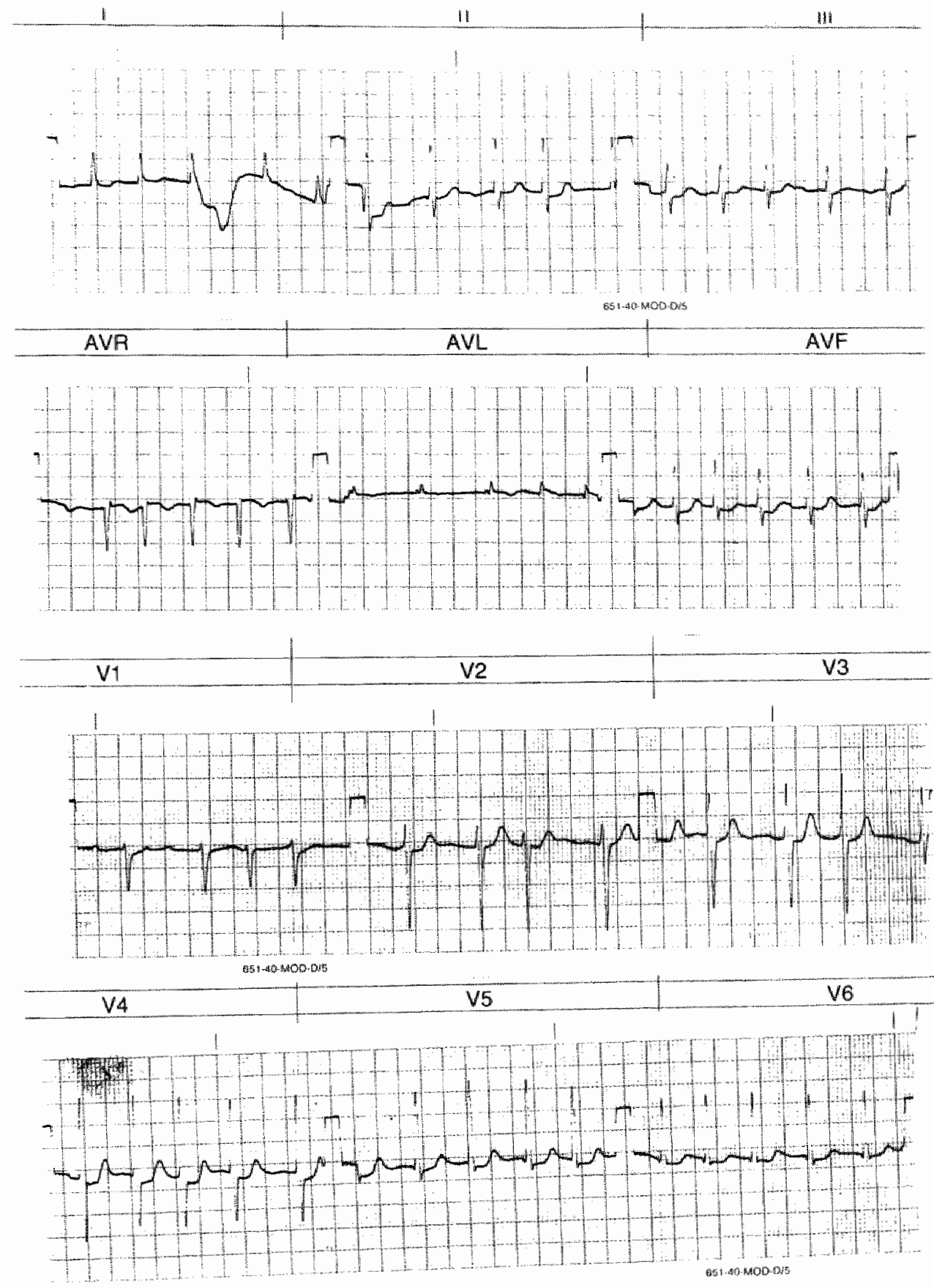